\title{
Molecular remodelling during atrial fibrillation
}

Citation for published version (APA):

Thijssen, V. L. J. L. (2002). Molecular remodelling during atrial fibrillation. [Doctoral Thesis, Maastricht University]. Datawyse / Universitaire Pers Maastricht. https://doi.org/10.26481/dis.20021101vt

Document status and date:

Published: 01/01/2002

DOI:

$10.26481 /$ dis.20021101vt

Document Version:

Publisher's PDF, also known as Version of record

\section{Please check the document version of this publication:}

- A submitted manuscript is the version of the article upon submission and before peer-review. There can be important differences between the submitted version and the official published version of record.

People interested in the research are advised to contact the author for the final version of the publication, or visit the DOI to the publisher's website.

- The final author version and the galley proof are versions of the publication after peer review.

- The final published version features the final layout of the paper including the volume, issue and page numbers.

Link to publication

\footnotetext{
General rights rights.

- You may freely distribute the URL identifying the publication in the public portal. please follow below link for the End User Agreement:

www.umlib.nl/taverne-license

Take down policy

If you believe that this document breaches copyright please contact us at:

repository@maastrichtuniversity.nl

providing details and we will investigate your claim.
}

Copyright and moral rights for the publications made accessible in the public portal are retained by the authors and/or other copyright owners and it is a condition of accessing publications that users recognise and abide by the legal requirements associated with these

- Users may download and print one copy of any publication from the public portal for the purpose of private study or research.

- You may not further distribute the material or use it for any profit-making activity or commercial gain

If the publication is distributed under the terms of Article $25 \mathrm{fa}$ of the Dutch Copyright Act, indicated by the "Taverne" license above, 
Molecular Remodelling

during Atrial Fibrillation 
2002 V.L.J.L. Thijssen

ISBN : 90-5278-358-6

Druk : Datawyse | Universitaire Pers Maastricht 


\section{Molecular Remodelling during Atrial Fibrillation}

\section{PROEFSCHRIFT}

ter verkrijging van de graad van doctor aan de Universiteit Maastricht, op gezag van de Rector Magnificus, Prof.Dr. A.C. Nieuwenhuijzen Kruseman, volgens het besluit van het College van Dekanen, in het openbaar te verdedigen op vrijdag 1 november 2002 om 12.00 uur

door

Victor L.J.L. Thijssen

geboren te Tegelen op 8 maart 1972.

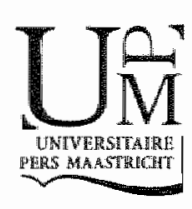


Promotor

Prof. Dr. M. Borgers

Co-promotores

Dr. J. Ausma

Dr. G.J.J.M. van Eys

Beoordelingscommissie

Prof. Dr. R. Reneman (Voorzitter)

Prof. Dr. H.J.G.M. Crijns

Prof. Dr. M.H. Hofker

Prof. Dr. F.C.S. Ramakers

Prof. Dr. B. Wieringa (Katholieke Universiteit Nijmegen)

Financial support by the Netherlands Heart Foundation for the publication of this thesis is gratefully acknowledged.

Additional financial support for the publication of this thesis was provided by Vitatron Medical BV (Arnhem. The Netherlands). 
The great tragedy of Science - the slaying of a beautiful hypothesis by an ugly fact.

Thomas Henry Huxley, 1825 - 1895 


\section{Contents}

Chapter 1 | Introduction

Structural Changes of Atrial Myocardium during Chronic Atrial Fibrillation

$$
\text { Aim of this Thesis }
$$

Chapter 2 |

Structural Remodelling of Atrial Myocardium in Patients with Cardiac Valve Disease and Atrial Fibrillation

Chapter $3 \mid$

Altered Expression of Troponin I Isoforms in Patients with Atrial Fibrillation 
Analysis of troponin I isoform expression during chronic atrial fibrillation in the goat

Analysis of altered gene expression during sustained atrial fibrillation in the goat

Chapter $6 \mid$ Discussion

Structural remodelling during chronic atrial fibrillation: act of programmed cell survival

Summary

Samenvatting

Curriculum Vitae

List of Publications

Dankwoord

References 



\section{Chapter 1 Introduction}

adapted from

STRUCTURAL CHANGES OF ATRIAL MYOCARDIUM DURING CHRONIC ATRIAL FIBRILLATION

V. Thijssen, J. Ausma, G-S. Liu, M. Allessie, G. van Eys, M. Borgers

Cardiovasc Pathol 2000; 9: 17-28 


\section{$1 \mid$ Intraduction}

Atrial fibrillation (A.F) is a cardiac arthythmia that is electrocardiographically characterised by irregular and disorganised atrial activity with respect to both rate and rhythm. At present. $A F$ is one of the most frequently detected arrhythmia's in the clinical setting. In the western population, AF occurs with a prevalence of $0.9 \%$ and AF is strongly related to increasing age. In people over 40 years, prevalence already is $2.3 \%$, rising up to $5.9 \%$ for those older than 65 years? Apart from advanced age, risk factors for $A F$ include diabetes, hypertension, congestive heart failure, rheumatic and non-rheumatic valve discase, myocardial infarction, and ischemic heart disease $e^{2-5}$. Furthermore, AF is not only an independent risk factor for stroke, but AF by itself is also associated with a 1.5- to 1.9-fold increase in mortality risk ${ }^{5-7}$.

The mechanism(s) by which AF is sustained have been a great puzzle for many decades and several theories were proposed ". Nowadays, Gordon K. Moe's 'multiple wavelet' hypothesis is generally accepted to describe the cause and maintenance of AF ${ }^{2.13}$. In the development of this hypothesis as well as in the understanding and knowledge of the various mechanisms and behaviour of different cardiac arrhythmia's, experimental models have played an important role $\mathrm{e}^{1+16}$. The last 20 years, animal models on AF have been mainly used to study anti-arrhythmic therapeutic interventions ${ }^{17-?}$. The last decade research more and more shifted towards cellular aspects of $\mathrm{AF}$, concentrating on possible mechanism(s) and underlying cellular changes ${ }^{21-24}$.

\section{$2 \mid$ Structural remodelling in patients with AF}

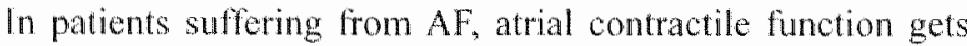
disturbed and the time and extent of recovery of function following cardioversion is related to the duration of $A F^{253}$. It was observed that immediately after cardioversion, atrial contraction was usually weak, but its strength increased progressively during the initial weeks of regained sinus thythm ${ }^{5.2}$. Whether the delayed recovery after longer periods of AF was caused by calcium overload or due to changes in atrial function and/or structure remained unknown. In 1983, Mary-Rabine et al. described the presence of cellular degeneration in the atrial cardiomyocytes of patients suffering 
from atrial arrhythmia's. This degeneration consisted of focal accumulation of sarcoplasmic reticulum, mitochondrial aggregation, widening of the undifferentiated portions of the intercalated discs, and replacement of myofibrils by glycogen granules ${ }^{39}$. Similar observations were made in patients with lone atrial fibrillation by Frustaci et $a l^{30}$, in patients with combined valvular disease and atrial fibrillation by Thiedemann et al. ${ }^{31}$, and in our group ${ }^{88}$. In the latter group of patients, a clear differentiation could be made between adaptive and maladaptive

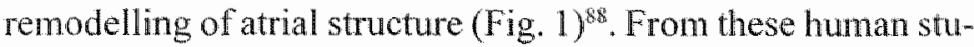
dies it was not clear whether there was a causal relationship between observed changes and arrhythmia. In order to elucidate this issue, animal models in which time related events of AF could be studied had to be developed.

\section{Structural remodelling in animal models on AF}

In 1997, two papers were published, which addressed the structural changes in atrial myocardium of goats after prolonged periods of sustained $\mathrm{AF}^{32,33}$. In atrial myocytes from such animals, the following structural changes were observed using lightand electron microscopy (Fig. 2): i) Cardiomyocytes gradually disposed of their contractile material, starting from the perinuclear region towards the periphery of the cell. Remnants of the sarcomeres, especially clumps of Z-band material, were frequently observed; ii) Glycogen had accumulated in sarcomere depleted areas; iii) A network of disorganised membranes, probably altered profiles of sarcoplasmic reticulum, were present in myolytic areas; iv) Mitochondria took on an elongated shape with longitudinal orientated cristae which appeared in cross sections as small, doughnut-like structures; v) Nuclear heterochromatin showed a homogenous distribution throughout the nucleoplasm ${ }^{32}$, In 1982 Boyden et al. described that in the enlarged atria of dogs suffering from mitrall valve fibrosis, a condition often accompanied by arrhythmia's, a small number of altered cells, characterised by sarcomere disruption, myolysis and giycogen accumulation, the presence of collapsed tubules of sarcoplasmic reticulum, and aggregates of abnormally shaped mitochondria, were present ${ }^{34}$. These observations in dogs as well as those described by Mary-Rabine in humans, showed several similarities to the findings after prolonged sustained atrial fibrillation in goats (Table 1) ${ }^{32}$. However, the structural chan- 


\section{Figure 1}

Electron microscopy of adaptive and maladaptive ullastructurat changes in atrall myocardium of patients whth cardiac wabe disease and atrial fibrillation.

a) A hypertrophed atriat cardiormocyte in which adsaptive structurat remodelling, i.e. myolysis, glycogen 5 torage (gl) and rutumerouls small arnd abnormatly shaped mitachondria (m), are visible

(Original magn $: \times 1425)$.

Inset: light microsicopy of atrial myocardium from patient, suined with PAS/ tolutine blue, in which large amount of glycogen is visible

as darkly stained material

Coriginal magn.: $\times 400$ ).

b) Detat of an adaptive atrial

cardionyocyte sitiowing extensive myolysis and storage of huge amounts of

glycogen (gl) in which numerous small and abmormally shaped mitochondria (m) are visibie

(Original magn.: $\times 2940$ ).

c) Maladaptive atrial cardionyocyte showing typical degeneratiwe freatures such as numerous secondary lysosome-litke bodies most probably of attophagic origin. Also an increase in extracellular natrix (em) can be seen (Orighinal magn.: x1760). Inset: light michoscopy of atrial myocardistm from patient with

degererated cells in which vacuoles (w) are visible within

the cytasol. PAS -stained glycongen is wistle as darkly stained naterial (Originat magn: $x 250$ ). d) Detail of a

maladaptive atrial cardiamyocyte showing

cylosolic blebs filled with membranewound wesicles and amorphous bodies of unknown onigin priginal magn: x 280$)$

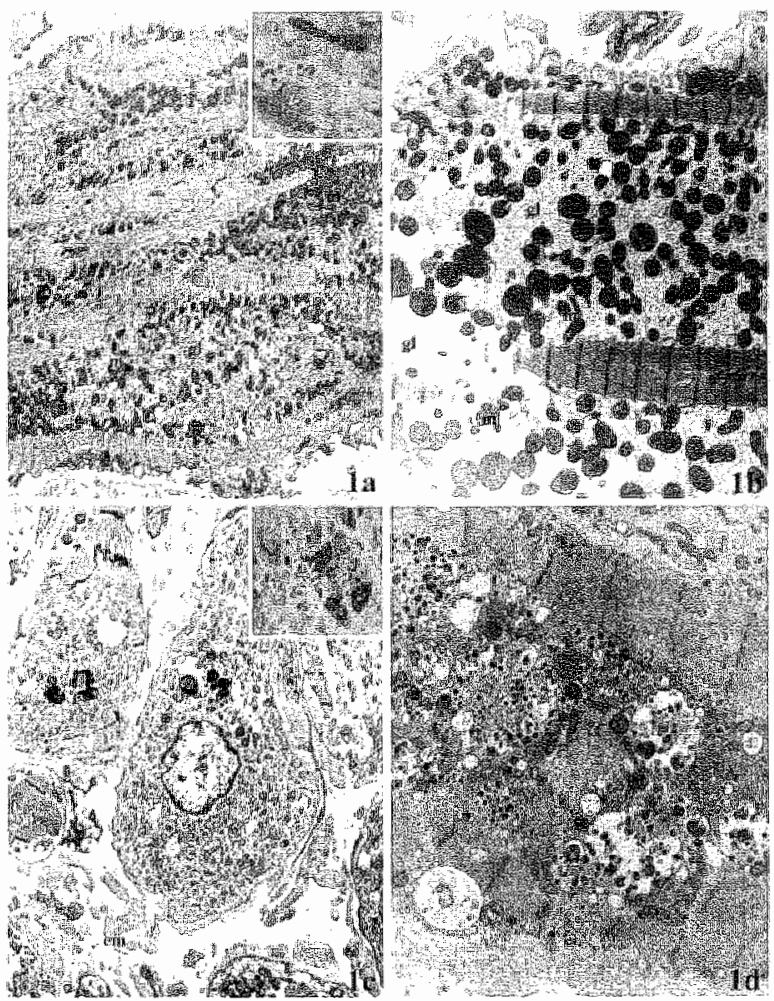

ges in the goat study were not interpretated as 'degenerative', because typical degenerative changes, such as cytoplasmic vacuolisation and oedema, mitochondrial swelling, loss of membrane structure and organisation, accumulation of secondary lysosomes, and lipid droplets appeared to be virtually absent ${ }^{32}$. Moreover, morphological changes specific for apoptosis, such as increased cytoplasmic density occurring with cell cytoplasm shrinking, the appearance of apoptotic bodies or condensation of nuclear chromatin were not present after chronic atrial fibrillation in the goat ${ }^{35}$. In addition, neither altered expression of $\mathrm{Bcl}-2, \mathrm{P} 53$ or proliferating cell nuclear antigen nor an increase in TUNEL reactivity could be demonstrated ${ }^{35}$, suggesting that apoptosis does not play an important role in the observed remodelling of cardiomyocyte structure during $\mathrm{AF}$. The lack of increase in extracellular space (fibrosis) suggested that prominent cell death, resulting either from apoptosis or necrosis, had not taken place. However, Mongeon et al. (unpublished) observed that after extensive periods of AF in dogs (up to 18 months), more severe changes do occur, including an increase of extracellular space, eluding to the fact that cell 


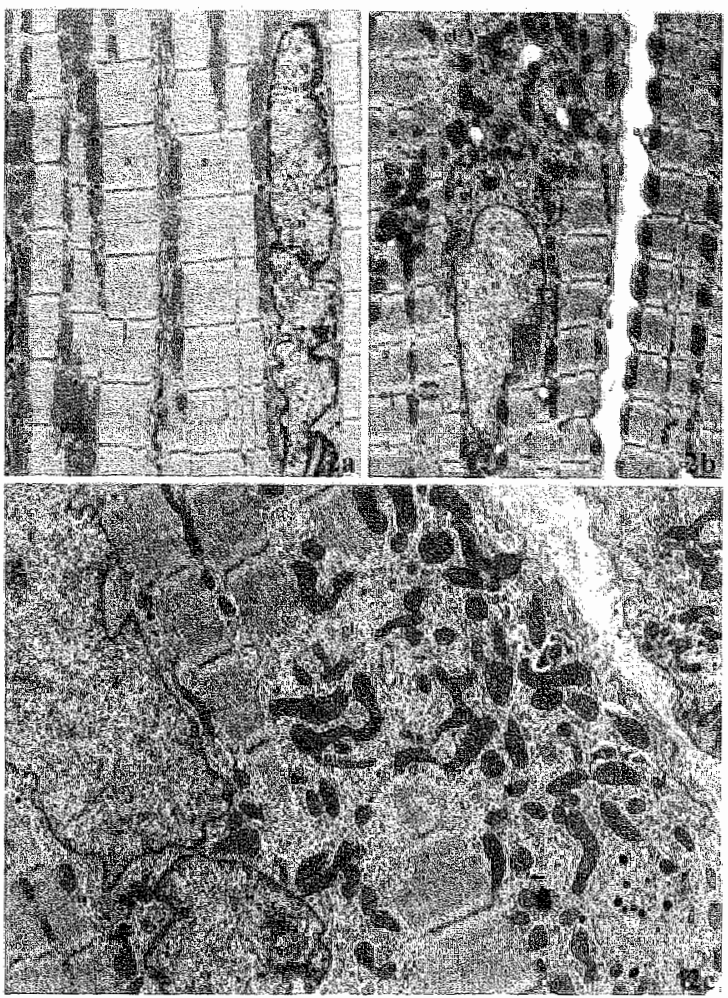

death might have occurred (Fig. 3).

Ausma et al. ${ }^{32}$ hypothesised that the perceived structurall alterations represented an adaptive response of dedifferentiation rather than cardiomyocyte degeneration, because many of the features seen in the atrial myocytes during sustained AF were also present during myocyte development. To determine whether chronic atrial fibrillation incited atrial myocytes to adopt a dedifferentiated state, the expression and organisation of proteins that are characteristic of cardiomyocyte development were examined ${ }^{33}$. A number of observations were made supporting the hypothesis that chronic AF induced myocardial dedifferentiation (Fig. 4): i) $\alpha$-Smooth muscle actin, of which the expression in normal cardiomyocytes is gradually lost during cardiac development, was re-expressed during AF; ii) Titin epitopes gradually disappeared in a pattern reverse to the pattern seen during cardiac development, resulting in a molecular organisation similar to that in the fetal stage; iii) Cardiotin, a sarcoplasmic reticulum related protein, of which the expression has not been seen during fetal development, disappeared during chronic AF; iv) Desmin co-localisation with desmoplakin and

\section{Figure 2}

Electron microscopy of atrial mycoardium from goats in sinus thythm and after prolonged sustained atrial fibrillation.

a) Detail of an atriat myocyto from a goat in sinus rothym. Sarconeres. (s) are regularly structured and surrounded by rows of mitochondria $(m)$. In the mucleus (17), dustered heterochromatin (arows) is visible at the nuclear membrane (original magn: $\times 3400$ ).

b) Detail off an atriat myocyte from a goat after 4 weeks of sustained $A F$. Although normally structured sarcomeres ( $s$ ) are still present, myolysis has occured in the vicinity of the nucleus ( $n$ ). In the myolytic area, glycogen (gl) is present together with odd shaped mitochondria (m). Instead of a clustered pattern, heterochromation is evenly distributed throughout the nucleoplasm (originat magn.: $\times 2000)$.

c) Detail of an atrial myocyte from a goat after 16 wereks of sustained AF showing a myolytic area with glycagen (gl) accumulation, numerous. albonomaly sinaped mitochondría (m), and rennants of sarcoplasmic reticulum (arrows). Also, the nudreus $(n)$ with dispersed chromatin is visible (original magn.: $x$ $4600)$. 


\section{Table 1}

structural changes in atriat cardiomyocytes after Af

Hwhuman, Düdog, Grigoat, $S R=$ sarcoplasmic neticulum a Wouters at. umpublished $)$, b $(29) ; c$ (32), d (Mongeon et al., unpublished): $(34)$;

(31). Features that appeaf in italic are also present in fetal cardiomyocytes.

\begin{tabular}{|c|c|}
\hline \multicolumn{2}{|c|}{ structural changes } \\
\hline adaptive & maladaptive \\
\hline 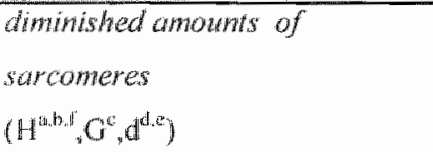 & $\begin{array}{l}\text { increased extracellular matrix } \\
\left(\mathrm{H}^{\mathrm{a}}, \mathrm{D}^{4}\right)\end{array}$ \\
\hline accumulated glycogen & cytosolic blebbing \\
\hline$\left(H^{3,6,6}, \mathrm{G}^{\mathrm{e}}, \mathrm{D}^{\mathrm{d}, \mathrm{e}}\right)$ & $\left(H^{\mathrm{a}}\right)$ \\
\hline small, elongated mitochondria & mitochondriat disruption \\
\hline$\left(H^{a+r}, \mathrm{O}^{\mathrm{e}}, \mathrm{D}^{\mathrm{d}}\right)$ & $\left(H^{a, b},{ }^{\prime}, D^{d}\right)$ \\
\hline disorganised $S R$ & focal accumulation of SR \\
\hline$\left(H^{\mathrm{i}}, \mathrm{G}^{\mathrm{e}}, \mathrm{D}^{\mathrm{d} d \mathrm{~s}}\right)$ & $\left(\mathrm{H}^{b+f}\right)$ \\
\hline increased cell size (hypertrophy) & increased cell size (hypertrophy) \\
\hline$\left(H^{\mathrm{r}}, \mathrm{G}^{\mathrm{e}}\right)$ & $\left(\mathrm{H}^{\mathrm{f},}, \mathrm{D}^{\mathrm{d}}\right)$ \\
\hline homogenous distribution of & secondary lysosomes \\
\hline heterochmomatin $\left(\mathbb{H}^{\mathrm{a}}, \mathrm{G}^{\mathrm{e}}, \mathrm{D}^{\mathrm{d}}\right)$ & $\left(H^{3 i n}\right)$ \\
\hline
\end{tabular}

desmoglein, which play a role in the myofibril attachment to the junctional membrane, was lost. This detachment of desmin from the intercalated disc resembled its organisation in certain stages of cardiomyocyte development ${ }^{3 \hat{3}}$. All the observed structural changes as well as the changes in expression and organisation of muscle cell specific proteins, were indicative of a fetal-like phenotype. However, the cardiomyocyte dedifferentiation was limited because markers of early myocardial development could not be detected (vimentin, cytokeratin 8 and 18) and in cardiac myocytes in which normal sarcomeres were present, the expression of sarcoplasmic proteins also appeared to be normal ${ }^{33}$.

To evaluate the time course of the process of dedifferentiation, the structural changes in cardiomyocytes were analysed after 1, $2,4,8$, and 16 weeks of burst pacing induced $\mathrm{AF}$ in goats and compared to normal cardiomyocytes. The first change to be observed was a redistribution of chromatin in the nucleus. Progressive increase in myolysis and subsequent glycogen storage was seen till 8-16 weeks, simultaneously with depletion of sarcoplasmic reticulum and gradually increasing numbers of 


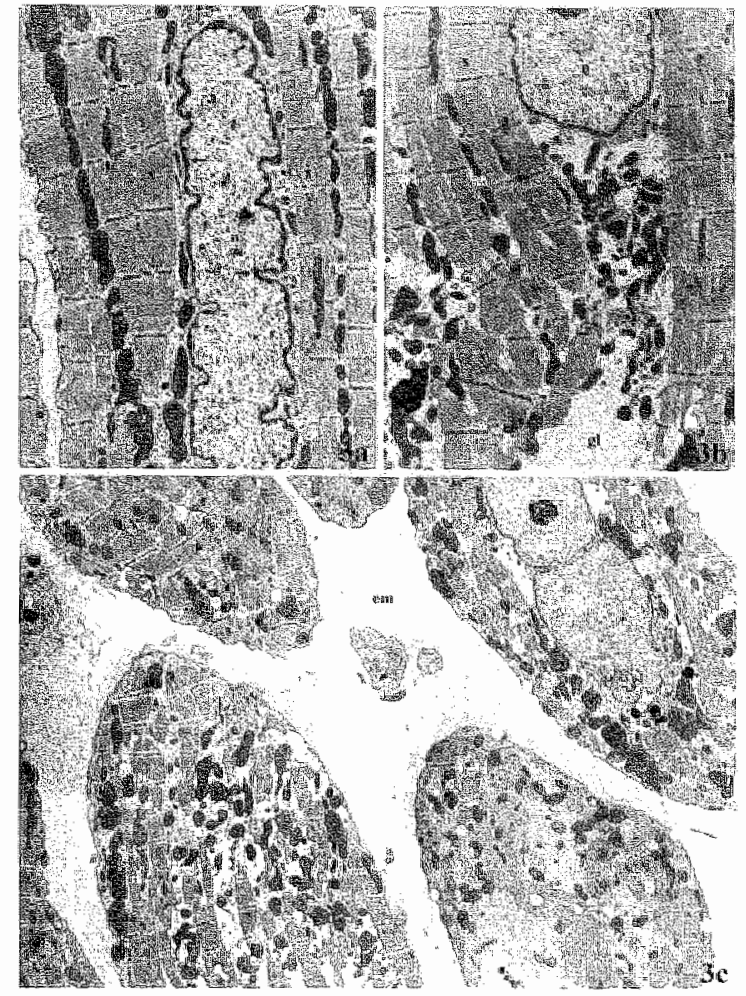

small mitochondria ${ }^{36}$. Immunohistochemical studies showed changes in the presence of structural proteins. Proteins normally present in differentiated cardiomyocytes, i.e. cardiotin, titin and desmin, gradually disappeared whereas $\alpha$-smooth muscle actin, a fetal protein, reappeared ${ }^{37}$.

\section{$4 \mid$ Mechanisms of structural remodelling}

The cause and mechanisms underlying the structural changes during $\mathrm{AF}$ are not well understood, and several factors may be involved in the onset of dedifferentiation of cardiomyocytes.

\section{1 | Ischemia}

In 1982, White et al. showed that induction of AF resulted in a more than twofold increase of blood flow and oxygen consumption in the atriall tissue $e^{3 \%}$. As a result, the flow reserve during $\mathrm{AF}$ will be markedly reduced and a further increase in metabolic demand might lead to atrial ischemia. Opposite to this, Jayachandran et al. reported a reduced atrial blood flow in

\section{Figure 3}

Electron microscopy of atrial myocardium from dogs in sinus mythrm and after prolonged sustanined atrial fibrillation.

a) Detail of an atmal myocyte from a hog in sinas rhythm, showing monnaly structured sarconeres (s) bordered by rows of mitochondria (n) and heterochomiatin clustering (arrows) at the membrane of the nucleus (n)(Onginal magn.: $\times 3400$ ) b) Detail of an atrial mocylte from a dog with sustcined AF for 18 montlis. Sarcomeres (s) are depleted and replaced by glycogen (gl). Numerous addly shaped mitochondrita (m) are present and nuclear (n) chromatin is dispersed (Oniginal magn.: $\times 2720$ ). c) Aurial myocandum from a dog with sustained AF for 18 months. Apart from typical changes, i.e. myolysis, glyogon accumulation and the presence of oddly shaped mitochondria, also a clear increase in extracellular matrix (em) is visiblite (Original magn .: $x 1320$ ). 


\section{Figure 4}

Inmunohistachemistry on atrial myocartum from goats in sinus whtrin and after 16 weeks of sustumed atrial fibrillation

a,c) In cardionnorytes from a goat in sinus rhythm a clear titun double-band cross strition is vistble (a: arighnat magn: $: 400$ ). Affer 16 weeks of sustained atrial fionilation, the crossstriations are interrupted and a crily a dotted pattern remains visible at the pertiohery of the cardionyocyte ( $c_{*}^{*}$ original magr.: $\times 400)$. b.d) In cardionyocytes from a grate in sinus whythm a single banded crossstriation pattern together with intercalated disc staining can be seen for desmin (b; original magn.: $\times 400)$. Sixteen weeks of results in a less apparent. staining of the cross striations als well as the intercalated disc $(d$; oniginal magn.: $\times 200$ ).
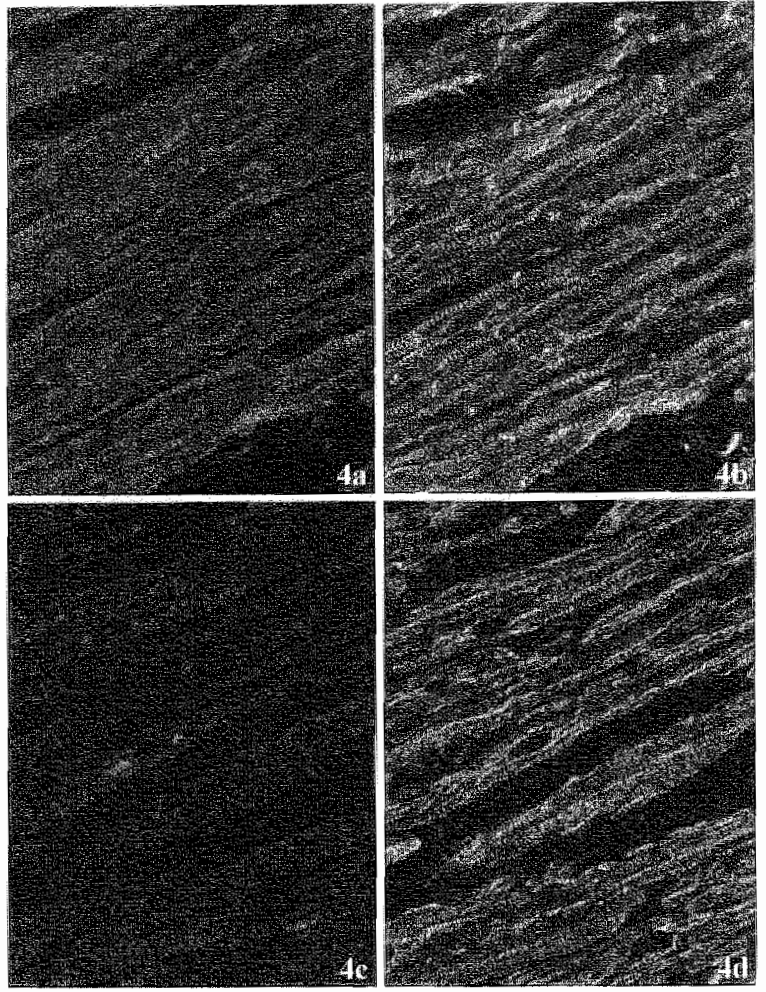

dogs with rapid pacing induced $\mathrm{AF}$, but again the result would be atrial ischemia ${ }^{39}$. In chronic hibernating myocardium, a condition occurring in patients as a result of low-flow ischemia, the ventricular cardiomyocytes display structural changes that are similar to the changes seen in chronic AF ${ }^{40.41}$. These changes have been suggested to be an adaptive response of the cardiomyocytes to a lowered oxygen supply, to resist the ischemic environment present in chronic hibernating myocardium ${ }^{42}$. In contradiction to the previous studies, it has been suggested that in the goat model of AF ischemia was absent because neither changes in cytochrome c oxidase, NADH oxidase and proton-translocating ATPase activities, nor changes in adenine nucleotides and their degradation products have been found ${ }^{43}$. A decrease in creatine phosphate which has been observed in goats and pigs after AF was probably the result of increased metabolism rather than an effect of ischemiat:44. Whether ischemia actually occurs during AF, giving rise to cardiomyocyte remodelling, is unknown. 


\section{2 | Stretch}

Early after the induction of atrial fibrillation a diminished contractility occurs ${ }^{44}$, and a decrease or absence of regular contractile activity results in increased passive stretch, due to volume overload. Stretch has been shown to influence atrial protein expression ${ }^{4548}$. Furthermore, passive stretch might explain the observed increase in cell size of the cardiomyocytes ${ }^{40}$ 5. Mary-Rabine et al. and Ausma et al. found a clear correlation between the degree of myolysis and cell size, with an almost 2 fold increase in size of severely affected cells $\mathrm{s}^{29,32}$. This increase in cell size of the cardiomyocytes after AF might therefore reflect stretch induced hypertrophy.

Apart from these direct effects on atrial myocytes, atrial stretch has also been shown to facilitate the development of sustained AF by heterogeneously prolonging the atrial effective refractory period within the atrial tissue $e^{52.53}$. Therefore, atrial stretch might not only be a result of atrial fibrillation but it may also be held responsible for the maintenance of both electrical and structural atrial remodelling.

\section{3 | Calcium homeostasis}

There are several major differences between calcium handling in the fetal and adult heart, as reviewed by Nijjar et al. and Vornanen $^{3.45}$, and it is beyond the scope of this introduction to describe them in detail. However, one of the possibly important changes in calcium homeostasis which occurs at the onset of AF is calcium overload ${ }^{44.56-5 k}$. In goats with AF there was clear evidence of calcium overload, but it appeared that after two weeks of AF, cardiomyocytes were able to adapt to the new calcium homeostasis and after 16 weeks of AF, no more signs of calcium overload could be found ${ }^{5 \%}$. This adaptation of the calcium homeostasis coincided with the structural remodelling of cardiomyocytes during AF, and it was proposed that cardiomyocyte dedifferentiation served as a protective mechanism against calcium overload ${ }^{39}$.

In dogs, a reduction in the transient L-type calcium current $\left(I_{\text {Car }}\right)$ has been described after rapid atrial pacing for 1 or 6 weeks ${ }^{24}$. In these dogs, the amplitude of calcium release was reduced and the kinetics of calcium release and re-uptake was slowed down, indicating an impaired calcium homeostasis and 
depressed contractility ${ }^{60}$. Although short term inhibition of Ltype calcium channels might be the result of high intracellular calcium concentration, i.e. calcium overload ${ }^{61}$, it was suggested that regulation of expression of L-type calcium channels might be involved in the long term changes of $I_{\text {Cal }}$ as observed in dogs ${ }^{60 .}$. Studies in rat and rabbit cardiomyocytes have demonstrated that there is an increase in peak $I_{C a l}$ density during development and after birth ${ }^{626.63}$. Therefore, the observed decrease of $I_{C a !}$ during AF might reflect a return to a less differentiated state.

\section{5 | Future perspectives}

\subsection{Reversibility}

As already mentioned, it has been observed that patients suffering from AF show a delay in recovery after cardioversion ${ }^{25.28}$. A delay in the restoration of contraction after treatment of cardiomyocytes in vitro with verapamil, was also reported by Sharp et al. ${ }^{64}$. Ausma et al. hypothesised that the delayed contractile recovery might be due to the time needed by atrial cardiomyocytes to undo the structural changes that occur during extended periods of $\mathrm{AF}^{32}$. Furthermore, the time course of structural changes indicated that longer episodes of AF resulted in increased severity of structural alterations ${ }^{36}$. Whether the cardiomyocytes were able to return to their normal phenotype after induction of normal sinus rhythm or if there was a point of no return, remained unknown. Studies on the possible reversibility of structural remodelling after AF might answer these questions and provide leads to improve efficacy of clinical interventions.

\section{2| Molecular mechanisms}

The molecular mechanisms leading to the adaptive phenotype of cardiomyocytes during AF are largely unknown. In fact, little is known about the molecular response of cardiomyocytes to AF. Van Wagoner et al. found that in patients with chronic AF, the outward potassium current densities were reduced together with a $50-60 \%$ decrease of KV $1.5 \alpha$ subunit expression ${ }^{6.5}$. They implied calcium overload as a possible trigger responsible for this observation.

Calcium overload was also suggested to cause a reduced sodium 
current density in atrial myocytes of dogs after 7 days of rapid atrial pacing, possibly by downregulation of sodium channel expression level ${ }^{\text {st }}$. Previously, increased calcium concentration had been shown to downregulate sodium channel expression in rats $^{67}$. Although the changes in potassium and sodium current densities were associated with a shortening of atrial effective refractory period, thereby serving as possible substrates for sustaining AF, their involvement in the observed dedifferentiation of cardiomyocytes is unknown.

To investigate the molecular mechanisms that are involved in cardiomyocyte adaptation to chronic AF, expression screening techniques like differential display as described by Liang and Pardee ${ }^{6.8}$ can be applied. This technique has already been used to identify or confirm altered expression of genes that are involved in several cardiac diseases ${ }^{69-74}$. Studies in which differential display has been used on cardiomyocytes after AF have not been presented so far, probably because differential display is a rather new technique and animal models on AF only recently became available. Comparing expression patterns in the atria of goats at different time intervals of AF might identify not only unknown genes that are upregulated or downregulated but also genes which are transiently expressed during AF. These genes might be important in expression regulation and control of structural remodelling, and they might provide information about the underlying pathways. A better understanding of the causes and triggers for structural remodelling could offer leads for better treatment of patients suffering from chronic AF by slowing down, blocking or even reversing the structural remodelling, thereby improving atrial conduction and contractile function.

\section{$6 \mid$ Concluding remarks}

Atrial fibrillation has fascinated numerous investigators from various scientific fields ever since it was described. Almost the entire twentieth century efforts to elucidate the mechanisms of this intriguing arrhythmia have been made by anatomists, morphologists, electrophysiologists, and since the last decade also by molecular biologists. All have provided information on the changes during $A F$, but essential questions remain to be answered. What triggers the atrium to end normal sinus rhythm and start fibrillating? Does structural remodelling precede, 
coincide or follow electrical remodelling? To what extent are the consequences of $\mathrm{AF}$, i.e. electrical and structural remodelling, reversible? Is structural remodelling really a protective adaptation or merely a delayed degeneration? Which molecular mechanisms are involved in AF? Is susceptibility to AF genetically imprinted? All these aspects, and more have to be studied to fully comprehend how atrial rhythm gets disturbed and how this irregularity persists and eventually results in atrial dysfunction or even death.

Experimental models are essential tools for investigating AF and it is important that such models mimic the in vivo situation in humans as much as possible. However, most models availlable at present represent 'Ione' fibrillation, i.e. fibrillation in the absence of other cardiac complaints, whereas in general, AF patients suffer from an underlying heart disease. Hence, in models of lone AF, the influence of a heart disease on $\mathrm{AF}$ and their relationship remains unknown. Furthermore, in humans, AF often occurs at a later age and lasts for many years, a situation which is difficult to simulate in animal models. Thus, age related and long term effects of AF can not be easily studied using animal models. Despite these limitations, experimental models have proven to contribute considerably in the study of AF and refinement of these models will only increase their value.

Up to now, experimental models of AF have predominantly been used to elucidate the electrical and structural aspects. Electrical remodelling has been found to occur at the onset of $\mathrm{AF}$ and appears to be completed after two weeks. The first obvious signs of structural remodelling become apparent after 2 to 4 weeks of $A F$ and reach a steady state between 8 to 16 weeks. However, little is known about the molecular mechanisms that underlie both electrical and structural remodelling. Changes in the expression levels of channels appear to be involved in electrical remodelling whereas in structural remodelling expression of structural proteins appears to be altered.

During $\mathrm{AF}$, cells have to translate changes in activation patterns, stretch, and/or oxygen availability into new cellular structures by inducing/suppressing different sets of genes. One of the first changes seen in cardiomyocytes after AF is the redistribution of heterochromatin within the nucleus, which indicates that the cell is actually reorganizing its genetic material to cope with the new situation. Our lack of knowledge about such a shift in gene expression, which might be considered as molecular 
remodelling, emphasises the increased demand for molecular biological input. The development of new molecular techniques to screen differences in gene expression, e.g. differential display, serial analysis of gene expression, and DNA arrays, together with the advancement of knowledge in functional genomics, will help to answer questions related to the nature of molecular remodelling and its role in electrical and structural remodelling during AF. A combined implementation of (electro)physiological, morphological, and molecular biological techniques, will enable scientists to unravel the nature of this fascinating arhythmia.

\section{$7 \mid$ Aim of this thesis}

The main goal of this study was to establish the role of altered gene expression (molecular remodelling) on the induction and maintenance of atrial remodelling during AF. The first part of the study focussed on structural remodelling in the atria of patients with $A F$. Subsequently, the changes in the composition of Troponin I isoforms in patients with AF were studied. Due to the complex etiology in patients, the Troponin I expression was further analysed in the goat model of AF. Finally, the goat model was used to analyse the changes in atrial gene expression during AF. Differential display was performed to identify unknown genes involved in atrial remodelling during atrial fibrillation in order to unravel the molecular mechanisms underlying the pathophysiology of AF. 



\title{
Chapter 2
}

\section{STRUCTURAL REMODELLING OF ATRIAL MYOCARDIUM IN PATIENTS WITH CARDIAC VALVE DISEASE AND ATRIAL FIBRILLATION}

\author{
L. Wouters, G-S. Liu, W. Flameng, V. Thijssen, F. Thonë, M. Borgers
}

Exp Clin Cardial 2000; 5:158-163

Objectives: The aim of this study was to assess both qualitatively and quartitatively the structural alterations in atrial myocardium associated with cardiac walve disease with or without atrial fibrillation (AF).

Methods: Of sixty-two consecutive patients from two hospital centres that underwent surgery for mitral, tricuspid, or aortic valve repair, a biopsy was obtained from the right atrium appendage. Light microscopic morphometry was carred out and the percentage of myocytes with either myolytic or degenerative changes, the anount of connective tissue, and the average cell surface area were scored.

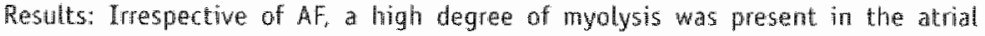
cardiomyocytes. Atrial myocytes in patients with AF were significantily larger than in patients without AF. There was a significant positive correlation between cardionyocyte size and structural changes. Electron microscopy showed that the majority of altered cardiomyocytes displayed the structural characteristics of foetal heart cells sucth as a decreased amount of myofibrits, large increase in glycogen, unorganised sarcoplasmic reticulum, mitachondria of varying size and shape, and nuclei with dispersed heterochromatin.

Comelusions: Atrial myocytes of patients with valvular heart disease and Af show structural changes similar to those seen in wentricular myocytes from chronic hiberrating myocardium and atrial myocytes in a goat model of sustained chronic AF. These structural changes may explain the depressed contractile behaviour of the atriat myocaidiun during AF and the delay in recovery of contractility after cardioversion. 


\section{1) Introduction}

Atrial fibrillation (AF) occurs quite commonly in various types of valvular heart disease and it may be reverted to normal sinus rhythm by means of pharmacological or electrical cardioversion. However, a delay in recovery of atrial contractile function after cardioversion of atrial fibrillation is often noticed. Usually, after cardioversion, contractile strength increases progressively to reach normal values ${ }^{25.28 .75}$. It has been shown that the time course of recovery of atrial function is related to the duration of $\mathrm{AF}^{3}$ ${ }^{27}$. Up to now, it is still not clear whether this delay in recovery is due to functional or structural changes of the atrium.

Structural changes, such as cell hypertrophy and degenerative changes in the right atrium of patients with valvular heart disease were already reported in the $1970 \mathrm{~s}^{33.76}$. Complex structural changes were also described by Mary-Rabine et al. in atrial myocytes of patients with heart disease of various causes ${ }^{29}$. In about $30 \%$ of the patients these authors observed degenerative changes accompanied by changes in cellular substructures, such as loss of myofibrils, presence of glycogen granules, accumulation of sarcoplasmic reticulum-like material and aggregates of mitochondria. In the majority of patients with degenerative changes, the changes were accompanied by the presence of hypertrophied cells with an increased number of myofilaments, lobulated nuclei, and focal widening of $Z$-bands ${ }^{29}$. Furthermore, a relationship between these degenerative changes and the occurrence of atrial arrhythmias could be established. However, at that time, the concept of dedifferentiation of cardiomyocytes, as observed in the left ventricle of patients with coronary artery stenosis, had not been put forward ${ }^{40}$. This idea of cardiomyocyte dedifferentiation raised the question whether the ultrastructural changes, originally described as degenerative could correspond to dedifferentiation rather than to degeneration and if so, is the dedifferentiation a cause rather than a consequence of atrial arrhythmias?

Recently, in a goat model of sustained AF, structural changes were observed which resemble dedifferentiation, more than degeneration ${ }^{32}$. After 9-23 weeks of sustained AF, most of the atrial myocytes showed a number of cellular changes including myolysis, accumulation of glycogen, changes in mitochondrial shape and size, and dispersion of nuclear chromatin. The dedifferentiation of the atrial myocytes was accompanied by an 
increase in celfular size and reorganisation of protein expression to a more foetal like pattern ${ }^{33}$. Degenerative changes were present only to a small extent and there were no obvious signs of apoptosis $^{\text {32.35. }}$. Myolysis, glycogen accumulation, dispersion of nuclear chromatin and increased cardiomyocyte size were also reported by Aimé-Sempé et al in patients with dilated right atria and $\mathrm{AF}^{77}$. However, in addition to these adaptive changes and in contrast to the study in goats, a number of cardiomyocytes in these patients also showed signs of degeneration/apoptosis.

The purpose of the present study was to establish whether dedifferentiation rather than degenerative changes were involved in cardiac valve disease with or without chronic AF.

\section{2 | Methods}

\section{1 | Patients}

The study included sixty-two consecutive patients from two hospital centres located in Belgium $(n=32)$ and China $(n=30)$, who underwent surgery for mitral, tricuspid, or aortic valve repair. The study was approved by the local ethical committees for research. The diagnostic characteristics of the patients are listed in Table 1. In addition, atrial samples of 5 patients undergoing coronary bypass surgery without valvular involvement were taken as controls. In the Belgian study, there were 17 women and 15 men with age ranging from 43 to 83 years (median 69). The Chinese patients consisted of 17 women and 13 men, ranging in age between 20 and 59 years (median 42). The majority of the patients suffered from AF (Belgium 17/32, China 25/30).

\begin{tabular}{lcc}
\hline & Belgium & China \\
\hline Mitral valwe involvement & 23 & 28 \\
Tricuspid valve involventent & 7 & 14 \\
Aortic valve involwement & 14 & 15 \\
Rheumatic heart disease & 0 & 28 \\
Coronary heart disease & 14 & 0 \\
\hline
\end{tabular}

Table 1 |

clinical diagnosis of patients. 


\section{$2.2 \mid$ Microscopic examination}

Small biopsies, measuring $2 \mathrm{~mm}$ in diameter, were obtained from the right atrium during valvular and/or coronary surgery. The tissue samples were fixed in $3 \%$ glutaraldehyde buffered to $\mathrm{pH} 7.4$ with $90 \mathrm{mM} \mathrm{KH}_{2} \mathrm{PO}_{4}$, adjusted with $0.1 \mathrm{~N} \mathrm{KOH}$. After fixation for at least 24 hours at room temperature, the samples were washed in the same buffer for 24 hours and postfixed for 1 hour in $1 \% \mathrm{OsO}_{4}$ buffered to $\mathrm{pH} 7.4$ with $0.05 \mathrm{M}$ veronal acetate. Next, the samples were rapidly dehydrated through a graded ethanol series, and routinely embedded in the epoxy resin Epon. Light microscopic morphometry was performed on $2 \mu \mathrm{m}$ thick Epon sections. To quantify the degree of myolysis and to identify myolytic cells with accumulation of glycogen, sections were stained with periodic acid-Schiff (PAS) and counterstained with toluidine blue. In order to quantify the extent of myolysis in the cardionyocytes, a minimum of 100 myocardial cells (107-1277) per sample was evaluated. The extent of cellular changes was evaluated only in cells in which the nucleus was present in the plane of the section. Cells were identified by morphometry as myolytic if myolysis involved at least $10 \%$ of the cytosol. Cells were considered to be degenerative when secondary lysosomal structures (large inclusion bodies) were abundantly present.

To assess the amount of connective tissue in the myocardium, morphometry was carried out using a special grid with vertical and horizontal lines providing 121 intersections (points). This technique has been used in a previous study ${ }^{78}$. In accordance with the principles of morphometry, counting the number of points overlying a certain structure results in the quantitative determination of the volume of the structure under investigation in relation to the volume of the entire tissue under the square grid. The total number of points (121) was regarded as $100 \%$, and the points counted in the connective tissue were expressed as the percentage of the entire tissue within the limits of the grid. The axis of the grid was then rotated approximately 45 degrees and the points were counted again. The same procedure was performed on a different area of the same section. Longitudinal sections at magnification $\times 250$ were evaluated. Blood vessels and perivascular interstitial cells were excluded from the connective tissue.

Average cell surface area $\left(\mu \mathrm{m}^{2}\right)$ was evaluated by counting the number of cells in a $\| \mathrm{cm}^{2}$ grid with corrections for the amount 
of connective tissue $\mathrm{e}^{32}$.

Ultrastructural examination of the subcellular and extracellulat composition was performed on $50 \mathrm{~mm}$ thin sections. These were examined, either unstained or counterstained with uranium acetate and lead citrate, in a Philips CM 100 electron microscope.

\section{3 | Statistical Analysis}

Data on myolytic cell changes are summarised as median values and range. Differences between groups were tested for statistical significance by means of stratified Wilcoxon-Mann-Whitney rank sum test with the two hospital centres as the different strata. The relation between different morphometric measurements was evaluated using the partial Spearman rank-order correlation. In this particular application, the partial rank order correlation corresponds to a Pearson correlation on the ranked data, from which the average rank of the corresponding hospital centres is subtracted. This avoids bias due to differences in baseline. Exact two-sided P-values and 95\% confidence intervals for the Spearman rank correlation were obtained by Mont-Carlo sampling. In the decision making process, exact two-sided Pvalues less than or equal to 0.05 were considered to indicate statistical significance. Statistical computations were carried out in StatXact 4.0 and SAS6.12.

\section{3 | Results}

\subsection{Qualitative structural. changes}

Light microscopy: As expected, atrial tissue samples derived from non-fibrillating / non-valvular diseased patients showed uniformly well preserved cardiomyocytes surrounded by normal connective tissue (figure la). In all valvular diseased patients, irrespective of concomitant atrial fibrillation, changes were noticed which varied in number and extent from patient to patient (vide infra). These changes comprised depletion of sarcomeres (myolysis), accumulation of glycogen, and in general cell surface enlargement (figure $1 \mathrm{~b}$ ). In addition to these alterations, a number of clearly degenerative changes occurred in a limited number of patients. Cells were classified as degenerative when the cytosol became filled with huge secondary lysosomal structures (inclusion bodies) and/or vacuoles containing amorphous 


\section{Figure 1 |}

Highe micoscopic pictures of 2 un thin sections from atrial myocardiun.

a) Contro bisue with nomally structured cardiompyocytes. Sarcomeres, stained with toluidine blue, are present throughout the cytoplasm of the cardiomyocytes whereas glycogen (dark ancas) is wirtually absent (Original magn.: 400 ). b) Sectron from a patient showing myalytic areas in which the sarcomeres are replaced by glycogen (gl). Some remmants of sancomeres are still visible (arrows). il = nucleus (0righinal magn.: $\times$ s00).

c) Section from a patient showing a severely alfected area with cells containing huge glycogen filled vacuoles $(v)$ and versicles containing amorphous structures of unknown origin (arrows; original magn.: $\times 800)$.

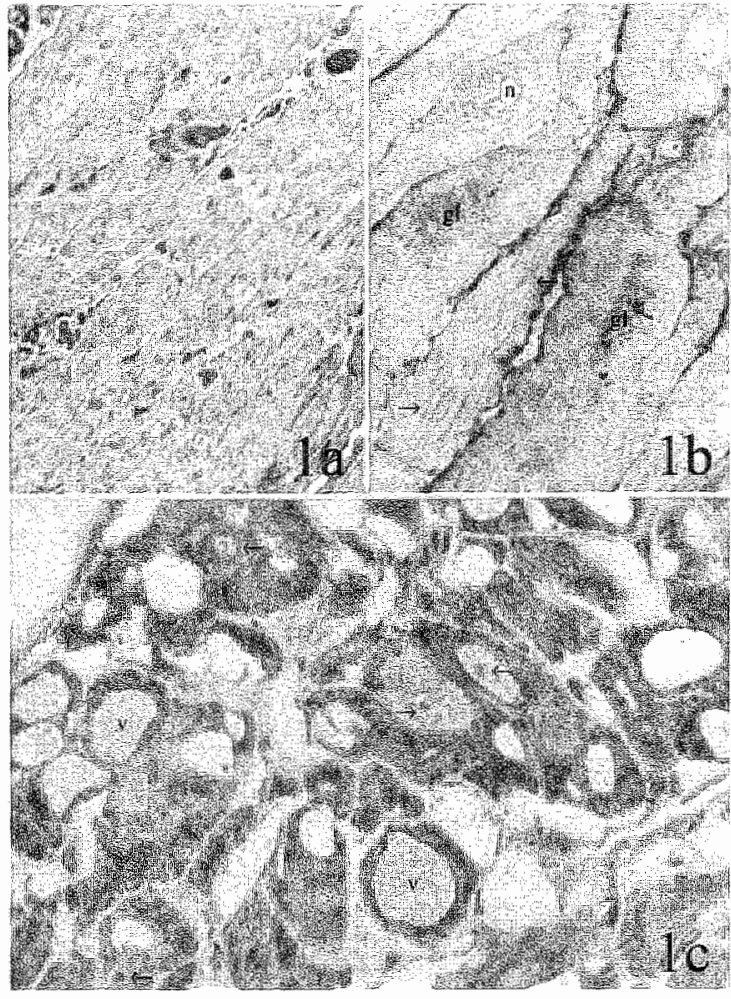

structures (figure $1 \mathrm{c}$ ). A remarkable difference between the Belgian and Chinese patients was the presence of glycogen filled vacuoles in the latter group.

Electron microscopy: Depletion of sarcomeres and the huge storage of glycogen, as observed by light microscopy, were confirmed by ultrastructural examination. In addition, other changes of a non-degenerative nature were seen in all samples of valvular diseased patients. Characteristic observations in such affected cells were (figure $2 \mathrm{a}-\mathrm{c}$ ): i) The presence of a large number of small, abnormally shaped mitochondria, embedded in a matrix of glycogen granules. ii) The depletion of smooth sarcoplasmic reticulum. iii) The frequent occurrence of strands of rough endoplasmic reticulum. iv) Golgi fields producing huge numbers of ANF containing granules. v) Nuclei with dispersed heterochromatin. As for the degenerative changes, cytosolic blebs filled with membrane-bound vesicles and amorphous bodies of unknown but most probably autophagic origin, were seen (figure $3 a$ ). In some samples, ultrastructural features were observed that might be related to the presence of apoptosis. These occurred in the most severely affected areas and presented 


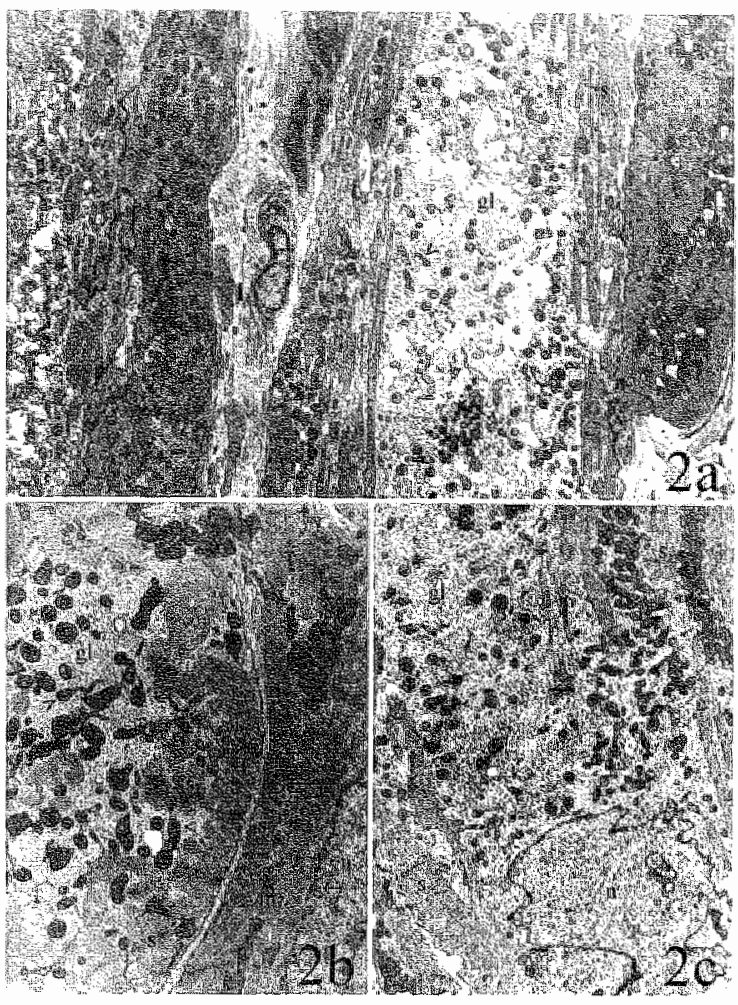

'horse-shoe' shaped nuclei with marked clumping of heterochromatin, and condensation of cytosolic compartments. These cells, in contrast to the above mentioned myolytic cells, were not hypertrophied and showed no signs of sarcomere loss (figure $3 b$ ).

\subsection{Quantitative structural changes}

Structural changes in patients with or without AF from the two hospital centres are summarised in Table 2. In patients, both with and without $\mathrm{AF}$, a considerable but highly variable proportion of the atrial myocytes (up to $97 \%$ ) was affected. The structural changes could be attributed mostly to myolytic changes, while more severe, degenerative changes were present only to a minor extent. Myolytic and degenerative changes did not differ significantly among patients with and without AF. Median values for cell surface area of atrial myocytes in patients without chronic AF corresponded to a shortest axis diameter of 10-12 $\mathrm{\mu m}$, values considered as normal by other authors ${ }^{29,77}$. However, a significant increase of cellular size was noted in

\section{Figure 2}

Electron micrascopic pictures of $50 \mathrm{~nm}$ thin sections from atrial myocardium.

a) Overviat of cardiomyocytes with different degrees of ultrastructural changes. The niddile cell shows extensive myolysis and sarcomeres (s) are only present at the cell border. The myolytic area is filled with glycogen (gl) and mamy oddly shaped mitochondria (arrow heads) are wisible. The darly stanned vesicles represent atrial granulles. Both neighbouring cells also show signs of myolysis. although less extensive. Again vumerous small and oddly shaped mitochondria are present in the myolytic areas (Original man.: $x$ 1800 ).

b) Detaul of a myolytic cardiomyocyte adjacent to a nomal cardiomyocyte. In the normal cardionyocyte (right), regularly structured sarcometes (s) are wisible with rows of mitochondria (m) in between. In the nucleus (n). clumped heterochromatin (arrows) is present at the nucleat membrane. Hhe myolytic cardiomyocyte (left) is filled with glycogen $(g l)$ and sarcomerems are only present at the border of the cell. Note the oddly shiped mitochondria (arrow head; original magri. $\times 3400$ ). c) Devail of at severely affected cell containing huge amounts of glycagen (gi) and only remants of sarcomeres (s). Note the evenly distributed chrornatin in the nucleus (n; original magn: $\times 2100$ ). 


\section{Figure 3}

Electron microscopic pictures of cardionyocyte degeneration.

a) Detat of severe degeneration comprising mecrotic remants, cylosolic blebs filled with vericles. and the presence of indefinable bodies of unknown origin (Original magn: $x 2500 \%$

b) Detall of a possibly apoptotic cardionyocyte. A huge vacuole containing glycogen (gl) is surrounded by nomally structured sarcomeres (s) and mitochondria (m), white the horse-shoe' shaped nucleus (n) shows marked clumping of the metterochromatin (arrows: original magn.: $x$ 7700).

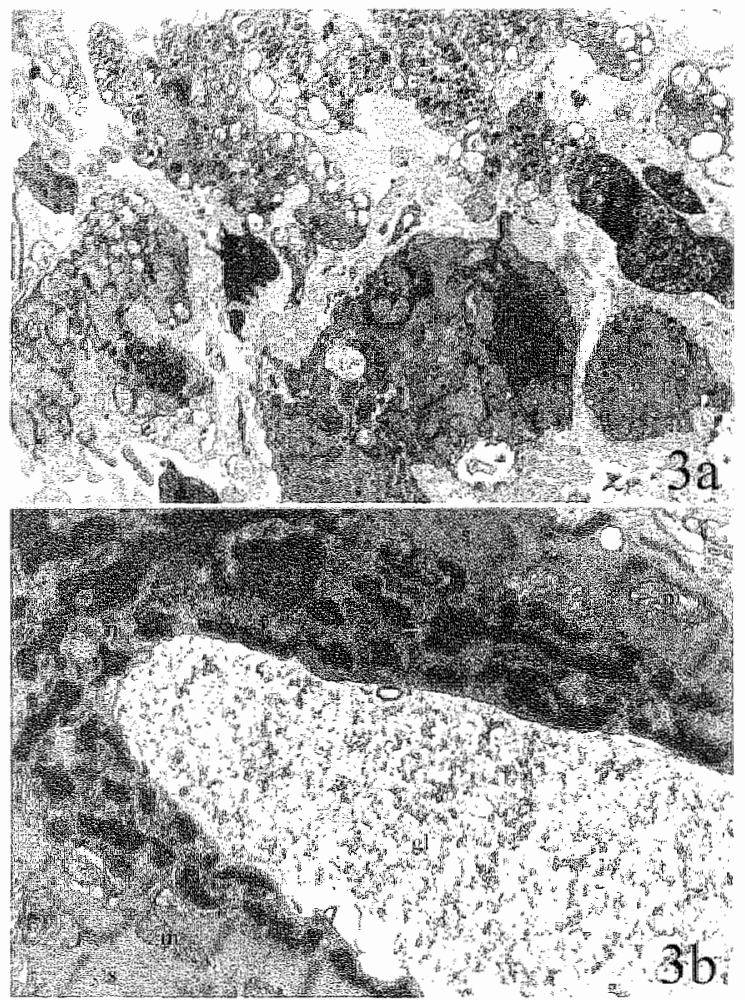

chronic AF patients. Median values for cell surface area of atrial myocytes in these patients were $37-44 \%$ larger compared to patients without chronic AF. No significant difference between the two groups was found regarding the amount of connective tissue.

Table 3 contains the partial Spearman rank correlation coefficients between cell surface area and the other morphometric measurements, adjusted for the hospital centre. The size of the atrial myocytes correlated signilicantly with the total number of affected atrial myocytes. A significant correlation was also found for the amount of connective tissue and the percentage of myocytes with degenerative changes.

\section{4 | Discussion}

A variety of ultrastructural degenerative changes in atrial myocytes has been reported by several authors in patients with atrial disease ${ }^{29.31 .7 \%}$. Mary-Rabine et al. observed myolysis and degeneration of atrial cardiomyocytes and suggested, however without substantial quantification, the changes were most 


\begin{tabular}{|c|c|c|c|c|}
\hline & Stratum & No AF & $\mathrm{AF}$ & P.Value \\
\hline \multirow{4}{*}{$\%$ Tolal changes } & $\mathrm{B}$ & 64 & 70 & \multirow{4}{*}{0.430} \\
\hline & $B$ & $(11-97)$ & $(18-90)$ & \\
\hline & \multirow{2}{*}{$C$} & 58 & 77 & \\
\hline & & $(41-94)$ & $(11 \cdot 100)$ & \\
\hline \multirow{3}{*}{$\begin{array}{l}\text { \% Myolytic } \\
\text { changes }\end{array}$} & B & 42 & 51 & \multirow{3}{*}{0.175} \\
\hline & $B$ & $(9-76)$ & $(18-83)$ & \\
\hline & $\mathrm{C}$ & $\begin{array}{c}55 \\
(29-60)\end{array}$ & $\begin{array}{c}65 \\
(111-97)\end{array}$ & \\
\hline \multirow{2}{*}{$\begin{array}{c}\text { Orogenerative } \\
\text { changes }\end{array}$} & B & $\begin{array}{c}10 \\
(2-58)\end{array}$ & $\begin{array}{c}9 \\
(0-55)\end{array}$ & \multirow{2}{*}{0.292} \\
\hline & $\mathrm{C}$ & $\begin{array}{c}12 \\
(0-35)\end{array}$ & $\begin{array}{c}5 \\
(0-52)\end{array}$ & \\
\hline \multirow{2}{*}{$\begin{array}{l}\text { Cell suface area } \\
\text { (mm2) } \\
\text { (hypertrophy) }\end{array}$} & B & $\begin{array}{c}426 \\
(352-755)\end{array}$ & $\begin{array}{l}613 \\
(266- \\
1190)\end{array}$ & \multirow[t]{2}{*}{0.001} \\
\hline & $\mathrm{C}$ & $\begin{array}{c}372 \\
(327-423)\end{array}$ & $\begin{array}{c}509 \\
(355-982)\end{array}$ & \\
\hline \multirow{2}{*}{$\begin{array}{l}\text { \% connective } \\
\text { tissue } \\
\text { (fibrosis) }\end{array}$} & $B$ & $\begin{array}{c}11 \\
(3-28)\end{array}$ & $\begin{array}{c}15 \\
(3-28)\end{array}$ & \multirow{2}{*}{1.000} \\
\hline & $\mathrm{C}$ & $\begin{array}{c}10 \\
(7-45)\end{array}$ & $\begin{array}{c}7 \\
(2-23)\end{array}$ & \\
\hline
\end{tabular}

Table 2

Summiary of Morphological datia.

Median walues (Ranges).

$t=$ Hospital centre:

Belgitum (B) or China (C)

pronounced in patients with atrial fibrillation ${ }^{29}$. The majority of the ultrastructural alterations seen in patients with atrial disease, were similar to those reported in patients with chronic hibernating myocardium ${ }^{40.41}$ and in goats with 'lone' atrial fibrillation, i.e. atrial fibrillation without any underlying cardiac disease $^{32}$. In these latter studies, the ultrastructural changes seen in the ventricular and atrial cardiomyocytes have been suggested to be of an adaptive nature rather than degenerative (reviewed by Thijssen et $a{ }^{79}$ ). Although the present study predominantly shows structural changes that appear to be of adaptive nature, degenerative changes are also observed, mainly in the severely affected areas. This is different from what has been observed in 'lone' AF in the goat, but in accordance with findings of other authors ${ }^{24.31 .37}$. Ultrastructural analysis, still the hallmark method to identify apoptosis ${ }^{86}$, shows that the observed degenerative changes resemble apoptotic degeneration. No involvement of cardiomyocyte apoptosis was found in patients with chronic hibernating myocardium and goats with sustained atrial fibrillation ${ }^{35}$, although it has been shown that apoptosis occurs in several cardiac diseases (reviewed by Anversa et al $\left.{ }^{81}\right)^{82-85}$. It 
Table 3 |

Patial Speaman rank correlation $195 \%$ confickere interwal) of structural changes with cell surface ared and interstitid space

\begin{tabular}{|c|c|c|c|c|}
\hline & \multicolumn{2}{|c|}{ Cell surface area } & \multicolumn{2}{|c|}{ Connective tissue } \\
\hline & $r$ & P-vestute & $r$ & 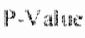 \\
\hline $\begin{array}{l}\text { \% Total } \\
\text { changes }\end{array}$ & $\begin{array}{c}0.520 \\
(0.315,0.725)\end{array}$ & $<0.001$ & $\begin{array}{c}0.285 \\
60.076,0.494\end{array}$ & 0.025 \\
\hline $\begin{array}{c}\% \text { Mylyic } \\
\text { changes }\end{array}$ & $\begin{array}{c}0.491 \\
(0.306,0.676)\end{array}$ & $<0,001$ & $\begin{array}{c}-0.027 \\
(-0.237 .0 .183)\end{array}$ & 0.834 \\
\hline $\begin{array}{c}\text { \%o Degenerative } \\
\text { changes }\end{array}$ & $\begin{array}{c}0.226 \\
(-0.025,0.477)\end{array}$ & 0.080 & $\begin{array}{c}0.378 \\
(0.167,0.589)\end{array}$ & 0.002 \\
\hline $\begin{array}{c}\text { Connective } \\
\text { tissue }\end{array}$ & $\begin{array}{c}0.154 \\
(-0.112,0.420)\end{array}$ & 0.233 & - & - \\
\hline
\end{tabular}

has been proposed that cardiomyocyte apoptosis occurs if already dedifferentiated cells are unable to adapt to a further decrease in oxygen supply ${ }^{82}$. However, apoptotic cells in this study did not show signs of accompanying dedifferentiation. In fact, there appeared to be a clear distinction between dedifferentiated, necrotic and apoptotic cardiomyocytes. This might indicate that cell degeneration and apoptosis are not the end-stage of ongoing dedifferentiation, but result from other underlying factors.

Morphometric data show remarkable differences between Belgian and Chinese patients, such as the appearance of large glycogen filled vacuoles in the latter group. Vacuolisation has been shown to occur during reversible myocardial damage ${ }^{86}$ and has been proposed to be a predictor of vulnerability to the development of atrial fibrillation following cardiac surgery ${ }^{87}$. Most of the differences can be explained by the difference in pathology, i.e. 28 out of 30 Chinese patients had a history of rheumatic heart disease. Despite these differences, our findings that the atrial myocytes of these patients show predominantly myolytic changes and that the occurrence of $\mathrm{AF}$ is accompanied by an increase in cellular size, were consistent in both groups of patients.

The present study shows that patients with different forms of valvular disease develop profound structural changes in their atrial myocytes, including a severe loss of contractile material. Presumably, this depletion of contractile material has reached such an extent that it is impossible for $\mathrm{AF}$, as an extra contributing 
factor, to induce more myolysis. Occurrence of AF is associated with a markedly enlarged cell size. This is in agreement with the results obtained in goats with sustained $\mathrm{AF}^{32}$. It is still not clear whether the changes observed in the present study as well as in the goat can be classified as reversible or irreversible. To address this question, time-related experiments in the goat have been set up to study the course of progression of the changes as well as the potential of reversibility. 



\title{
Chapter 3
}

\section{EXPRESSION OF TROPONIN I ISOFORMS IN PATIENTS WITH ATRIAL FIBRILLATION.}

\author{
V. Thijssen, J. Ausma, L. Gorza, I. Van Gelder, \\ M. Borgers, G. van Eys
}

In preparation

Background: Cardionyocyte differentiation is accompanied by a switch in expression from stow skeletal Iroponin I (ssTnI) to cardiac Troponin I (cTnI). Both atrial fibrillation (AF) and mitral valve disease (MVD) are characterised by structural remodelling that is indicative of cardiomyocyte dedifferentiation. We Hnestigated whether Tni isoform composition was affected in the atria of patients with AF and MWD. Methods: The following groups were included in this study: 1) patients undergoing coronaly artery bypass grafting with no previous AF, 2) patients with SR and MVD, 3) patients with chromic AF and MWD, 4) pathents with lone paroxysmal AF (PAF), and 5 ) patients with lone chronic AF (CAF). Western blotting was performed to detect alterations in the TnI isoform expression. Quantitative RT PCR (ORT-PCR) was used to establish changes in the mRNA composition of $55 \mathrm{TnI}$ and crnl as well as the ratho between $5 \mathrm{sTm} / \mathrm{cT}$. Results: Western blot analysis with a TnI antiobdy revealed the presence of an adiditional lower band beside the expected cThI band. This additional band was identified as s5Tn because it moved at the same clectrophoretic rnobility as ssTnI and could not be detected with a cTrI specific antibody. Fe bard was present in approxinately $60 \%$ of the patients in eacly group, except for patients with CAF with or without MVD. ORT-PCR showed that the $55 \mathrm{TnI} / \mathrm{C}$ m mRNA ratio in patients wh an additional band was in favour of a shift towards sSTnI expression. In patients with sirus thytho the absolute anount of CTnI MRNA was 600-fold higher as compared to ssTnI mRNA. In the presence

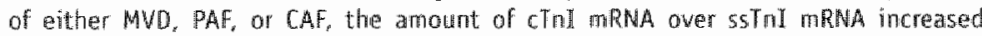
significantly, up to 3,500-fold in patients wh both MVD and CAF. Conclusions: Atrial expression of ssTnI protein does occur in patients, irfespective of the presence of PAF of MVD. The expression of SsTnl is not the result of ongoing cardiomyocyte dedifferentiation becaluse patients with CAF do not display ssTnI expression. Rather than 55 TnL, the expression of $c$ Trnil increases both as a resut of MVO, PAF, and CAF. The alterations in Thi isoform composition during MVo and AF could be irvolved in the contracte dysfunction of the atriun duning AF following cardioversion. 


\section{Introduction}

Atrial fibrillation (AF) is accompanied by electrical and structural remodelling of the atrium which results in reduced atrial function. Both in patients and in animal models it has been shown that the structural alterations are indicative of cardiomyocyte dedifferentiation ${ }^{32.79 .88}$. The most prominent changes consist of extensive myolysis, increased glycogen storage, cardiomyocyte hypertrophy, mitochondrial shape changes and redistribution of heterochromatin 3288.89 . Furthermore, the morphological changes are accompanied by protein expression and cellular organisation patterns that are reminiscent of foetal cardiomyocytes ${ }^{3,90}$. Morphological changes, similar to those found during $\mathrm{AF}$, are found in the atria of patients with mitral valve disease (MVD) even in the absence of $\mathrm{AF}$.

Different Tnl isoforms have been described for fast-twitch skeletal muscle (fsTnI), slow-twitch skeletal muscle (ssTnI), and cardiac muscle (cTnI) ${ }^{9192}$. In the foetal human heart ss'TnI is the predominant isoform, which is gradually replaced by cTnI during cardiac development ${ }^{93.94}$. In the adult heart, only the cTnI isoform is expressed, except for cells of the conductive tissues

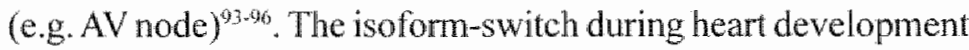
has been described for several species ${ }^{97-100}$.

Apart from a shift during heart development, Tnl status is influenced by cardiac disease. Regulation of $\mathrm{TnI}$ activity has been suggested to be involved in altered $\mathrm{Ca}^{2+}$ sensitivity of the myocardium ${ }^{101-1 / 3)}$, and changes in $\mathrm{Tnl}$ activity appear to be mainly regulated by protein phosphorylation ${ }^{103-106}$ and/or protein degradation ${ }^{\text {107-1iny }}$. Alterations in the expression level of the cTnI isoform during cardiac disease have not been found ${ }^{93}$, and reexpression of the ssTnl isoform has also not been detected ${ }^{93.104 .105}$. Recently, it was shown that activation of calpains was responsible for elevated Tnl degradation during increased preload or hypoxia 11.11 . Activation of calpains has also been found during atrial fibrillation ${ }^{12,113}$. As a consequence, AF might result in degradation of cTnl which could explain the decreased contractile function of the atrium. To determine the role of TnI isoform expression in cardiomyocyte dedifferentiation and contractile dysfunction during $\mathrm{AF}$ and MVD, we have analysed the composition of Tnl isoforms at the protein and mRNA level in patients suffering from MVD with or without AF. 


\subsection{Human atrial tissue}

Human material consisted of right atrial appendages obtained from patients as described elsewhere ${ }^{14.115}$. A total of 27 patients divided over 5 different groups were used in this study: 1) Control patients with normal sinus rhythm ( $\mathrm{SR}, \mathrm{n}=5$ ) undergoing coronary bypass surgery, 2) patients with mitral vallve disease and normal sinus rhythm (MVDSR, $n=4$ ), 3) patients with mitral valve disease and chronic atrial fibrillation (MVDAF, $n=4), 4$ ) patients with lone paroxysmal atrial fibrillation $(\mathrm{PAF}, \mathrm{n}=6), 5$ ) patients with lone chronic atrial fibrillation (CAF, $n=8)$. Atrial tissue was obtained during surgery, snap-frozen in liquid nitrogen and stored at $-80^{\circ} \mathrm{C}$. Patients characteristics have been described previously ${ }^{14.815}$. All the patients gave their written consent and the study was approved by the Institutional Review Board.

\subsection{Western blotting and antibodies}

Two monoclonal antibodies reacting with cardiac and/or skeletal Troponin I were used to detect cTnI degradation and reexpression of ss TnL. Monoclonal antibody Ti-54 recognises both cTnl and the ssTnl, whereas Ti-1 reacts specifically with the cardiac $\mathrm{TnL}$ isoform ${ }^{98}$. Cryostat sections from tissue samples were homogenised in electrophoresis sample buffer, boiled for $10 \mathrm{~min}$, and equal protein amounts of each sample, together with molecular weight standards (Biorad), were run at $100 \mathrm{~mA}$ on a $13 \%$ polyacrylamide gel. Subsequently, protein was transferred onto a nitro-cellulose filter, saturated for I hour with ovalbumin in TBST $(10 \mathrm{mM}$ Tris- $\mathrm{HCl}$ pH $8.0,150 \mathrm{mM} \mathrm{NaCl}$, $0.5 \%$ Tween 20 ) and incubated with the primary antibody (Ti$54,1: 3000 ; \mathrm{Ti}-1,1: 1000$ ) for 1 hour at RT in TBST. After washing $3 \times 10 \mathrm{~min}$ in TBST, filters were incubated for 1 hour with peroxidase conjugated secondary antibody (1:5000). Following $3 \times 10$ min washing in TBST, peroxidase activity was detected by the ECL method. All experiments were performed in triplicate. 


\begin{tabular}{|c|c|c|c|}
\hline \multirow{3}{*}{$\begin{array}{l}\text { Table } 1 \text { | } \\
\text { Primers and probes used for } \\
\text { guantitative real-time } R T \text {. } \\
\text { PCR }\end{array}$} & \\
\hline & Target & $\begin{array}{l}\text { Primiers } \\
\text { probe }\end{array}$ & Sequence/modification \\
\hline & \multirow{3}{*}{$\begin{array}{c}\text { human } \\
\text { ctal }\end{array}$} & Forward & 5GCCOACTCAAOCAGGTOZ. \\
\hline & & Reverse & STTGCGCCAGTCTCCOACCTC 3 \\
\hline & & Probe & $\begin{array}{l}\text { TAMKA } \\
\text { 5"AGAGGAGGACACGGAGAAGGAAAACCG } \\
\text { DABCYL }\end{array}$ \\
\hline & \multirow{3}{*}{$\begin{array}{l}\text { Guman } \\
\text { ssTnl }\end{array}$} & Fonward & S GCCCACCTCAAGCAGGTOS \\
\hline & & Reverse & 5'CATCAGGCTCTTCAGCAAGAG $3^{\prime}$ \\
\hline & & Probe & $\begin{array}{l}\text { FAM } \\
\text { 5'CCAAGATCACTGCCTCCOGCA3' } \\
\text { DABCYL }\end{array}$ \\
\hline
\end{tabular}

\subsection{Primers and probe design}

Primers and probes used for PCR are listed in table 1. The overall homology between the coding regions of $\mathrm{cTnl}$ and ssTnl is approximately $60 \%$. To avoid cross-reactivity the primer/probe combinations were confined to regions of poor homology between cTnI and ss'TnI. The primers and probes were specific for $\mathrm{cTnl}$ or $\$ \mathrm{TS} \mathrm{T} \mathrm{l}$, and designed using Primer Express software (PE Applied Biosystems). This software sets several requirements concerning GC-content, annealing temperature and amplicon length, which the primers and probe have to meet to ensure optimal primer/probe combinations. The probes for $\mathrm{cTnI}$ and ssTnl were labelled with the reporter dyes TAMRA and 6FAM respectively, in combination with $D A B C Y L$ as quencher. Primers as well as probes were synthesised by Eurogentec.

\subsection{Quantitative real-time RT-PCR}

Total RNA from $30 \mathrm{mg}$ human atrial appendage tissue was isolated using the RNeasy mini kit (Qiagen) according to the manufacturer's instructions. During the procedure, possible genomic DNA contamination was removed by on-column DNase treatment with the RNase-free DNase set (Qiagen). Total amount of isolated RNA was incubated at $65^{\circ} \mathrm{C}$ for 5 minutes and reverse transcription was performed for 1.5 hours at $37^{\circ} \mathrm{C}$ with $600 \mathrm{U}$ of M-MLV reverse transeriptase (GibcoBRL) in 50 $\mu \mathrm{L}$ of $50 \mathrm{mM}$ Tris- $\mathrm{HCl}$, pH $8.3,75 \mathrm{mM} \mathrm{KCl}, 3 \mathrm{mM} \mathrm{MgCl}, 10$ 
IMM DTT, I mM dNTPs in the presence of $40 \mathrm{U}$ RNase inhibitor RNasin(B) (Promega) and $0.5 \mu \mathrm{g}$ oligo(dT) primer (GibcoBRL). Subsequently, reverse transcriptase was inactivated by incubation at $95^{\circ} \mathrm{C}$ for 5 minutes and cDNAs were stored at $-20^{\circ} \mathrm{C}$. Real-time PCR, as described elsewhere ${ }^{16.117}$, was performed with the ABI PRISM $7700 \Leftrightarrow$ Sequence Detection System apparatus and software (PE Applied Biosystems) using the Real-time $\mathrm{PCR}$ Taqman Kit (Eurogentec). The $\mathrm{PCR}$ reaction was performed in a $50 \mu \mathrm{l}$ volume containing $3 \mu \mathrm{cDNA}, 1 \mathrm{x}$ PCR buffer, $200 \mu \mathrm{M}$ dATP, dGTP, dCTP, dTTP, and dUTP, 0.025 $\mathrm{U} / \mu$ l Hot Goldstar DNA polymerase, $100 \mathrm{nM}$ probe, and 150 $\mathrm{nM}$ of each primer. Cycling conditions consisted of a Hot Goldstar activation step of 10 minutes at $95^{\circ} \mathrm{C}$, followed by 50 cycles of 15 seconds at $95^{\circ} \mathrm{C}$ and 1 minute at $60^{\circ} \mathrm{C}$. Data were analysed with the Sequence Detection System software (PE Applied Biosystems). The parameter $\mathrm{Ct}$ (threshold cycle) was defined as the cycle number at which the fluorescent signal passed a fixed value (threshold) above baseline. Thus, there is an inverse relation between the $\mathrm{Ct}$ value and the level of expression. High levels of expression are represented by low $\mathrm{Ct}$ values because high levels of $\mathrm{mRNA}$ result in a rapid increase in the fluorescent signal and subsequently, the threshold value is reached earlier during PCR as compared to low amounts of mRNA.

\subsection{Statistical analysis}

Data are displayed as mean values \pm SEM of three independent experiments. For statistical analysis the mean values of the ss Tnl/ cTnl ratio were used. Significant differences between the groups were analysed by means of the Wilcoxon-Mann-Whitmey rank sum test. All $p$-values are two-sided and $p$-values $<0.05$ were considered to be statistically significant. Statistical computations were performed in SPSS 10.0.5.

\section{$3 \mid$ Results}

\section{1 | Patients}

A total of 27 patients was included in this study, with a mean age of 58 years (range 37 - 74). Nineteen patients were male and 8 patients were female. The patients could be divided in 3 
groups when atrial rhythmic activity was used as the sole selection criteria: sinus rhythm ( $S R, n=9$ ), paroxysmal $A F$ ( $P A F$, $n=6)$, and chronic $A F(C A F, n=12)$. When also the underlying disease was taken into account, 5 different groups could be distinguished: normal sinus rhythm ( $\mathrm{SR}, \mathrm{n}=5), \mathrm{SR}+$ mitral valve disease (MVDSR, $n=4), C A F+$ mitral valve disease (MVDAF, $\mathrm{n}=4$ ), lone paroxysmall AF (lone PAF, $\mathrm{n}=6$ ), and lone chronic AF (lone CAF, $n=8$ ). The characteristics of the patients, subdivided over either 3 or 5 groups are given in table 2 .

\section{2 | Degradation of $\mathrm{cTnI}$}

Western blotting was used to detect degradation of $\mathrm{cTnl}$ and to determine whether or not expression of ss Tnl could be found in any of the patient groups. Figure $\mathbb{L}$ shows a typical example of a Western blot with atrial tissue from several patients stained with Ti-54 (upper panel), an antibody that recognises both

\section{Table 2}

Patients characteristics

Values are presented as meary \pm SD or number of patients, except where indicated different. $S R=$ sinus rhythm; PAF is paroxysmal $A F ; C A F=$ chonic AF; $5 R$ is normal strus thythm: MUDSR is mitral valve disease combined with SR, lone PAF - Lone paroxysmal Af: MWDAF mitral value disease combined with AF: lone CAF an lone chrosic AF; * p 0.05, PAF VS. CAF; $10 \times 0.05$, Ione PAF vs. SR: NYHA $=$ New York Heart Association flass for exercise tolerance.

\begin{tabular}{|c|c|c|c|c|c|}
\hline & & $\mathrm{SR}$ & PAF & \multicolumn{2}{|c|}{$\mathrm{CAF}$} \\
\hline male/female (n) & & $6 / 3$ & 610 & \multicolumn{2}{|c|}{$7 / 5$} \\
\hline age (yrs) & & \pm 10 & $48 \pm 8^{*}$ & \multicolumn{2}{|c|}{$61 \pm 12$} \\
\hline $\begin{array}{l}\text { duration } \mathrm{PAF} \\
\text { (median, range (hours)) }\end{array}$ & & - & $\begin{array}{c}9 \\
(0.2-14.4)\end{array}$ & \multirow{2}{*}{\multicolumn{2}{|c|}{$\begin{array}{c}- \\
8.6 \\
(0.5-20)\end{array}$}} \\
\hline $\begin{array}{l}\text { duration } \mathrm{CAF} \\
\text { (median, range (months)) }\end{array}$ & & - & - & & \\
\hline NYHA & & & & & \\
\hline Class 1 & & 5 & 3 & \multicolumn{2}{|c|}{3} \\
\hline Class II & & 4 & 3 & \multicolumn{2}{|c|}{1} \\
\hline \multirow[t]{2}{*}{ Classill } & & 0 & 0 & \multicolumn{2}{|c|}{8} \\
\hline & NSR & MVDSR & lone $\mathrm{PAF}$ & MVDAF & lone CAF \\
\hline$n$ & 5 & 4 & 6 & 4 & 8 \\
\hline malefemale (n) & $2 / 3$ & $4 / 0$ & 60 & $2 / 2$ & $5 /$ \\
\hline age (yrs) & $67 \pm 9$ & $52 \pm 12$ & $48 \pm 8^{+}$ & $62 \pm 8$ & $60 \pm 12$ \\
\hline $\begin{array}{l}\text { duration PAF } \\
\text { (median, range (hours) }\end{array}$ & - & - & $\begin{array}{c}9 \\
(0.2-14.4)\end{array}$ & - & - \\
\hline $\begin{array}{l}\text { duration } \mathrm{CAF} \\
\text { (median, range (months)) }\end{array}$ & - & - & - & $\begin{array}{c}4.5 \\
(0.5-13)\end{array}$ & $\begin{array}{c}10.6 \\
(6-20)\end{array}$ \\
\hline \multicolumn{6}{|l|}{ NYHA } \\
\hline Class I & 4 & 1 & 3 & 0 & 3 \\
\hline Class II & 1 & 3 & 3 & 0 & 1 \\
\hline Classill & 0 & 0 & 0 & 4 & 4 \\
\hline
\end{tabular}




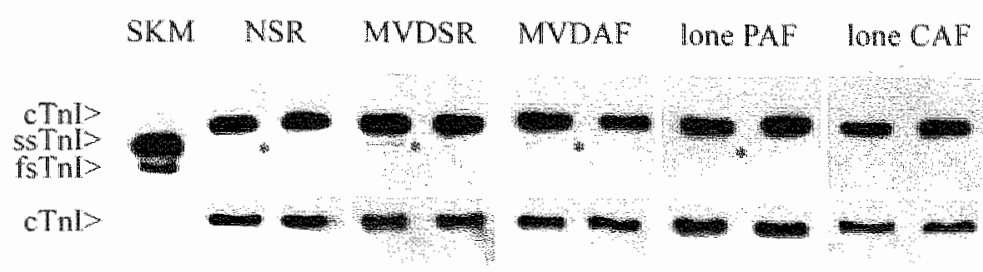

cardiac and skeletal TnI. In human skeletal muscle, two bands were visible representing SsTnI and fs TnI. In human cardiac tissue one prominent band was found that represents cTnI. In addition to this cTnI band, several patients displayed a faint band at the same electromobility shift as the ssTnl band in skeletal muscle. To distinguish between cTnl degradation and ssTnl expression, Western blotting was performed with Ti-1, a cTnI specific antibody (figure 1, lower panel). Using this antibody, no additional bands could be found, even when Ti-1 antibody was used at 10-fold concentration or after extensive detection time following ECL (up to 45 minutes). This indicates that the faint bands represent ssTnl expression rather than $\mathrm{cTnl}$ degradation. The overall results of the Western blot analysis are shown in table 3. In the SR and PAF group, an additional band could be observed in approximately $60 \%$ of the patients, whereas in the CAF group only 1 out of 12 patients $(8 \%)$ displayed and additional band.

\begin{tabular}{c|cc|cc}
\hline patient group & \multicolumn{2}{|c|}{ Ti-54 additional band } & \multicolumn{2}{|c}{ Ti-1 additional band } \\
\hline NSR & $3 / 5$ & SR $5 / 9(56 \%)$ & $0 / 5$ & SR $0 / 9(0 \%)$ \\
MVDSR & $2 / 4$ & & $0 / 4$ & \\
LPAF & $4 / 6$ & PAF $4 / 6(67 \%)$ & $0 / 6$ & PAF $0 / 6(0 \%)$ \\
MVDAF & $1 / 4$ & & $0 / 4$ & CAF $0 / 12(0 \%)$ \\
LCAF & $0 / 8$ & & $0 / 8$ & \\
\hline
\end{tabular}

\section{$3.3 \mid$ Expression of TnI isoforms}

To determine the mRNA expression levels of $\mathrm{c} T n \mathrm{I}$ and ssTnI we performed quantitative real-time RT-PCR. With this technique, the time course of a PCR can be followed by measuring the release of a fluorescent dye. The $\mathrm{Ct}$-value, which
Figure $1 \mid$

Western blot analysis of $\mathrm{Th}$ isoform expression

The upper parinel shows at representative Western blot on two patients from each group wath Th-54 which recognises both cinl and s5TnL. The asteristl indicates the additional band which moves with the same electronobility as $5 s T$. The lower panel shows a representative Westem blot on the same patients witly a cTnI specific antibody (Ti-1). Note that in none of these samples an additional band is visible. ECl detection time was $-10 \mathrm{~min} .5 \mathrm{KM}=$ skeletal muscle: $5 \mathbb{R}=$ sinus rhythm; MVOSR mitral valve disease with sinus riythrin: MVOAF mitral walve diseases with atrial fibrillation: PAF paroxysmal atrial fibrillation: CAF = chronic atrial fibrillation; clal = cardiac Troponin 1; 55TrL slow-twitch sketetal Troponin I; FsTnI = Fast. twitch skeletal Troponin I.

\section{Table 3 |}

Tril isoform composition during AF.

$S R=$ sinus thythmi: PAF is paroxysmal AF; CAF chronic AF; MVDSR is mitral valve disease combined with SR: lone PAF = lone paroxysmal AF; MUDAF" mitral valve disease combined with AF; lone CAF - lone chronic At. 
Figure 2

Quaritutive RT-PCR

Hororesertative amplification curves generated duning Quantitative RTPCR on a patient with SR. QRT-PCR was performed wh priments spection for cim I lopen squares) or seint (closed squares). Determination of the ct-matues is indicated by the dotted bines.

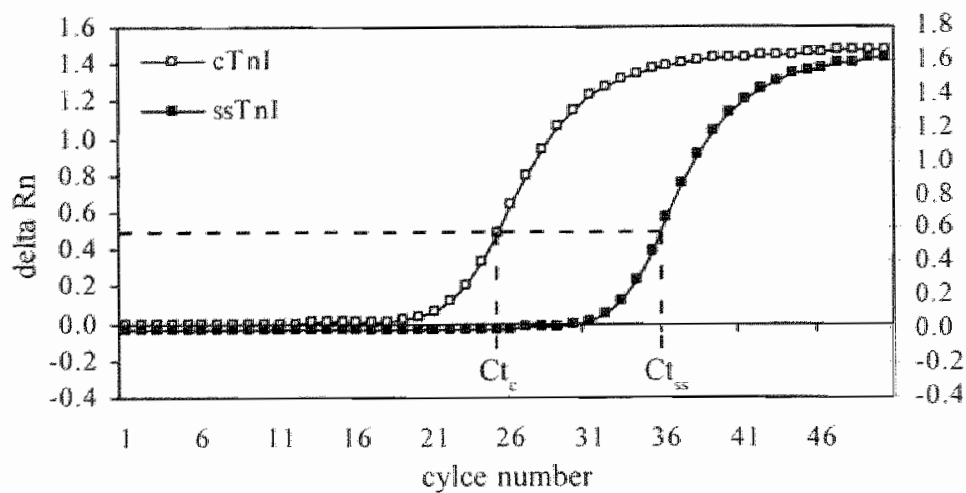

indicates the cycle number at which the generated fluorescence passes a given threshold, is a direct representation of the amount of mRNA present in the sample ${ }^{117}$. It is important to note that low Ct-values represent high levels of expression, because it takes less cycles to reach the threshold value. Within the range of $100 \mathrm{ng}$ to $10 \mathrm{pg}$ template DNA, a linear relationship between the $\mathrm{Ct}$ and the logarithm of DNA could be observed for both cTnl and ssTnl (data not shown). Figure 2 shows an example of the amplification plots of $\mathrm{cTnI}$ and ssTnI generated during PCR on atrial tissue from a patient with sinus rhythm. The derived $\mathrm{Ct}$ values, $\mathrm{Ct}_{\mathrm{c}}$ and $\mathrm{Ct}_{\mathrm{ss}}$ respectively, are also indicated.

Because changes in the absolute $\mathrm{Ct}$ values between different samples might also be influenced by differences in tissue integrity or the efficiency of RNA isolation and subsequent reactions, we determined the ratio between the $\mathrm{Ct}_{\mathrm{ss}}$ and $\mathrm{Cl}$. Changes in the $\mathrm{Ct} / \mathrm{Ct}$ ratio thus indicate a shift in expression towards either cTnI or ssTnI. In figure $3 \mathrm{~A}$ the different ratios are shown for the different patient groups. Compared to SR, CAF resulted in a statistically significant increase in $\mathrm{Ct}_{s i} / \mathrm{Ct}$ ratio which suggests higher expression of CTnl. However, when also the underlying mitral valve disease was taken into account, all patient groups with PAF or CAF displayed a statistically significant increase in their $\mathrm{Ct} / \mathrm{Ct}$ ratio as compared to patients with sinus rhythm (Figure $3 \mathrm{~B}$ ). To determine whether a change in the $\mathrm{Ct} / \mathrm{Ct}$ ratio reflected the changes at the protein level we compared the $\mathrm{Ct} / \mathrm{Ct}$ values of patients in which no ss Tnl could be observed and patients which displayed a ssTnI band on a Western blot. The latter group showed a significant lower $\mathrm{Ct}$ / 


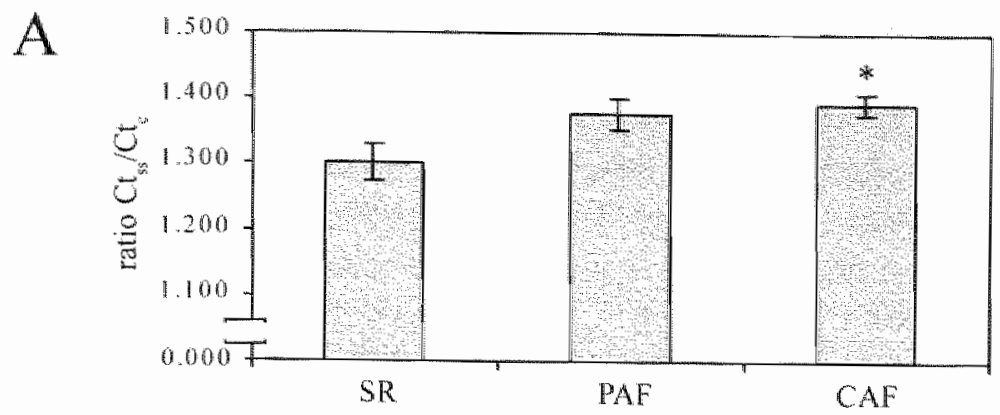

B

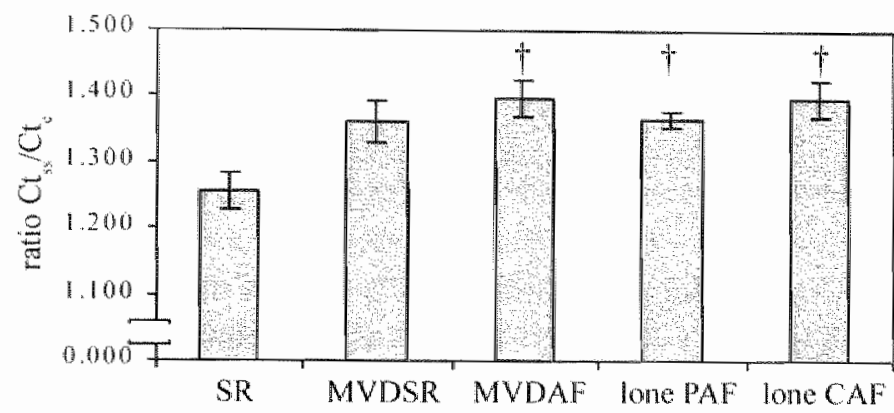

C

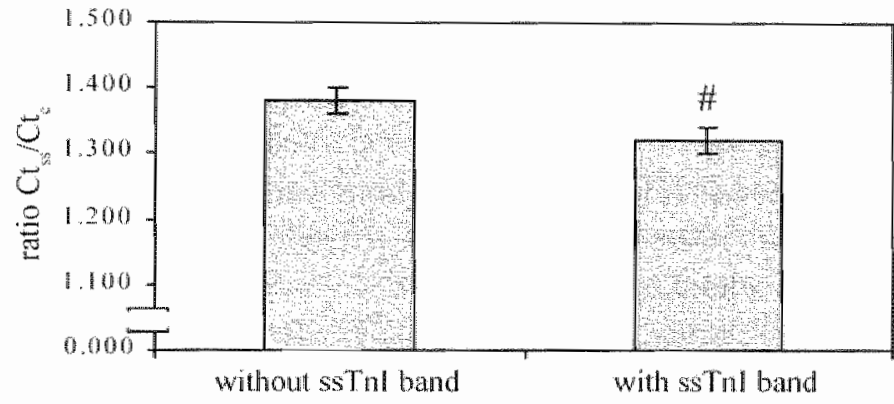

$\mathrm{Ct}$ ratio indicating a shift towards ss Tnl expression (Figure $3 \mathrm{C}$ ). All data of the quantitative RT-PCR analysis are summarised in table 4.

Based on a standard curve, the $\mathrm{Ct}_{\mathrm{c}}$ and $\mathrm{Ct}_{\mathrm{ss}}$ values were also used to determine the absolute mRNA levels in each sample. During sinus rhythm, the amount of cTnI mRNA was approximately 600-fold higher as compared to ssTnI mRNA (Table 4). The presence of either MVD or AF increased this value significantly up to approximately 2,200 -fold. When

\section{figure 3}

Quantit.ative analysis of $\mathrm{Ct} /$ $\mathrm{Ct}$ - ratio's between different patient groups

A) Diagram showing the $\mathrm{Ct}_{\mathrm{si}} / \mathrm{Ct}_{\mathrm{t}}$ ratio's in patient groups on the basis of atrial activity.

B) Diagram showing the $\mathrm{Ct}_{\mathrm{s} s} / \mathrm{Ct}_{\mathrm{s}}$ ratio's in patient groups on the basis of both the atrial activity and the underlying valve disease. c) Diagram showing the $\mathrm{Ct}_{\mathrm{z}} / \mathrm{Ct}$ ratio in patients baser on the presence of an additional (ss $1 n I)$ band in Westem blotting. $S R=$ sinus rhythm; PAF is paroxysmal AF; CAF as chronic AF; MVDSR is mitral valve disease combined with SR: lone PAF o lone paroxysmal. AF; MVDAF = mitral valve disease combined with AF; lone CAF

- lone chronic AF;" $\mathrm{p}<$ 0.050 vs. $5 R ;$ i $<<0.05$ vs. $S R ; \#$; $p=0.05$ vis. no 


\section{table 41 \\ overall results from QRT- PCR analysis}

$S R=$ sinus ithython; PAF is paroxysmal $A F$ : CAF = chronic AF; MVDSR is mitral walve disease combined with SR; lone PAF = lone pairoxysmal AF; MVEAF = mitral valve disease combined with AF; lone CAF $=$ lone chronic AF;" $p<0.05$ vs. SR $(n=9) ;+p \in 0.05$ vs. $S R(n=5) ; \#$ pe0.05 vs. no additional band

\begin{tabular}{|c|c|c|c|c|}
\hline pationt group & $\mathrm{Ct}_{\text {ष: }}$ & $C t$ & Ravio Cl: $/ \mathrm{CL}$ & $\begin{array}{c}\text { absolute } \\
\text { chussTn mRNA }\end{array}$ \\
\hline$S R=9$ & $27.64+40.38$ & $21.424 / 40.33$ & $1.29+1-0.03$ & $1.384+468$ \\
\hline$P A F=6$ & $28.27+40.61$ & $20.62+1-0.49$ & $1.37+1.0 .03$ & $2.124+578$ \\
\hline$C A \| n=12$ & $28.19+1.0 .59$ & $20.39+/-0.47$ & $1.38 \div-0.02$ & $2,666+1-510^{*}$ \\
\hline NSR $n=5$ & $27.00+1-0.46$ & $21.67+\% / 0.34$ & $1.26+1-0.0 .3$ & $574+143$ \\
\hline MVDSR $n=4$ & $28.44+1-0.35$ & $21.11+40.63$ & $1.36+10.03$ & $2.396+1-81166^{\circ}$ \\
\hline$M V D A F=4$ & $28.48+40.39$ & $20.57+1 / 0.15^{t}$ & $1.40+6.00 .03^{4}$ & $3.525+1.1 .339^{+}$ \\
\hline I.PAD $n=6$ & $28.27+10.61$ & $20.62+1-0.49$ & $1.38+80.02^{7}$ & $2_{n} 124+1578^{7}$ \\
\hline UCAF $n=8$ & $28.04+1408$ & $20.29+-0.72$ & $1.39+1.0 .02^{4}$ & $2,236+/-386^{4}$ \\
\hline no add. band $n=17$ & $28.17+\%-0.45$ & $20.56+1-0.38$ & $1.38+1-0.02$ & $2.646+442$ \\
\hline add. band $n=10$ & $27.77+1-0.39$ & $21.16+1-0.33$ & $1.32+4.602^{3}$ & $1.220+1.160^{\circ}$ \\
\hline
\end{tabular}

patients suffered from both MVD and AF the value increased even up to 3,500-fold. As expected the amount of $\mathrm{cTnl} \mathrm{mRNA}$ over SSTnI mRNA was significantly lower in patients which displayed an additional band in Western blotting as compared to those in which no additional band could be detected $(1,200-$ fold vs. 2,600-fold, respectively).

\section{4| Discussion}

It has been shown that throughout cardiac development two different Tnl isoforms are expressed in the heart. The expression of the skeletal isoform (ss TnI) decreases around birth while at the same time the cardiac isoform (cTnl) increases ${ }^{95.4}$. Consequently, the Tnl isoform expression pattern reflects the differentiation state of the cardiomyocyte. Dedifferentiation of cardiomyocytes is a characteristic feature of $A F$ and $M V D^{32.79,88}$, and this dedifferentiation might lead to alterations in the expression of Tnl isoforms. Furthermore, a relation was found between $A F$ and the activity of Calpain $I^{n 13}$, a protein which is involved in degradation of $\mathrm{CTnI}^{110.11 !}$. Both the degradation of CTnl and changes in the Tnl isoform expression could contribute to the contractile dysfunction during AF. In this study we analysed the composition of Tnl isoforms in the atria of patients with MVD and AF by Western blotting and quantitative RTPCR.

In patients with SR, MVD, or PAF atrial expression of SsTmI 
could be observed. This expression was not the result of cardiomyocyte dedifferentiation because patients with CAF did not show ssTnI expression. In addition, the expression of $\mathrm{cTnI}$ increased in patients with MVD, PAF, and CAF. These alterations in Tnl isoform composition during $\mathrm{MVD}$ and $\mathrm{AF}$ are possibly involved in the contractile dysfunction of the atrium during AF.

\subsection{Changes in TnI protein composition during AF}

Westem blot analysis with an antibody that recognises both cTnl and ssTnI revealed that apart from cTnI, an additional band with the same electrophoretic mobility as ss Tnl could be detected in almost all patient groups, irrespective of the presence of MVD or PAF. Only in patients with longstanding (chronic) AF without any underlying disease no additional band could be detected. Western blotting on the same patients with a cTnl-specific antibody did not reveal any additional bands, even when a 10 fold increase in antibody concentration was used or after extensive elongation of the detection time following ECL. In other species the cTnI specific antibody also detects cTnI degradation which indicates that the absence of a degradation band in our patients is not due to a change in the epitope (Chapter 4). These results suggest that expression of $\mathrm{ss} \mathrm{TnI}$ does occur in atrial tissue of patients irrespective of the presence of MVD or AF. Up to now, there have been no reports on the presence of ssTnI protein in adult cardiac tissue, except for Gorza et al. who did detect ssTnI mRNA in cells of the conductive tissue throughout adulthood ${ }^{25}$.

Although expression of ssTnl supports the hypothesis of cardiomyocyte dedifferentiation, patients with chronic AF did not express ssTnI. In contrast, chronic AF resulted in increased expression of $\mathrm{TnI}$. The discrepancy between these observations could be explained by a difference between the arrhythmic activity of paroxysmal AF and chronic AF. In a goat model on AF there appeared to be an increase in the mRNA level of ssTnI at the onset of AF, although not significant and ssTn protein could not be detected by Western biot. The increased ssTnl mRNA level was no longer present after prolonged (chronic) AF (Chapter 4). Thus, in patients with CAF no ss Tnl protein could be detected due to normalisation of expression in response to the persistent arrhythmic activity whereas in patients suffering from PAF, the repetitive cycles of AF followed by SR might 
result in repeated activation of ssTnl expression subsequently leading to detectable levels of ss TnI protein. The fact that ss Tnl expression was also observed in patients with sinus rhythm indicates that in these patients the underlying cardiac disease (coronary ischaemia) results in repetitive atrial stress (ischaemia, stretch), which in turn leads to increased ss Tnl expression. The reason for re-expression of ss $\mathrm{TnI}$ is not known. ss $\mathrm{Tnl}$ increases calcium sensitivity and renders the myofilaments resistant to acidosis 101.102 .118 . Thus, re-expression of ssTnI could be a protective mechanism against increased cardiomyocyte stress/ acidosis at the onset of AF.

There have been several reports on cTnI degradation as a result of increased preload, ischaemia/reperfusion, and in patients undergoing coronary artery bypass grafting ${ }^{107-109.111 .1149}$. In our patients, no degradation of $\mathrm{cTnl}$ could be detected. The discrepancy between our findings and those of other authors appears to be related to the duration and the severity of cardiac stress. Thomas et al. reported that in a swine model of stunned myocardium, representing mild cardiac stress, no increase in degradation of cTnl could be found ${ }^{120}$. In most studies that show degradation of cTnI, there was an acute and severe cardiac stress (increased pressure, ischaemia) and degradation was observed in the time-frame immediately following this cardiac stress 107.108 .111 . We have also found some evidence of cTnl degradation at the onset of AF in the goat model. In goats subjected to sustained AF, limited cTnI degradation could be observed within the first 4 weeks following initiation of AF ( 1 out of 6 after one or two weeks of AF and 2 out of 6 after 4 weeks of AF). After longer periods of AF, degradation of cTnl was no longer detectable (Chapter 4 ). The degradation corroborated with the calcium overload in these goats which occurred in the first weeks of $\mathrm{AF}^{59}$. Calpain $\mathrm{I}$, a calcium induced proteolytic protein that has been shown to be activated during Af 12,13 might be responsible for the observed degradation 107.110.111. The patients described in this study all suffered for prolonged periods of time from MVD and repetitive paroxysms or chronic AF. Thus, the early phase of cardiac stress, calcium overload and subsequent cTnI degradation was not represented in this study. Furthermore, cTnI could be protected from degradation by a protective response of the cardiomyocytes by e.g. heat shock proteins ${ }^{121}$ or by increased cTnl phosphorylation ${ }^{14}$. Phosphorylation also affects the calcium 
sensitivity of $\mathrm{Cn} n$ 12:-124 $^{12}$ which might contribute to the contractile dysfunction of the atrium during chronic AF. Preliminary results on the phosphorylation state of $\mathrm{cTnI}$ in patients with $\mathrm{AF}$ indicate an increased amount of phosphorylated cTnI protein during AF (unpublished data).

\subsection{Changes in TnI mRNA expression during AF}

Further analysis of the changes in $\mathrm{TnI}$ isoform expression was performed by quantitative RT-PCR ${ }^{16.17}$. Rather than using a house-keeping gene like GAPDH to correct for differences in mRNA content and integrity we determined the ss Tnl.cTnI ratio. Changes in this ratio are indicative of a shift in expression towards either ssTnI or cTnI. In the atria of patients with sinus rhythm, low levels of ssTnl expression could be detected. cTnl was the main isoform which was expressed at a 600 -fold higher level as compared to ssTnl. Previous studies, using either in situ hybridisation or Northern blotting techniques, did not find any evidence for the presence of ss TnI mRNA in normal adult cardiac tissue or re-expression of $\mathrm{ssTnl}$ during cardiac disease ${ }^{93.93 .96}$. However, quantitative RT-PCR is more sensitive than these techniques, which might explain the detection of the relatively low levels of ssTnI mRNA in the current study. In the presence of either MVD, PAF or CAF, the level of cTnI mRNA was approximately 2,200 -fold higher as compared to $s s \mathrm{TnI}$ mRNA. The presence of both MVD and CAF increased the value even up to 3,500-fold. When patients with an additional band on the Western blat were compared with patients in which no additional band could be found, there was a significant decrease in the $\mathrm{Ct} / \mathrm{Ct}$ ratio which favours the idea of ss Tnl re-expression. In patients with no additional band on the Western blot, the mRNA level of cTnl was 2,600 fold higher as compared to ss TnI, but this dropped to 1,200-fold when an additional band was detected. This value is in the same range as the value in patients with sinus rhythm (1,384-fold). Whether the increased expression of $\mathrm{CTn}$ is a result of cardiac hypertrophy which also occurs during $\mathrm{AF}^{88.89}$ or whether the mRNA turnover increases is unknown. The increased expression of $\mathrm{cTnl}$ might also be a response of the cardiomyocytes to compensate for the decreased calcium sensitivity as a result of increased cTnl phosphorylation ${ }^{122-124}$. 


\section{3 | Limitations to the study}

Although our data show re-expression of ssTnl in the atria of patients with MVD or lone PAF, it still needs to be established whether the ssTnl protein is functionally incorporated in the contractile apparatus of the cardiomyocytes. The simultaneous expression of both $\mathrm{cTnI}$ and ssTnI during embryogenesis ${ }^{93.94}$ and the observation that adenovirus mediated replacement of cTnl with ssTnI results in functional sarcomere architecture ${ }^{118}$ show that both isoforms can co-operate within a single cardiomyocyte. Whether this is also true for the low levels of ssTnl expression found in this study still needs to be established. All patients with sinus rhythm were either undergoing coronary artery bypass surgery or suffered from mitral valve disease. For both groups of patients it has been shown that the cardiac disease is accompanied by structural remodelling of the cardiomyocytes which, similar as for AF, is reminiscent of cardiomyocyte dedifferentiation ${ }^{40.88}$. Thus, rather than being a control group, the patients with SR might represent a group with similar cellular changes as the AF groups but to a lower extent and with a different underlying cause. Furthermore, the use of drugs might influence gene expression of $\mathrm{Tn} I$ isoforms. To minimise this effect, drugs were discontinued before surgery, when possible. The use of an animal model on AF might provide a better way to determine the actual effect of AF on the expression of ssTnI and cTnl.

\section{Acknowledgements}

The authors would like to thank $\mathbb{H}$. Kuijpers en $\mathrm{M}-\mathrm{H}$ Lenders for their excellent technical assistance throughout this study. 


\title{
Chapter 4
}

\section{TROPONIN I ISOFORM EXPRESSION DURING CHRONIC ATRIAL FIBRILLATION IN THE GOAT}

\author{
V. Thijssen, J. Ausma L. Gorza, M. Allessie, M. Borgers, G. van Eys
}

In preparation

Background: Atrial fibrilation (Af) results in structural changes in the atrial myocytes. These changes are reminiscent of candiomyocyue dedifferentation and might be induced by activation of proteolytic erizymes. Both dedifferentiation and proteolysis ane likely to influence the composition of Troponin $\mathbb{I}$ (TnI) isoforms during AF, either by reexpression of the foetal ThI isoform (slow-skeletal TnI; 55 TnI) or by degradation of cardiac TnI (CTnI). We examined changes in the composition of TrI isoforms in a goat modet of AF. Methods: Degradation of cIn protein and rewexpression of ssThl protent were analysed by Western blotting in the atria of foetal goats, goats with normal sinus rhythm (SR). and goats after $1,2,4,8$, and 1 weeks of AF. Changes in the mRNA amount of both isoforms were quantified by means of the quantitative RT.PCR technique. Results: Sinular to other species, cardiac development in the goat was accompanied by a switch from SETn to cTal expression both at the level of protein and makA. Westert blotting revealed degradation of cTnI in only a few samples during the first f weeks of AF 11 out of 6 after one and two weeks of AF and 2 out of 6 after 4 weeks of AF). During SR and after longer periods of Af no deguadation of CTnL could be detected. SSTnI protein expression was undetectable up to 16 weeks of AF. There were also no significart. differences in mRNA content of CTnI and ssTnI duning AF as compared to $5 R$. Conclusions: Limited CInI degradation occurs duning the first 4 weeks of AF. After longer periods of AF. Chil degradation is inhibited. Surprisingly, cardiomyocyte dedifferentiation during AF was not accompanied by re-expression of the foetal sslnI isoform. 


\section{1 | Introduction}

Troponin I (TnI) is a subunit of the troponin complex which facilitates actin-myosin interaction during contraction of striated muscle. TnI is differentially expressed in distinct muscle types and during muscle development ${ }^{125}$. Tnl isoforms have been described for fast-twitch skeletal muscle (fsTnl), slow-twitch skeletal muscle (ssTnI), and cardiac muscle (cTnI) ${ }^{9.92}$. The expression of these isoforms, encoded by three separate genes, is not completely restricted to a specific muscle type. Several species, including humans, show a switch in TnI isoform expression from ssTnI to $\mathrm{cTnI}$ during heart development ${ }^{93.95 .47}$. 100

Tnl isoform composition is not only regulated during heart development, but appears to be affected by cardiac disease as well. Rather than regulation of mRNA expression", the cTnI activity during cardiac disease appears to be regulated by protein phosphorylation ${ }^{103-106}$ and/or protein degradation ${ }^{107-109}$. The importance of regulating $\mathrm{cTnl}$ activity is most likely related to altering the $\mathrm{Ca}^{2+}$ sensitivity of the diseased myocardium ${ }^{101-103}$. Apart from cTnI modifications, several authors have looked at the expression of ssTnl during cardiac disease. No evidence of ssTnl re-expression was found during end-stage heart failure or decompensated cardiac hypertrophy ${ }^{93,104,105}$, suggesting that reexpression of ssTnI plays no role in cardiac disease. Our group could also not detect ssTnl expression in the atria of patients with chronic atrial fibrillation (CAF). However, in patients with paroxysmal atrial fibrillation (PAF) as well as in patients with mitral valve disease we did find indications of ssTnl reexpression (Chapter 3). The contribution of atrial fibrillation (AF) to the observed re-expression of ssTnI was not fully understood.

$\mathrm{AF}$ is characterised by morphological changes that are indicative of cardiomyocyte dedifferentiation ${ }^{32}$. Similar changes are also found in patients with hibernating myocardium and they consist of extensive myolysis, increased glycogen storage, mitochondrial shape changes and redistribution of heterochromatin ${ }^{32.126}$. These morphological changes are accompanied by expression patterns and subcellular organisation of structural and functional proteins, characteristic of foetal cardiomyocytes $^{33}$. In addition, AF results in activation of calpains ${ }^{12.213}$, which could result in increased TnI degradation 
as previously shown during increased preload or hypoxia ${ }^{\text {mu.1!! }}$. The exact effect of AF on Tnll isoform expression in the atria is still poorly understood. During AF, Tnl isoform expression might be influenced by calcium overload induced degradation or by dedifferentiation related changes in gene expression. To evaluate the role of AF in TnI isoform expression, we examined the composition of $\mathrm{TnI}$ isoforms in atrial cardiomyocytes during chronic atrial fibrillation in the goat.

\section{2 | Materials and Methods}

\section{1 | Animal tissue}

The goat model of AF, first described by Wijffels et al. ${ }^{127}$, was used to obtain tissues from right and left atrial appendages from animals in either sinus rhythm (SR) or after $1,2,4,8$, or 16 weeks of sustained AF as previously described by Ausma er al. ${ }^{59},(\mathrm{n}=6$ in each group). Briefly, under anaesthesia an Itrelpacemaker (Medtronic(i)) was implanted in the neck of the goat and a bipolar screw-in electrode was inserted through the jugular vein in the right atrium. AF was maintained by burst pacing as described previously ${ }^{59}$. Thirty-six goats $(61 \pm 13 \mathrm{~kg})$ were used and animal handling was carried out according to the Dutch Law on Animal Experimentation (WOD) and The European Directive for Protection of Vertebrate Animals Used for Experimental and Other Scientific Purposes. At the end of the experimental period, the goats were anaesthetised and thoracotomy was performed. Foetuses (Foetal, $n=5$ ) at different days of gestation (from 4 weeks prior to end-term up to a few days before birth) were obtained from the abattoir. Of all animals, the right and left atrial appendages were excised and inmediately frozen in liquid nitrogen precooled isopentane. From 1 adult animal, additional tissues were taken (skeletal muscle, diaphragm) and immediately frozen in liquid nitrogen precooled isopentane.

\section{$2.2 \mid$ Western blotting and antibodies}

The monoclonal antibodies Ti-1, which reacts specifically with rat and bovine cTnJ isoform and Ti-54 which reacts with both cTnl and ssTnl were used to detect changes in Tnl isoform constitution ${ }^{98}$. Cryostat sections from tissue samples were 
homogenised in electrophoresis sample buffer and boiled for 5 minutes. Equal protein amounts of each sample, together with molecular weight standards (Biorad), were run at $100 \mathrm{~mA}$ on a $13 \%$ gradient polyacrylamide gel, transferred onto a nitrocellulose filter, saturated for 1 hour with ovalbumin in TBST

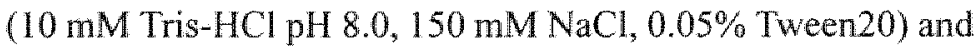
incubated with the primary antibody (Ti-54, 1:3000; Ti-1, 1:1000) for 1 hour at RT in TBST. After washing $3 \times 10 \mathrm{~min}$ in TBST, filters were incubated for 1 hour with peroxidase conjugated secondary antibody (1:5000). Following $3 \times 10 \mathrm{~min}$ washing in TBST, the peroxidase activity was determined by the ECL procedure.

\subsection{Isolation of goat TnI cDNA}

To obtain the goat-specific sequence for $\mathrm{cTn} I$, a goat atrial cDNA library (kindly provided by Dr. H.M.W. van der Velden ${ }^{128}$, Utrecht Medical Centre) was screened according to standard procedures. In short, cloned cDNAs were transferred onto Hybond $\mathrm{N}^{+}$filters (Amersham) and hybridised with a fragment of human cTnI cDNA. Positive clones were isolated and sequenced on the $A B I$ PRISM $B$ ) 310 genetic analyser (PE Applied Biosystems) using the ABI PRISM® Bigdye ${ }^{T M}$ terminator cycle sequencing kit (PE Applied Biosystems).

The goat-specific sequence of ssTnI was obtained by rapid amplification of cDNA ends with the 5'RACE-kit (Life Technologies), procedure as described by the manufacturer from I $\mu \mathrm{g}$ of RNA isolated from goat diaphragm tissue. Gene specific primer sequences (GSP-1: CCCGCAGATCCATGGACACCTTGTG; OSP-2: CGCTTGAACTTCCCACGGAGGTC) were selected according to optimal sequence homologies between ssTnI of human, rat and mouse. PCR products were cloned into pUC19 and subsequently sequenced on the ABI PRISM $B 310$ genetic analyser using $A B I$ PRISM(B) Bigdye ${ }^{T M}$ terminator cycle sequencing kit.

\subsection{Quantitative real-time RT-PCR}

Total RNA from $30 \mathrm{mg}$ atrial appendage tissue was isolated using the RNeasy mini kit (Qiagen) according to the manufacturer"s instructions. To remove genomic DNA contamination, on-column DNase treatment with the RNase- 


\begin{tabular}{|c|c|c|}
\hline Target & $\begin{array}{l}\text { Primens } \\
\text { probe }\end{array}$ & Sequence/modification \\
\hline \multirow{3}{*}{$\begin{array}{l}\text { goat } \\
\text { cTrl }\end{array}$} & Forward & 5GCCCACCTCAAGCAGGTO 3 \\
\hline & Reverse & 5' TTGCGCCAGTCTCCTACOTC 3 \\
\hline & Probe & $\begin{array}{l}\text { TAMRA } \\
\text { 5.AGAGGAGGACACGGAGAAGGAAAACCG }^{2} \\
\text { DABCVI }\end{array}$ \\
\hline \multirow{3}{*}{$\begin{array}{l}\text { goat } \\
\text { ssTnI }\end{array}$} & Forward & 5"CATGCCGGAAGTCGAGAGAAA3" \\
\hline & Reverse & 5' CATCAGGCTCTRCAGCAGGAG 3 \\
\hline & Probe & $\begin{array}{r}\text { PAM } \\
\text { 5.CCAAGATCACTGCOTCOCOCAY } \\
\text { DABCYL }\end{array}$ \\
\hline
\end{tabular}

free DNase set (Qiagen) was performed. Following incubation of the RNA at $65^{\circ} \mathrm{C}$ for $5 \mathrm{~min}$, reverse transcription was performed for 1.5 hours at $37^{\circ} \mathrm{C}$ with $600 \mathrm{U}$ of M-MLV reverse transcriptase (GibcoBRL) in $50 \mu \mathrm{L}$ of $50 \mathrm{mM}$ Tris-HCL, pH $8.3,75 \mathrm{mM} \mathrm{KCl}, 3 \mathrm{mM} \mathrm{MgCl}, 10 \mathrm{mM}$ DTT, and $1 \mathrm{mM} \mathrm{dNTPs}$ in the presence of $40 \mathrm{U}$ RNase inhibitor RNasin $($ ) (Promega) and $0.5 \mu \mathrm{g}$ oligo(dT) primer (GibcoBRL). Reverse transcriptase activity was inactivated by incubation at $95^{\circ} \mathrm{C}$ for $5 \mathrm{~min}$ and cDNAs were stored at $-20^{\circ} \mathrm{C}$. Quantitative real-time PCR (described elsewhere ${ }^{16,117}$, was performed using the Real-time PCR Taqman Kit (Eurogentec) with the ABI PRISM 7700(B) Sequence Detection System apparatus and software (PE Applied Biosystems). Primer Express software (PE Applied Biosystems) was used to design the specific primers and probes, based on the isolated cDNAs of cTnl or ssTnI, and all primers/probes were synthesised by Eurogentec. Primers and probes used for PCR are listed in table 1. Quantitative PCR was performed in a $50 \mu \mathrm{l}$ volume containing $3 \mu \mathrm{l} \mathrm{cDNA}, 1 \times$ PCR buffer, $200 \mu \mathrm{M}$ dATP, dGTP, dCTP, dTT,P, and dUTP, $0.025 \mathrm{U} / \mu$ l Hot Goldstar DNA polymerase, $100 \mathrm{nM}$ probe, and $150 \mathrm{nM}$ of each primer. Cycling conditions were as follows: a Hot Goldstar activation step of $10 \mathrm{~min}$ at $95^{\circ} \mathrm{C}$, followed by 50 cycles of $15 \mathrm{sec}$ at $95^{\circ} \mathrm{C}$ and $1 \mathrm{~min}$ at $60^{\circ} \mathrm{C}$. After each cycle, the fluorescence of the reporter dye was measured and the parameter $\mathrm{Ct}$ (threshold cycle) was defined as the cycle number at which the fluorescent signal passed a fixed value (threshold). Thus, the $\mathrm{Ct}$ value reflects the point during the reaction at which a sufficient number of

\section{Table 1}

Specific primers and probes used for quantitative reattime RT-PCR 
amplicons have accumulated to be at a statistically significant point above the baseline. Data were analysed with the Sequence Detection System software (PE Applied Biosystems). The absolute $m R N A$ amounts were calculated using a standard curve generated by quantitative real-time PCR on a dilution series of both cTnl and ss TnI.

\section{5 | Statistical analysis}

Data are given as mean values \pm SEM of 3 independent experiments. Significant differences between the groups were analysed by means of the Wilcoxon-Mann-Whitney rank sum test. All p-values are two-sided and p-values $<0.05$ were considered statistically significant. Statistical computations were performed in SPSS 10.0.5.

\section{3 | Results}

\section{1| TnI protein expression during chronic atrial fibrillation}

To establish whether AF could affect TnI isoform expression we performed Western blotting on atrial tissue from goats in sinus rhythm and after $1,2,4,8$, and 16 weeks of AF. As in other species, there are three TnI isoforms expressed in goat muscle tissue ${ }^{94.98}$. In adult heart, only the cardiac TnI isoform could be detected by Western blotting. In foetal heart, both the cardiac and the slow-twitch skeletal isoform were present, and skeletal muscle contained the slow-twitch as well as the fasttwitch skeletal isoforms (Figure 1A). Western blotting with Ti54 which recognises both $\mathrm{c} T \mathrm{nI}$ and $\mathrm{Ss} \mathrm{Tn} \mathrm{I}$ revealed an additional band in only a few atrial samples (Table 2). To distinguish between ssTnl re-expression and cTnl degradation, Western blotting was also performed with an antibody specific for $\mathrm{cTnL}$. Again, an additional band could be observed in the same atrial samples which displayed an additional band with Ti-54 (Figure (B), indicating degradation of $\mathrm{CTnI}$. rather than re-expression of ssTnl.

All the results of the Western blot analysis are summarised in Table 2. Atrial fibrillation resulted in sporadic degradation of cTnl to a level that could be detected by Western blotting. This occasional degradation occurred. both in the right and left atria but could only be observed within the first 4 weeks of AF. After 
A

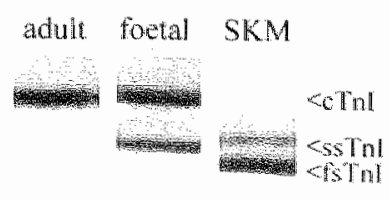

B
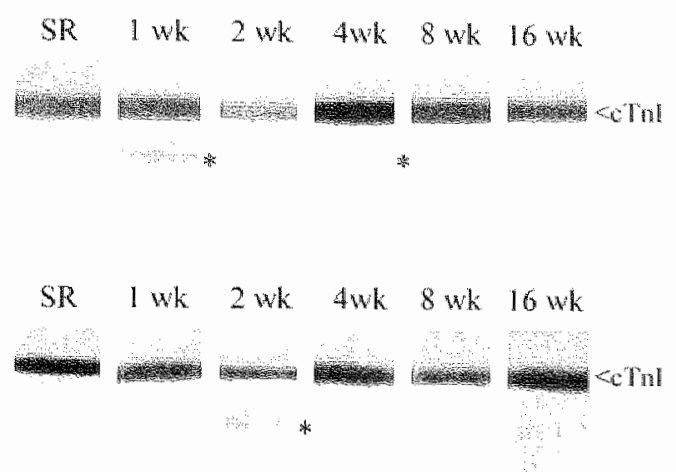

longer duration of AF no more cTnl degradation was detectable. Re-expression of ss Tnl did not occur, at least not at a level detectable by Western blotting.

\subsection{Isolation of goat Troponin I cDNAs and primer design}

In order to design goat-specific primers for quantitative RT-PCR analysis, cDNAs of the different $\mathrm{TnI}$ isoforms were isolated. A partial cDNA encoding $330 \mathrm{nt}$ of the 3-prime end of cTnI (GenBank accession number: AY033589) was picked up from a goat heart cDNA library. Overall homology with human cTnI was approximately $90 \%$ at nucleotide level and $97 \%$ at the protein level (Figure 2A). ssTnl cDNA was isolated using 5' RACE on mRNA from goat diaphragm tissue. The partial cDNA of ssTnI (GenBank accession number: AY033587) contained $330 \mathrm{nt}$ of the $5^{\prime}$ end, and homologies at the nucleotide and the protein level were $88 \%$ and $93 \%$ respectively (Figure 2B).

Figure $2 \mathrm{C}$ shows the primers/probe combinations of $\mathrm{cTnl}$ and ss Tnl used for real time quantitative RT-PCR which were based on the sequences derived from the partial CDNA's. In humans, the overall homology between the coding regions of $\mathrm{cTnl}$ and ssTnI is approximately $60 \%$. Therefore, goat specific primers/ probe combinations were confined to regions of poor homology

\section{Figure 1 |}

Western blot andysis of ThI isoform expression

Typical examples of westery blot analysis.

A) Western blot with Tis 5 \&

on normal goat atrium,

foetal goat attrum, and

nornial goat skeletal muscte (SRM).

B) Western blots with Tin on atrial tissue from goats in sinus rhythm and after 1 week, 2 waeks, 4 weeks, 8 weeks, and 16 weeks of At. The asterisk indicates the location of a band which was detected with both $T$. 54 and $7-1$. 


\begin{tabular}{|c|c|c|c|c|c|}
\hline \multirow{3}{*}{ 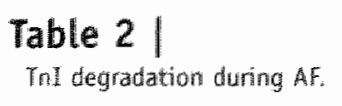 } & \multirow{3}{*}{ group } & \multirow{2}{*}{\multicolumn{2}{|c|}{ cTnl degradation }} & \multirow{2}{*}{\multicolumn{2}{|c|}{ ssTnl expression }} \\
\hline & & & & & \\
\hline & & $\mathrm{RA}$ & $\mathrm{LA}$ & $\mathrm{RA}$ & LA \\
\hline \multirow{7}{*}{$\begin{array}{l}R A=\text { right atrium; } L A=\text { left } \\
\text { atrium; } S R \text { a sinus shythm. }\end{array}$} & $\mathrm{SR}$ & $0 / 6$ & $0 / 6$ & $0 / 6$ & 016 \\
\hline & $A F$ & 116 & $1 / 6$ & 016 & $0 / 6$ \\
\hline & $A F_{2}$ & $1 / 6$ & $1 / 6$ & $0 / 6$ & $0 / 6$ \\
\hline & AF4 & $2 / 6$ & $0 / 6$ & $0 / 6$ & $0 / 6$ \\
\hline & $\mathrm{AFB}$ & $0 / 6$ & $0 / 6$ & $0 / 6$ & 016 \\
\hline & $A F 16$ & $0 / 6$ & $0 / 6$ & $0 / 6$ & 016 \\
\hline & FOETAL & $0 / 5$ & $0 / 5$ & $5 / 5$ & $5 / 5$ \\
\hline
\end{tabular}

between both sequences to avoid cross-reactivity. Furthermore, both the primers and the probes were designed to meet several requirements concerning $\mathrm{G}-\mathrm{C}$ content, stretches of identical nucleotides, melting temperature, and the size of the amplicon, directed by the primer design software. The probes for cTnl and ss Tnl were labelled with the reporter dyes TAMRA and 6FAM respectively, in combination with DABCYL as the quencher (Table 1). This allows the use of the probes in a multiplex PCR analysis to analyse both isoforms simultaneously within the same sample. However, in this study both amplifications were performed separately because the detection software did not support the multiplex PCR approach.

\subsection{TnI mRNA expression during chronic atrial fibrillation}

Real time quantitative RT-PCR was performed to analyse changes in the mRNA expression level of Tnl and ss Tnl (Figure 3). A control PCR with cTnl primers on a dilution series of the partial cTnl cDNA from the goat generated an amplicon of the expected size (Figure 3A). Figure 3B shows the amplification plots obtained during real time RT-PCR on the same dilution series in the presence of both the cTnl primers and the cTnl probe. The cycle number at which the fluorescence crossed a fixed threshold value represented the $\mathrm{Ct}$ value which was used to generate a standard curve (inset). The standard curve had a linear detection range from $10 \mathrm{pg}$ up to $\mathbb{0 0} \mathrm{ng}$. Similar results were obtained for ssTnl (data not shown). In figure 3C and 3D typical examples are shown of the amplification plots generated with $\mathrm{cTnl}$ and ss Tnl primers on $\mathrm{mRNA}$ isolated from atrial tissue of goats in sinus rhythm, after $1,2,4,8$, and 16 weeks of atrial 


\begin{tabular}{|c|c|c|c|}
\hline$A$ & & cTn & \\
\hline $\begin{array}{l}\text { hantan } \\
\text { gort }\end{array}$ & 95 & 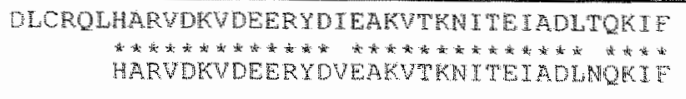 & 33 \\
\hline $\begin{array}{l}\text { human } \\
\text { goat }\end{array}$ & 134 & 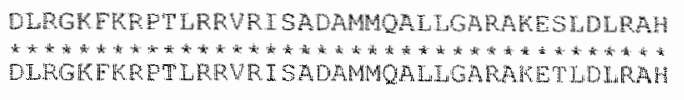 & 172 \\
\hline $\begin{array}{l}\text { humati } \\
\text { goat }\end{array}$ & 173 & 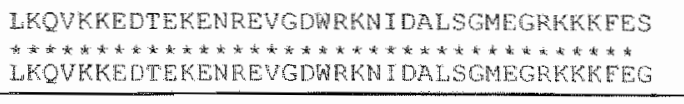 & 210 \\
\hline $\mathrm{B}$ & & ssTnl & \\
\hline $\begin{array}{l}\text { humian } \\
\text { goat }\end{array}$ & 1 & 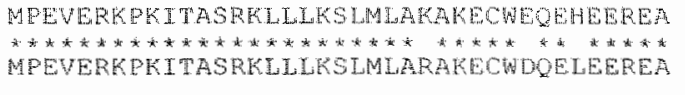 & 39 \\
\hline $\begin{array}{l}\text { human } \\
\text { goat }\end{array}$ & 10 & 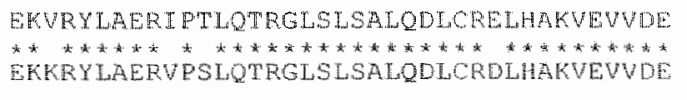 & 78 \\
\hline $\begin{array}{l}\text { Mumath } \\
\text { goat }\end{array}$ & 79 & 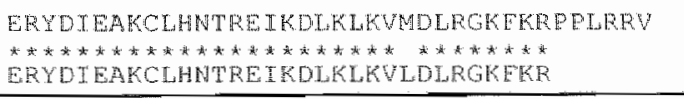 & 116 \\
\hline
\end{tabular}

\begin{tabular}{|c|c|c|}
\hline$C$ & crnl & $\operatorname{ssTn} 1$ \\
\hline Fonward & 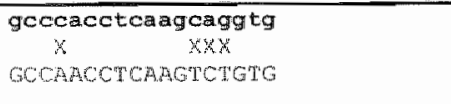 & $\begin{array}{l}\text { catgceggragtogagagaa } \\
x \times x \times x \times x \\
\text { COAGCCOCACGCCAAGAARA }\end{array}$ \\
\hline Probe & 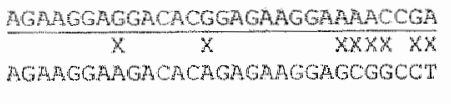 & 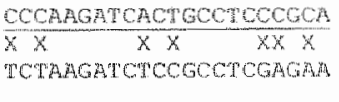 \\
\hline Reverse & 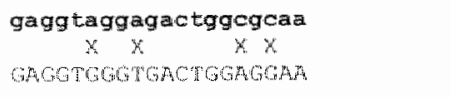 & 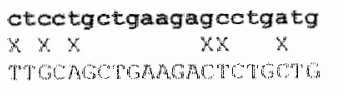 \\
\hline
\end{tabular}

\section{Figure 2 |}

Isolation of goat. Troponin I CDNAs and primer destign

\section{A) Protein homology} between human (hs, homo sapiens) (Tru and the 110 ala. frament of goat (ch, capra hircus) cThL.

B) Protein homology between human s5TinI and the 110 ad. fragment of goat ss Thi

C) Specificity of primers and probes used for quantitative RT-PCR. Primer sequences are shown in bold, probe sequences are underlined. The laft pand shows the primers/probe for cTrl. The right panel shows the primers/probe for ssTin. Mismatches with either the homologous s5Tif or cinl sequence are indicated by $x$.

fibrillation, and foetal goats. As expected, the expression of ss Tnl was the highest in the foetal goat which results in a leftward shift of the foetal amplification curve. Figure 4 shows diagrams representing the mean $\mathrm{Ct}$ values of three independent QRT-PCR experiments on the different experimental groups. There was no significant change in the mRNA levels of cTnl between all groups (Figure 4A). The same was true for ssTnI mRNA levels. Only in the atria of foetal goats a significant drop in $\mathrm{Ct}_{\mathrm{sg}}$ could be observed which indicates an increased level of ss TnI mRNA (Figure 4B). To exclude an effect of differences in the quantity or quality of the mRNA on the $\mathrm{Ct}$ values between the different 
Figure 3

Real time quantitative RT. Prof analysis for CTnI and ssinl in goats with Af

A) Amplicons generated during PCR with cThI primers on a dilution series of goat clnol COWA. PCR products were analysed on a $2 \%$ agarose get stained with ethidium bromide. MTC = no template control. NAC - no amplification control.

B) Amplification curves gerterated during QRT-PCR on the same dilution series in the presence of both primers and the crit probe.

* $100 \mathrm{ng}: \square$ as $10 \mathrm{ng}$ : $\Delta-1 \mathrm{rg}: 0=100 \mathrm{pg}$ :

$$
\Delta=10 \mathrm{pg} ;=\mathrm{NTC} \text {; }
$$$$
\text { - NAC. }
$$

Inset) Standard curve based on Ct values derived from QRT PCR on CTII dilution series.

C. clnI amplification curves generated during QRT PCR $58 \mid$ on atria from foetal goat. goat in $S R$ and goats after $1,2,4,8$, and 16 weeks of AF. D) Amplification curves generated during QRT.PCR on same samples as in $($ ) but now with primers/pobe specific for $55 \mathrm{Tn}$.
A

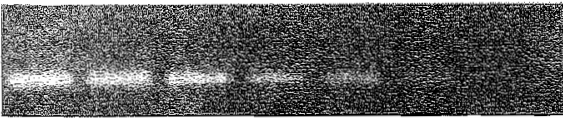

100 rig long lng loopg $10 \mathrm{pg}$ NTC NAC
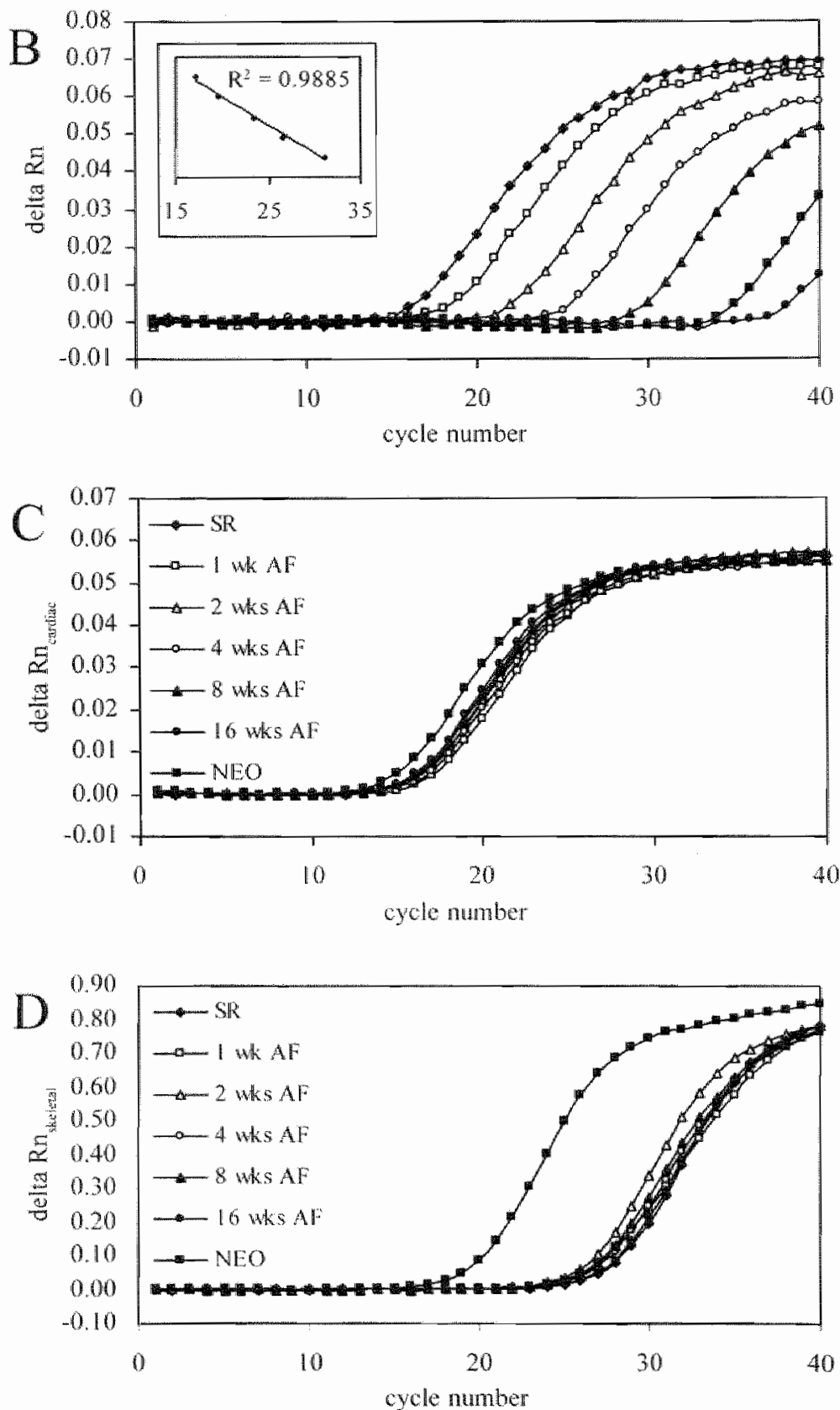
A

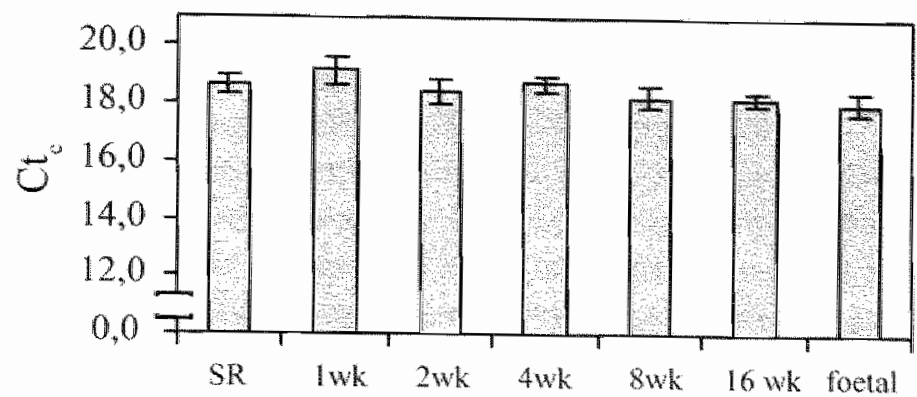

B

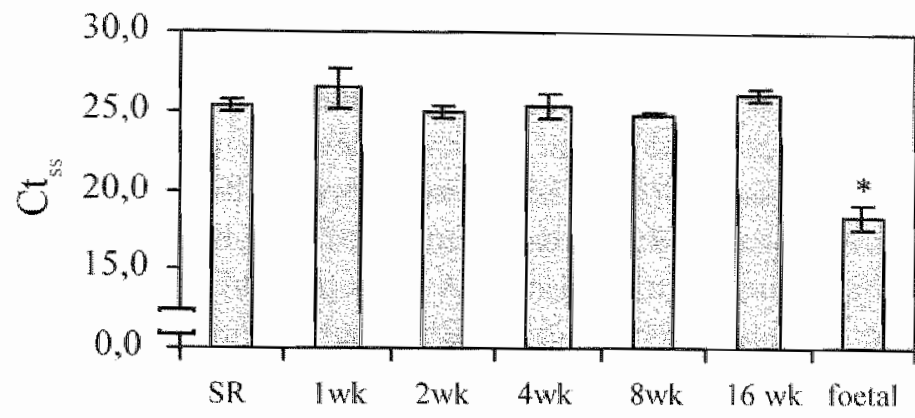

$\mathrm{C}$

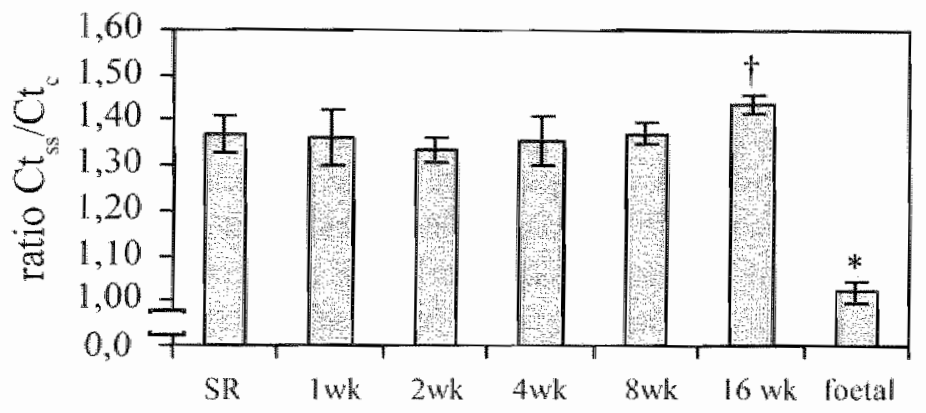

groups, we determined the ratio between $\mathrm{Ct}_{\mathrm{ss}}$ and $\mathrm{Ct}_{\mathrm{f}}$ (Figure $4 \mathrm{C}$ ). As expected, there was a significant decrease of the $\mathrm{Ct}_{\mathrm{s}}$ $\mathrm{Ct}_{\mathrm{c}}$ ratio in foetal goats as compared to all adult groups, due to the increased expression of ssTnl. There was no significant change in the $\mathrm{Ct}_{\mathrm{ss}} / \mathrm{Ct}_{\mathrm{c}}$ ratio of any of the $\mathrm{AF}$ groups as compared to goats with SR. However, there appeared to exist a trend towards lower ratios at the onset of $\mathrm{AF}$ and increasing ratios after longer periods of AF. This trend was confirmed by a significant change in $\mathrm{Ct}_{\mathrm{ss}} / \mathrm{Ct}_{\mathrm{c}}$ ratio after 16 weeks of $\mathrm{AF}$ as compared to 2 weeks of AF.

Based on the standard curves, we also calculated the ratio
Figure 4 ।

Ct-values and $c t$ ratios of ssTnI and CTrI in goats whth $A F$.

A) Diagram showing the mean Ct values derived from ORT PCR for CHri on the different experimental groups.

Q) Diagram showing the mean Ct values derived From QRT.PCR for sstul on the different expenimental groups. C) Diagram showing the mean $\mathrm{Ct} / \mathrm{Ct}$ ratio of the different expenmental groups. * $p<0.010 \mathrm{vs}$, all other groups, $1 \rho<0.050$ ws. 2 weeks At 
Table 31

Overall results of quantatative RT-PCF

* p $0.010 \mathrm{ws}$. dill other groups, $p<0.050$ ws. AF2

\begin{tabular}{|c|c|c|c|c|}
\hline group & $C t_{y g}$ & $\mathrm{Ct}_{\mathrm{s}}$ & ratio $\mathrm{Ct}_{\mathrm{s}} \mathrm{Ct}_{\mathrm{c}}$ & $\begin{array}{c}\text { absolute amount } \\
\text { cTnIsssTnl }\end{array}$ \\
\hline $\mathrm{SR}$ & $25.35+1-0.32$ & $18.65+0.35$ & $1.37+1-0.04$ & $11,277+1-5,859$ \\
\hline $\mathrm{AFI}$ & $26.44+1-1.25$ & $19.15+-0.49$ & $1.36+1-0.06$ & $8,302+/-2,899$ \\
\hline $\mathrm{AF} 2$ & $24.95+1-0.43$ & $18.42^{-\frac{1}{3}} y=0.41$ & $1.33 \% /-0.02$ & $3,188+1-601$ \\
\hline AF4 & $25.42+1-0.78$ & $18.70+-0.22$ & $1.36+/-0.05$ & $8,576+1-3,516$ \\
\hline AF\& & $24.85+-0.19$ & $18.27+1-0.41$ & $1.37+1-0.02$ & $6,254+1-1,968$ \\
\hline$A F \| 6$ & $26.15+0.45$ & $18.24+0.18$ & $1.44+-0.027$ & $12125+1-3,521$ \\
\hline Foetal & $18.35+/-0.71$ & $18.03+1.0 .36$ & $1.02^{\frac{5}{2}} /-0.02^{*}$ & $30+1-10$ * \\
\hline
\end{tabular}

between the absolute amounts of $\mathrm{cTnI}$ and ssTnl which confirmed the observations that were made using the $\mathrm{Ct}$ values (Table 3). In the foetal heart the level of cTnI mRNA was approximately 30 fold higher as compared to ssTnI mRNA. In the adult heart this increased up to 11,000 fold. AF resulted in a drop of the cTnl:ssTnI mRNA ratio to nearly 3,000 fold after two weeks of AF but this gradually increased and after 16 weeks of $A F$ the ratio had normalised. All the results of the quantitative real time RT-PCR analysis are summarised in Table 3.

\section{4 | Discussion}

The results of the present study show that during heart development in the goat, the same switch in TnI isoform expression can be found as described for other species. Western blotting revealed that degradation of $\mathrm{cTnI}$ occurred in only a few samples during the first 4 weeks of AF ( $\|$ out of 6 after one and two weeks of AF and 2 out of 6 after 4 weeks of AF). Although quantitative RT.PCR did not show a significant change in the $\mathrm{mRNA}$ expression levels of $\mathrm{cTnl}$ and ss Tnl there appeared to be a trend towards increasing expression of $\mathrm{cTnl}$ after 16 weeks of AF. Neither the limited degradation in the early phase of AF nor the increasing CTnI expression after longer duration of AF appeared to be accompanied by re-expression of ssTnl.

\subsection{TnI isoform expression during cardiac development}

Several authors have described the expression pattern of TnI during cardiac development in different species. TnI expression appears to follow a pattern that consists of three phases: expression of ssTnl during early development, co-expression of ssTnI and cTnI during late development, and exclusive 
expression of $\mathrm{cTnl}$ in adulthood ${ }^{93.96 .99 .400}$. The same shift from ssTnI to cTnI can be found in the goat. Although we did not look at the early embryonic stages of goat heart development, Western blotting revealed the presence of both ssTnl and $\mathrm{cTnI}$ in foetal goat heart up to near end-term, whereas in adult heart only cTnI could be detected. These results support the general concept that $\mathrm{TnI}$ isoform expression during cardiac development is similarly regulated in a wide variety of species. The observations at the protein level were confirmed by QRT-PCR. Near end-term foetal heart displayed an almost 1:30 ratio with respect to ssTnL and $c \operatorname{TnI} m R N A$ levels. This ratio increased in the adult heart up to approximately $1: 11,000$, which shows that cTnl is the predominant isoform expressed in the adult heart. Nevertheless, QRT-PCR did reveal that a low level of ssTnI expression remains present in adult atrial myocardium. Previous studies did not find any ssTnI mRNA expression in adult myocardium ${ }^{93.95}$, except for Gorza et al. who showed by in situ hybridisation that cells of conductive tissues (e.g. AV node) did maintain some level of ssTnl mRNA throughout adulthood ${ }^{96}$. Whether the observed ssTnI mRNA expression actually results in the production of ssTnI protein and whether the protein is utilised in the contractile apparatus is unknown, but appears unlikely in view of the low mRNA expression level.

\subsection{Degradation of CTnI protein during CAF}

It has been suggested that AF results in calcium overload affecting both the contractile function and the electrical remodelling of the atrium ${ }^{56.58 .127}$. Ausma et al., who found evidence of increased calcium deposits at the sarcolemma and in the mitochondria in the first two weeks of AF, proposed that the increased calcium levels might activate proteolytic pathways thus initiating the structural remodelling of cardiomyocytes during $\mathrm{AF}^{59}$. Recent studies show that $\mathrm{AF}$ results in increased levels of Calpain $1^{112.113}$, a calcium activated proteolytic protein involved in degradation of $\mathrm{cTn} \mathbf{1}^{107.110 .111}$. The Western blotting results in this study show that only a very limited amount of cTnI degradation can be detected in goat atria during AF, and only within the first 4 weeks of $A F$. This might be related to the increased calcium levels which are also limited to the first weeks of AF in the goat ${ }^{59}$. After prolonged periods of AF, no cTnI degradation could be detected by Western blotting, which could 
indicate normalisation of calcium homeostasis, a decreased activity of Calpain $\mathrm{I}$, or an increased protection against degradation. The absence of $\mathrm{cTnI}$ degradation after longer periods of AF is in agreement with our observation that in patients with paroxysmal and chronic AF no cTnI degradation can be detected (Chapter 3). The limited occurrence of cTnI degradation in the goat and the absence of degradation in patients with paroxysmal or chronic AF is suggestive of a protective response of the cardionyocytes. This protective response might be the result of activation of heat shock proteins ${ }^{121}$ or an increase in cTnI phosphorylation which protects cTnI from degradation ${ }^{109}$. We are currently analysing the phosphorylation state of cTnl in patients with CAF to determine whether or not increased cTnl phosphorylation protects cTnl from calpain mediated degradation.

\subsection{Expression of cTnI and ssTnI mRNA during CAF}

QRT-PCR is a sensitive and reliable technique to quantify mRNA levels within a population of cells ${ }^{117}$. In this study we quantified the levels of cTnl and ssTnI in the goat atrium during AF to analyse whether AF had any influence on the expression levels of both mRNAs. In late stages of foetal development, the amount of $\mathrm{c}$ TI mRNA in goat atria was approximately 30 -fold higher as compared to ss Tnl. In adult atrium this number increased to 11,000 -fold. AF appeared to have no significant effect on the mRNA concentration of either cTnI or ssTnl. However, when the $\mathrm{Cl}_{\mathrm{s},} / \mathrm{Cl}$, ratio's were analysed there was a trend towards decreased cTnl expression in the first weeks of AF and an increase in $\mathrm{CTnl}$ expression after longer periods of AF. This trend was confirmed by a significant increase in the $\mathrm{Ct} / \mathrm{Ct}$ ratio after 16 weeks of AF as compared to 2 weeks AF. Indeed, after two weeks of AF, cTnI mRNA levels were only 3,200-fold higher as compared to ssTnI whereas after 8 and 16 weeks AF this number increased to 6,000 -fold and 12,000-fold, respectively. Whether these changes are a response to altered mRNA turnover rate as a result of $\mathrm{AF}$ is not known. The increasing expression of cTnl after longer duration of AF could have several causes. First, a decreased stability of $\mathrm{CnI}$ mRNA might be compensated for by increased expression levels of cTnI mRNA. Secondly, the increased expression might reflect cardiomyocyte hypertrophy which has been shown to occur during $\mathrm{AF}^{32.79 .88}$. 
Furthermore, cTnll expression upregulation could be a response to an altered calcium sensitivity of cTnl as a result of increased cTnl phosphorylation ${ }^{122-424}$. Finally, it has been shown that after an initial increase in calcium levels in the first 2 weeks of AF, the intracellular calcium levels decrease after 8 to $\mathbb{1 6}$ weeks of $\mathrm{AF}$ to levels below those during $\mathrm{SR}^{54}$. The increased expression of cTnI might represent the cardiomyocyte's response to counterbalance this effect and to maintain optimal contractile activity. This is supported by the observation of Schotten et al. that in patients with chronic $A F$ the reduced contractile force could be completely restored by high calcium levels ${ }^{1296}$.

It is unknown whether the shift towards ssTnI at 2 weeks of AF actually results in increased SsTnI protein because Western blotting did not detect any ssTnl expression. ss Tnl expression increases calcium sensitivity and renders the myofilaments protected against acidosis ${ }^{101.102 .118}$. As such, expression of ssTnl might be beneficial in the acute phase of AF when cellular stress is high. Nevertheless, the amount of cTnL over ssTnI is still in favour of $\mathrm{cTnI}(1: 3,000)$. For comparison, in patients which displayed a ssTnl band with Western blotting, cTnI was only 800 fold higher as compared to ss TnI (Chapter 3).

\section{4 | Concluding remarks}

We set out to analyse the expression of Tnl isoforms in a goat model on AF. Induction of AF only occassionally resulted in degradation of cTnl in the first 4 weeks AF ( 1 out of 6 after 1 and 2 weeks of AF, and 2 out of 6 after 4 weeks of AF). Reexpressing ss $\mathrm{Tnl}$, which would coincide with the progressive changes reminiscent of cardiomyocyte dedifferentiation ${ }^{136}$, could not be detected. At the onset of AF, the limited cTnl degradation might be the result of calcium dependent activation of calpains. Following longer episodes of AF, cTnl seemed to be protected against degradation, possibly by heat shock proteins or increased protein phosphorylation.

\section{Acknowledgements}

The authors would like to thank $H$. Kuijpers en M-H Lenders for their excellent technical assistance throughout this study, and Dr. H.M.W. van der Velden (Utrecht Medical Centre) for providing them with the goat atrial cDNA library. 



\title{
Chapter 5
}

\section{ANALYSIS OF ALTERED GENE EXPRESSION DURING SUSTAINED ATRIAL FIBRILLATION IN THE GOAT}

\author{
W. Thijssen, H. van der Velden, E. van Ankeren, J. Ausma, \\ M. Allessie, M.Borgers, G. van Eys, H. Jongsma
}

Cardiovasc Res 2002; 54: 427-437

Objective: Atrial fibrillation (AF) is characterised by electrical, gap junctional and structunal remodeling. However, the underlying molecular mechanisms of these phemomena are largely unknown. fo get more insight into atrial remodelting at the molecular level we have analysed changes in gene expression during sustained AF in the goat. Methods: The differential display technigue (00) was used to identify geries. differentially expressed during sustained AF (13.9.5.2 weeks) as compared to sinus thythm (SR). Dot blot analysis was performed to confirn the altered gene expession and to establish the changes in expression after 1, 2, 4, 8 and 16 wees of AF. Immunohistochemistry and Western blotting were used to validate the Do approach and to further characterise the changed expression of the B-myosin heay chain gene at the protein level. Results: Of the approximately 125 fragments that showed changed expression levels daring AF, 34 were cloned and sequenced. lwenty-one of these represented known gerses involved in cardionyocyte stucture, menabolism, expression resgulation, or differentiation status. The changed expression of $70 \%$ of the isolated clones could be confrmed by dot-blot analysis. In addition, tine course andysis revealed different profiles of expression as well as transient re-expression of genes. e.g. the gene for bypoxia-inducible factor la during the fist week of AF. During sustained AF the frequency of cardiomyocytes expressing B myosin heavy chain (BMHC) increased from $21.842 .1 \%$ to $47.9 \pm 2.5 \%$ (SEM). The overall expression of MHC (aw 1 ) appeared to be down megulated durng Af. Conclushons: AF is accompanied by changes in expression of proteins involved in cellular stucture, metabolism, gene expression regulation and (de-)differentiation. Most alterations in expression confirm or support the hypothes is of cardiomyocyte de-differentiation. Furthermore, the results suggest a role for ischaenic stress in the early response of cardiomyocytes to AF, possibly via activation of hypoxia. induciblite factor 1 范. 


\section{1 | Introduction}

Atrial fibrillation (AF) is characterised by extensive electrical and structural remodelling of the atrium, both at the level of the single myocyte and the atrial tissue as a whole. Electrophysiological remodelling is characterised by shortening of the atrial effective refractory period (AERP), which (in part) is the result of changes in expression of the L-type $\mathrm{Ca}^{2+}$ channel. Several authors have reported, both in animal models ${ }^{131.132}$ and in patients ${ }^{13.134}$, a downregulated expression of the $\mathrm{L}$-type $\mathrm{Ca}^{\text {** }}$ channel during AF. In patients with paroxysmal or persistent $A F$ reduced protein levels of $L-t y p e \mathrm{Ca}^{2+}$ channel were shown to correlate with AERP shortening ${ }^{135}$. Besides the $\mathrm{L}_{-}$-type $\mathrm{Ca}^{2+}$ channel, the expression of several $\mathrm{K}$ channel subunits appears to be downregulated ${ }^{65.131-433.135 .137}$.

Since it was shown that time courses of AERP shortening and the increase in the duration of AF episodes did not match, it was concluded that other factors must be important for making the arrhythmia sustained ${ }^{12}$. A candidate is gap junctional remodelling, which was shown to occur both in a goat modell of $\mathrm{AF}$ and in patients suffering from sustained $A \mathrm{~F}^{128,338-141}$. Another factor involved in the stabilisation of AF appears to be structural remodelling ${ }^{1+2}$. Structural remodelling during AF includes a significant reduction in sarcomere number (myolysis), the accumulation of glycogen, changes in mitochondrial morphology, altered chromatin distribution and last but not least changes in cellular size (hypertrophy), phenomena known from hibernating myocardium in patients with chronic ischaemic heart disease $^{32,40,79.89}$. In addition, the expression pattern of several (structural) proteins adapts a foetal phenotype indicative of cardiomyocyte de-differentiation; e.g. re-expression of alphasmooth muscle actin and the disappearance of cardiotin ${ }^{33}$.

Apart from its effect on the stability of AF, structural remodelling of atrial myocytes is likely to be co-responsible for the temporarily impaired contractile function of the atria after cardioversion from $\mathrm{AF}^{129}$. It has been shown that following brief periods of $A F$, the electrical remodelling and contractile dysfunction are completely reversible within a few days ${ }^{143}$. However, after longer periods of AF, a discrepancy occurs between the normalisation of electrical properties (days to weeks) ${ }^{1+4-146}$ and the recovery of contractile function (weeks to months $)^{35.37 .1+7}$. Structural remodelling might be important in this 
context, although the downregulation and/or altered function of L-type $\mathrm{Ca}^{2+}$ channels seems to be largely responsible ${ }^{145}$.

Many aspects of AF-induced remodelling have been studied extensively in the goat model of AF. In fact, the principles of "AF begets $A F$ ' and 'AF-induced de-differentiation' originate from studies in which this model was used ${ }^{148}$. However, the exact molecular mechanisms underlying various aspects of atrial remodelling still remain unknown. In order to identify factors involved in the electrical and structural remodelling, we studied alterations in gene expression in the fibrillating goat atrium using the method of differential display ${ }^{68}$.

\section{2 | Materials and Methods}

\subsection{Animal model of atrial fibrillation}

For the first part of our studies 12 female goats were used (average weight $55 \mathrm{~kg}$ ). Of these, 6 were kept in SR while in the others sustained AF was induced as described by Wijffels et al. ${ }^{127}$. In brief, silicon strips containing multiple electrodes were stitched to the epicardial surface of both atria as well as to Bachmann's bundle. After recovery, the electrodes were connected to an external automatic fibrillator programmed to deliver a 1 second-burst of stimuli $(50 \mathrm{~Hz}, 4$ times threshold) each time an iso-electrical segment longer than $300 \mathrm{~ms}$ was detected. Following this protocol AF becomes sustained (episodes $>24$ hours) in most animals after 1-2 weeks. After at least two months of sustained AF samples of the right (RAA) and left atrial appendages (LAA) were immediately frozen in liquid $\mathrm{N}_{2}$ and stored at $-80^{\circ} \mathrm{C}$ until use.

For the second part of our studies 36 female goats were used (average weight $61 \mathrm{~kg}$ ) and instrumented as described by Ausma ef al. ${ }^{59}$. Six were kept in SR and used as controls. In the other animals an electrode was inserted via the jugular vein in the right atrium and connected to a pacemaker. Sustained (chronic) $\mathrm{AF}$ was induced by switching on the pacemaker, producing 2 second bursts $(50 \mathrm{~Hz}, 4$ times threshold) at 1 -second intervals. Initially AF was self-terminating within seconds whereas during the following days AF episodes became longer and more stable. The inter-burst period could gradually be prolonged to $30 \mathrm{~min}$ while sustained AF was being maintained. Animals were sacrificed after $1,2,4,8$ or 16 weeks of AF $(n=6)$ and RAA and 
LAA samples were prepared and stored as described above.

All animal handling was according to the Dutch Law on Animal Experimentation (WOD) and The European Directive for Protection of Vertebrate Animalls used for Experimental and Other Scientific Purposes.

\subsection{Differential display}

From pulverised atrial samples, total RNA was isolated using RNeasy (Qiagen). Chromosomal DNA contaminations were removed during incubation with RNase-free DNase $(10 \mathrm{U} / \mu \mathrm{l}$; Boehringer Mannheim) in the presence of an RNase inhibitor (1. U/Ml RNA-guard; Pharmacia). Concentrations were adjusted to $0.2 \mu \mathrm{g} / \mu \mathrm{l}$ and aliquots were frozen and stored at $-80^{\circ} \mathrm{C}$. For reverse transcription $1 \mu \mathrm{l}(0.2 \mu \mathrm{g})$ DNA-free total RNA and 1 $\mu \mathrm{l} 25 \mu \mathrm{M}$ anchored primer (T12VA ( $\mathrm{V}$ is 3 -fold degenerate for $\mathrm{A}, \mathrm{C}$ and $\mathrm{G}$ ), T12VC, T12VG or T12VT; final concentration $2.5 \mu \mathrm{M})$ in $8 \mu \mathrm{LEPC}$ treated $\mathrm{dH}_{2} \mathrm{O}$ was heated in a thermal cycler for $5 \mathrm{~min}$ at $65^{\circ} \mathrm{C}$ and quickly cooled down to $37^{\circ} \mathrm{C}$. Then $10 \mu$ l of a mixture of M-MLV Reverse Transcriptase (200 $\mathrm{U}$; GibcoBRL) in $100 \mathrm{mM}$ Tris-HCl, pH $8.3,150 \mathrm{mM} \mathrm{KCl}, 6$ $\mathrm{mM} \mathrm{MgCl}, 20 \mathrm{mM}$ DTT, $40 \mu \mathrm{M}$ dNTPs and $2 \mathrm{U} / \mu \mathrm{RNA}$ Ruard was added and incubations were performed for an additional $1 \mathrm{~h}$ at $37^{\circ} \mathrm{C}$, followed by $5 \mathrm{~min}$ at $95^{\circ} \mathrm{C}$ to heat inactivate the enzyme. Aliquots of $2 \mu \mathrm{l}$ were transferred to thin walled $200 \mu \mathrm{l}$ PCR tubes and used for differential display (DD) analysis. To each aliquot an equal volume of $25 \mu \mathrm{M}$ of the appropriate anchored primer was added followed by a mixture of 1 unit Taq DNA polymerase (recombinant; Gibco-BRL) and $0.5 \mu \mathrm{M}$ of a specific arbitrary 10-mer primer (twenty-six different ones; Operon) in $20 \mathrm{mM}$ Tris- $\mathrm{HCl}, \mathrm{pH} 8.4,50 \mathrm{mM} \mathrm{KCl}, 3 \mathrm{mM} \mathrm{MgCl}, 2 \mu \mathrm{M}$ of each dNTP, $0.02 \mu \mathrm{Ci} / \mu \mid\left\{\alpha-{ }^{32} \mathrm{P}\right\}$-dCTP (all final concentrations). Incubations were performed in a Perkin Elmer GeneAmp PCR System 2400 thermal cycler (Perkin EImer Applied Biosystems) according to the following program; 1 min at $94^{\circ} \mathrm{C}$ was followed by 40 cycles $\left\{30 \sec 94^{\circ} \mathrm{C}, 90 \sec 40^{\circ} \mathrm{C}, 30 \sec 72^{\circ} \mathrm{C}\right\}$ and an extension of $5 \mathrm{~min}$ at $72^{\circ} \mathrm{C}$. Stop buffer $(10 \mathrm{mM}$ ethylenediaminetetraacetic acid, $\mathrm{pH} 7.5,97.5 \%$ deionised formamide and $0.3 \%$ Bromophenol Blue) was added, samples were heated to $80^{\circ} \mathrm{C}$ for $2 \mathrm{~min}$ and $3 \mu$ l aliquots were electrophoresed on $6 \%$ denaturing sequencing gels. Each gel. was dried without fixation and exposed to Fuji RX safety film. 
Gel strips containing DD PCR fragments were excised, dried and soaked in $100 \mu \mathrm{ldH_{2 }} \mathrm{O}$ for $10 \mathrm{~min}$ at room temperature, followed by incubation for $15 \mathrm{~min}$ in a boilling water bath. Eluted DNA in the presence of a glycogen carrier was ethanol precipitated and re-amplified by Taq DNA polymerase ( 2 units) in $40 \mu$ of $20 \mathrm{mM}$ Tris- $\mathrm{HCl}$, pH $8.4,50 \mathrm{mM} \mathrm{KCl,} 3 \mathrm{mM} \mathrm{MgCl}_{2}$ containing $2.5 \mu \mathrm{M}$ each of the appropriate anchored primer and specific 10 -mer primer and $20 \mu \mathrm{M}$ of each dNTP. PCR conditions were as described above. Finally, DNAs were cloned into a T/A cloning vector (pGEM-T Easy, Promega) or pBluescript (Stratagene) and at least three clones of each ligation were sequenced using an ABI PRISM(B) 10 Genetic Analyzer (Perkin Elmer Applied Biosystems).

\section{3 | Slot(dot)-blot analysis}

For the screening of the DD DNA products a slot-blot procedure was applied as described by Mou et al. ${ }^{14}$. Of each plasmid DNA $250 \mathrm{ng}$ was denatured for 10 minutes at $100^{\circ} \mathrm{C}$ in $0.4 \mathrm{M} \mathrm{NaOH}$, $10 \mathrm{mM}$ EDTA and transferred onto a pre-cut nylon membrane (Zeta-Probe, Biorad). The DNA in each well was washed with $0.4 \mathrm{M} \mathrm{NaOH}, 10 \mathrm{mM}$ EDTA and immobilised by UV crosslinking. Each membrane was pre-hybridised for 1 hour at $60^{\circ} \mathrm{C}$ in $0.5 \mathrm{M} \mathrm{Na}_{2} \mathrm{HPO}_{4}, \mathrm{pH} 7.2,1 \mathrm{mM}$ EDTA, $7 \%$ SDS. For probes, $10 \mu \mathrm{g}$ of pooled (from 5 goats) total RNA and $2.5 \mu \mathrm{g}$ oligodT primers were incubated at $65^{\circ} \mathrm{C}$ for 10 minutes. Reverse transcription was performed for 1.5 hour at $37^{\circ} \mathrm{C}$ with $600 \mathrm{U}$ M-MLV reverse transcriptase (GibcoBRL) in $50 \mu 150 \mathrm{mM}$ Tris$\mathrm{HCl}, \mathrm{pH} 8.3,75 \mathrm{mM} \mathrm{KCl}, 3 \mathrm{mM} \mathrm{MgCl}, 10 \mathrm{mM}$ DTT, $1 \mathrm{mM}$ of dATP, dGTP and ATTP, in the presence of 40 U RNase inhibitor RNasin (Promega) and $50 \mu \mathrm{Ci}\left\{\alpha-\alpha^{32}\right\}$ dCTP. Following purification over Sephadex G50, probes were denatured for 5 minutes at $95^{\circ} \mathrm{C}$ and added to the pre-hybridisation mix. Following overnight incubation at $60^{\circ} \mathrm{C}$, membranes were washed in phosphate buffer/SDS with increasing stringency and exposed to a phosphorimaging screen (Biorad). For image analysis either Image Quant $B$ (Molecular Dynamics) or Quantity One(B) version 4.2.1. (Biorad) software was used. For analysis of the time series, $500 \mathrm{ng}$ amplified DNA fragments were transferred onto Hybond $\mathrm{N}^{+}$membranes (Amersham) following the same procedure.

The expression level of each clone was normalised to that of at 
least two out of four different controls; a clone from a goat atrium cDNA library encoding part of the GAPDH housekeeping gene and three cloned DD-DNAs selected on the basis of equal gel display in AF and SR.

\subsection{Immunohistochemistry}

Unfixed cryostat sections ( $8 \mu \mathrm{m}$ ) were stained essentially as described before ${ }^{150}$. They were incubated at room temperature in phosphate-buffered saline (PBS) containing $0.2 \%(\mathrm{v} / \mathrm{v})$ Triton $\mathrm{X}-100$ for 1 hour, followed by $30 \mathrm{~min}$ in $2 \%(\mathrm{w} / \mathrm{v})$ Bovine Serum Albumin (BSA) in PBS. Sections were washed with PBS and incubated overnight with primary mouse anti- $\alpha-M H C$ (Alexis Biochemicals, clone F88-12.F8) or mouse anti- $\beta$-MHC (169ID5; gift from Dr. A.F.M. Moorman, AMC) antibodies (1:5 and 1:10 dilution in PBS containing 1.0\% Normal Goat Serum, respectively). Samples were incubated for 2.5 hours with secondary antibodies against mouse $\lg G$, conjugated with Fluorescein Isothiocyanate (FITC; Jackson Laboratories) or Texas Red (TR; Jackson Laboratories). Sections were mounted with Vectashield (Vector Laboratories) and examined using a Nikon Optiphot-2 light microscope equipped for epifluorescence. Within each section, percentages of myocytes that did $(+-$ or +$)$ or did not (-) stain for $\beta-M H C$ were assessed.

\section{$2.5 \mid$ Western blotting}

Tissue samples were homogenised in RIPA solubilisation buffer $(50 \mathrm{mM}$ Tris- $\mathrm{HCl}$ pH 7.4, $150 \mathrm{mM} \mathrm{NaCl}, 1 \%$ Nonidet-P40, $1 \%$ sodium deoxycholate, $0.1 \%$ sodium dodecylsulfate) with protease inhibitors ( $2 \mathrm{mM}$ pheny/methylsulfonyl fluoride, $1 \mathrm{mM}$ iodoacetamide, $1 \mathrm{mM}$ phenantroline, $1 \mathrm{mM}$ benzamidine, 0.5 $\mathrm{mM}$ pefabloc, $5 \mathrm{mM}$ sodium bisulfate, $20 \mu \mathrm{g} / \mathrm{ml}$ pepstatin A). They were treated as described ${ }^{151}$. Heparin anti-coagulated blood control samples were immediately mixed with concentrated Laemmli's sample buffer. Of each sample 40 Hg of total cellular protein was electrophoresed on $8 \%$ SDS-polyacrylamide gels and transferred onto nitrocellulose membranes. Efficiency of transfer was checked by Ponceau Red staining. Membranes were blocked for th at room temperature with $5 \%$ Protifar in $0.1 \%$ Tween 20 in PBS (T-PBS). They were probed for the presence of $\alpha$ and $\beta-\mathrm{MHC}$ in an overnight incubation at $4^{\circ} \mathrm{C}$ using the 
antibodies ( $1: 40$ and $1: 10$, respectively) described in the previous section. After the primary antibody incubation, membranes were incubated for $1 \mathrm{~h}$ at $4^{\circ} \mathrm{C}$ with a horseradish peroxidase labelled secondary antibody (Bio-Rad; 1:7000). Peroxidase activity was detected using ECL detection reagents (Amersham). Film exposure times were 20 seconds for detection of $\alpha-M H C$ and 30 minutes for detection of $\beta-\mathrm{MHC}$ expression. Scans (Microtek ScanMaker 630) were analysed using Image Quant sofware (Molecular Dynamics).

\section{6 | Statistical analysis}

To identify statistically significant changes in expression between AF and SR, a Mann-Whitney rank sum test was used to compare the average normalised values (see methods 2.3 ) of 5 independent slot(dot)-blot analyses. Beta-MHC expression in AF was compared to SR using a paired Student's t-test or whenever the data did not have a normal distribution a MannWhitney rank sum test. Statistical significance was defined as $\mathbb{P}$ $<0.05$.

\section{3 | Results}

3.1 Analysis of differential gene expression between SR and chronic AF

To identify genes involved in AF-induced remodelling of the atrium, we used the DD technique ${ }^{\text {his }}$ to compare atrial mRNA expression patterns from 6 goats in sustained AF (induced as described by Wijffels et al. ${ }^{127}$ ) with those from 6 goats in SR. For PCR amplification primer combinations of one out of 4 degenerate anchored oligo(dT) primers with one out of 26 short arbitrary 10-mers (OP-DDRT1 through OP-DDRT26) ${ }^{152}$ were used. A typical example of expression patterns generated by DD is shown in figure 1 .

About 125 bands of amplified gene products, reproducibly displayed differently in AF as compared to SR, were excised from the gels. DNAs from $34 \mathrm{DD}$ fragments, ranging from 90 $375 \mathrm{bp}$ (average of $227 \mathrm{bp}$ ), were cloned and sequenced. They represented $16(47 \%)$ downregulated and $15(44 \%)$ upregulated genes, while 3 (clone 2.2,3.3, and 4.1) of them did not show any change in expression and were used as controls. Apart from 
Figure 1 |

Differential Gisplay expression patterns.

Typical examples of 0D expression patterns obtained by using two different anchored primers in combination with two 10-mer primers. Gel patterns from 2 goats in $S$ P and 3 goats in sustained AF were compared. The anrowhead indicates a $\mathrm{DD}$ band, representing a gene whose expression is up regulated in $A E$.

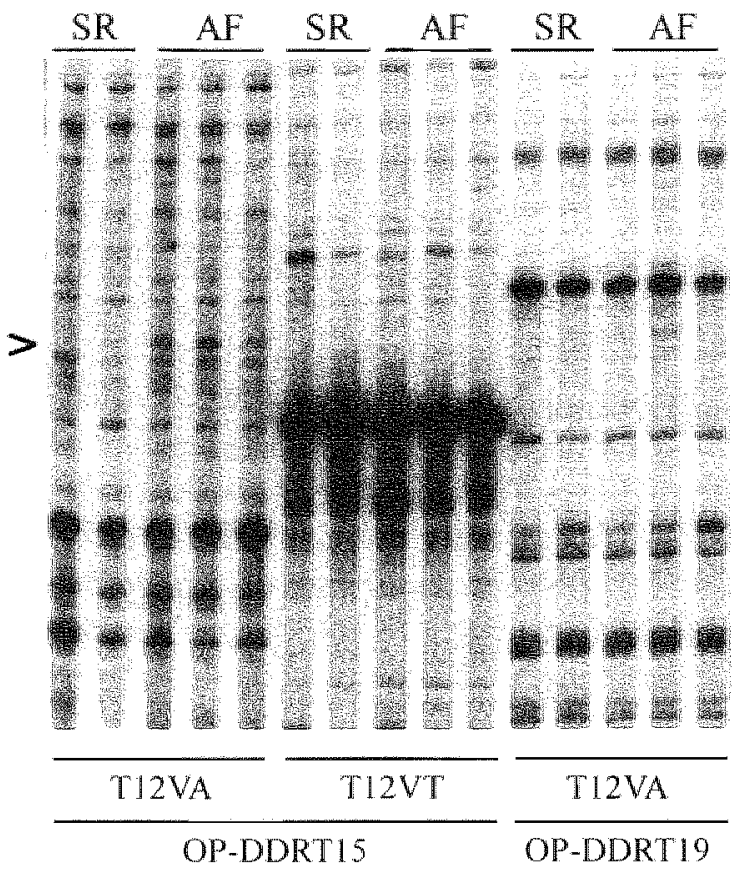

these controls, 21 (62\%) clones could be identified based on sequence homology to database entries of known eukaryotic genes. Most clones could be placed into one of four functional categories; "structure" (7/21), "metabolism" (4/21), "expression" (7/21) and "embryogenesis/(de-)differentiation" (3/21). Genes in the first category mainly encoded proteins involved in cardiomyocyte contractility, like $\alpha$-cardiac actin ( $\alpha$ CA), $\beta$-myosin heavy chain ( $\beta$-MHC), titin, and cardiac troponin I (cTnI). In addition, a sarcolemma associated protein (SLAP2) and a nuclear matrix protein (matrin 3 ) were identified. Genes involved in metabolic pathways included the VLDL receptor (VLDLr) gene, the myoglobin gene and the ubiquitin hydrolyzing enzyme I (UBH1) gene, encoding a deubiquitinating enzyme which prevents ubiquitinated substrates from degradation, like "fat facets" in Drosphilla ${ }^{153}$. In the category "expression", several genes were identified encoding ribosomal proteins, together with a transcriptional repressor (of c-myc) and a translational activator of EIF2 $\alpha$ (EIF2 $\alpha$ kinase). The remaining known genes $(3 / 21)$ encoded proteins ( $\mathrm{H}$ beta 58 , LAK-4p, KIAA1610/ER1) that have been associated with the 
differentiation status of an eukaryotic cell ${ }^{154.155}$. The 10 DD fragments placed in the category "unknown" matched with $E S T$ sequences, which means that they represent either unknown genes or known genes whose 3' non-translated sequences are not in the GenBank database.

\section{2 | Confirmation of altered gene expression}

Since one of the criticisms of the DD technique is the relatively high number of false positives, reported to range from $5 \%$ to $50 \%$, it is essential to confirm differential gene expression by a hybridisation-based assay such as Northern blotting. In order to screen large numbers of DD-products simultaneously without the need for large amounts of RNA, we used a reverse Northernlike procedure, essentially as described by Mou er al. ${ }^{149}$. A total of five independent experiments were performed to determine the ratios of normalised signals between AF and SR. It was assessed whether each ratio was statistically higher or lower than 1, indicating upregulation or downregulation of gene expression (table 1 ).

The 4 controls showed a maximal deviation of $1.0 \%$ in AF as compared to SR, which suggests that their expression level is stable. The DD data for $20(65 \%)$ of the remaining 31 clones could be confirmed by dot-blot analyses and ratios for 15 of these were statistically significant $(\mathrm{P}<0.05)$. The dot-blot data from 10 clones did not corroborate those from the $\mathrm{DD}$ analyses and showed either no change (1) or an opposite change ( 9 ) in expression. Although statistically significant, overall changes in the levels of expression for most genes were not very large; upregulation ranged from $+22 \%$ to $+107 \%$ and downregulation from $-7 \%$ to $-38 \%$.

\subsection{Time course of altered gene expression}

Changes in AF-induced gene expression levels were studied in a time course series by comparing dot-blot data after $1,2,4,8$ and 16 weeks of AF with those in SR. We also investigated a number of genes that were likely to undergo changes in expression during AF, i.e. the genes for $\alpha$-smooth muscle actin ( $\alpha-S M A)$, slow skeletal troponin I (ssTnl), and hypoxiainducible factor $1 \alpha(H I F \mid \alpha)$. The results are listed in table 2 . After 1 week of AF, 5 out of 13 genes investigated showed a 
Table 1.

Differential Display results.

* upregulated

- downuregulated

* unchanged:

$* P<0.05$

\begin{tabular}{|c|c|c|c|c|c|c|c|}
\hline & & & & & 21 known & & \\
\hline $\begin{array}{l}\text { Dol } \\
\text { donc }\end{array}$ & $\begin{array}{l}\text { fongth } \\
\text { (bp) }\end{array}$ & & & $\begin{array}{c}\text { ralio } \\
A F S R\end{array}$ & $\begin{array}{l}\text { mRNA sequence } \\
\text { homology }(\%)\end{array}$ & $\begin{array}{l}\text { Genbank } \\
\text { ace. no. }\end{array}$ & \\
\hline 3 & 180 & 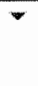 & $\nabla$ & 0.70 & $\begin{array}{l}\text { nouse bardac o aclin } \\
(\text { CA })(94 \%)\end{array}$ & NM 009608 & \\
\hline $3 \mathrm{~A}$ & 273 & 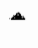 & $\bullet$ & 2.07 & rat macrin $3(90 \%)$ & $\mathrm{N} 63485$ & \\
\hline $4 A$ & 200 & $\rightarrow$ & $-*$ & 0.88 & $\begin{array}{l}\text { raboit sarcolomma } \\
\text { associated protem-2 } \\
\text { (SLAP-2), (93\%) }\end{array}$ & 021156 & $\underline{z}$ \\
\hline 411 & 375 & - & 4 & 0.67 & $\begin{array}{l}\text { pig cardiac } 8 \text { myosin } \\
\text { heary chatio }(\beta M H C) \text {, } \\
\text { (90\%) }\end{array}$ & $\times 91846$ & E \\
\hline 1 & 200 & $\checkmark$ & $* *$ & 0.91 & $\begin{array}{l}\text { bovine beta-aclin } \\
\text { pseudogene }(90 \%)\end{array}$ & 002295 & \\
\hline 13 & 90 & 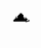 & 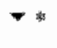 & 0.80 & human titin $(90 \%)$ & NM_003319 & \\
\hline 25 & 125 & 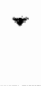 & $* *$ & 0.70 & $\begin{array}{l}\text { rat cardactroponin } \\
\text { (ctnl), }(95 \%)\end{array}$ & $N M 017144$ & \\
\hline 111 & 282 & $*$ & 4 & 1.31 & 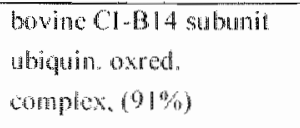 & $\times 63211$ & \\
\hline 4 & 130 & - & $\checkmark *$ & 0.62 & 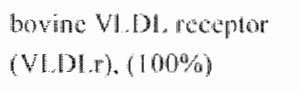 & A 1016537 & $\frac{5}{5}$ \\
\hline 64 & 325 & - & ४ & 0.98 & $\begin{array}{l}\text { hovine ribyoglobig? } \\
\text { mRNA, }(97 \%)\end{array}$ & 000409 & $\underset{b}{6}$ \\
\hline 711 & 150 & $\nabla$ & $\nabla *$ & 0.93 & 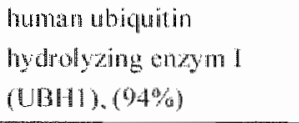 & AF022789 & \\
\hline $1 /$ & 326 & 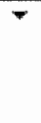 & $7 *$ & 0.87 & 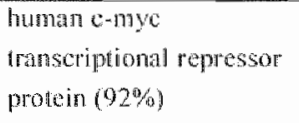 & D89667 & \\
\hline $3 H$ & 195 & $\checkmark$ & $\checkmark$ & 0.92 & $\begin{array}{l}\text { buman ribosomal } \\
\text { protein } 131 \text { (90\%) }\end{array}$ & $\times 15940$ & \\
\hline $5 n 1$ & 161 & - & $\checkmark *$ & 0.75 & $\begin{array}{l}\text { human ribosomal } \\
\text { protein } 1.17(92 \%)\end{array}$ & $\times 52839$ & 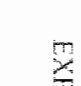 \\
\hline 16 & 250 & $*$ & \% & 0.73 & $\begin{array}{l}\text { human } 175 \mathrm{rRN} \\
(90 \%)\end{array}$ & M13932 & $\begin{array}{l}\bar{z} \\
n \\
n\end{array}$ \\
\hline $16 A$ & 224 & 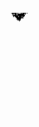 & $\checkmark$ 幽 & 0.78 & 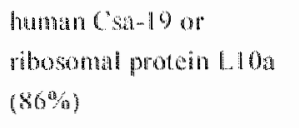 & l. 12404 & 8 \\
\hline 17 & 270 & at & $*$ & 0.70 & 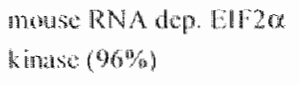 & M93663 & \\
\hline 22 & 300 & - & $-*$ & 0.72 & $\begin{array}{l}\text { Inman } 28 \mathrm{SRNA} \\
(1000 \%)\end{array}$ & $M \| 1167$ & \\
\hline $5 \mathrm{~A}$ & 285 & $m$ & - & 1.44 & $\begin{array}{l}\text { human } \mathrm{H} \text { beta } 58 \\
\text { homolog }\end{array}$ & Al0 054179 & \\
\hline $7 \mathrm{~A}$ & 347 & 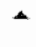 & $-*$ & 2.05 & human $L A K-4 p(84 \%)$ & $\mathrm{ABO} 002805$ & $2 \pm$ \\
\hline $11 \mathrm{~A}$ & 220 & 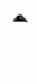 & - & 2.00 & $\begin{array}{l}\text { human KIAA } 6104 \\
(95 \%) \text { Trog CRH. }(85 \%)\end{array}$ & $\begin{array}{l}\text { XM } 0406221 \\
\text { AP015454 }\end{array}$ & 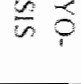 \\
\hline
\end{tabular}




\begin{tabular}{|c|c|c|c|c|c|c|c|}
\hline \multicolumn{8}{|c|}{10 wh monn } \\
\hline 2 & 180 & - & 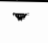 & 0.89 & whknowin & - & \\
\hline 7 & 320 & - & $*$ & 1.00 & unknown & - & \\
\hline 8 & 300 & $\checkmark$ & $\neq *$ & 0.79 & unknown & " & \\
\hline $8 A$ & 215 & 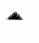 & - & 1.22 & Wnknown & - & \\
\hline $10 \mathrm{~A}$ & 256 & $*$ & $\sim$ & 1.78 & Lntiknown & - & $z$ \\
\hline 124 & 175 & - & $*$ & 0.58 & unk nowit & - & \\
\hline $13 \mathrm{~A}$ & 125 & - & - * & 1.81 & unk nowm & - & 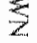 \\
\hline 14 & 150 & 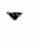 & $\omega *$ & 0.89 & whknown & - & \\
\hline $15 \mathrm{~A}$ & 234 & - & - ** & 2.05 & mknown & - & \\
\hline 18 & 180 & 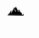 & 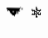 & 0.69 & ankmown & n & \\
\hline \multicolumn{8}{|c|}{4 controls } \\
\hline $\bar{G}$ & 275 & 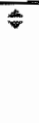 & $\approx$ & 0.91 & 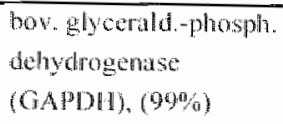 & 185042 & \\
\hline 2.2 & 224 & $\neq$ & $*$ & 1.02 & $\begin{array}{l}\text { gagt mitochundrial } \\
\text { genonne }(90 \% \text { ) }\end{array}$ & $\times 72965$ & \\
\hline 3.3 & 198 & 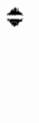 & $\Delta$ & 0.97 & $\begin{array}{l}\text { lowman regutaton of } 0 \text { - } \\
\text { protein signalling } 4 \\
(90 \%)\end{array}$ & NMOOSGG 13 & \\
\hline 4.1 & 211 & $\div$ & $\Leftrightarrow$ & 1.10 & $\begin{array}{l}\text { nowse mapk/ert tin. } \\
\text { kinase } 2(95 \%)\end{array}$ & Al.472964 & \\
\hline
\end{tabular}

similar change in expression as observed during sustained AF (average 12.7 weeks). At 4 weeks, this number had increased to 8 out of 13 and at 16 weeks, the expression level of most of the clones (12 out of 13 ) was similar or comparable to that measured before. Several genes were downregulated throughout the time course (titin, UBH1, $\alpha$-SMA, EIF $\alpha 2$ kinase), whereas others changed progressively $(\beta-\mathrm{MHC}, \mathrm{cTnl}$, ssTnl, VLDLr) or displayed transient alterations (HIF $1 \alpha, \alpha-C A$ ). In addition, genes that had not changed their overall expression in sustained AF as compared to SR did show changes during the time course. For example, the gene represented by DD-DNA 7 appeared to follow an expression pattern (0-8 weeks) similar to HIF 10 , while the gene represented by DD-DNA 2 showed a transient decreased expression early ( 1 week) in AF.

\subsection{Changes in myosin heavy chain isoform expression}

Since the results from the DD and dot-blot analyses with respect to the $\beta$-MHC mRNA expression were rather contradictory, we investigated the protein expression of $\alpha-M H C$ and $\beta-M H C$ by 
Table 2

Time course analysis of changes in expression during atrial fibrillation.

- upmegulated; - down-requlated: * unchanged; $N A=$ not applicable; a-CA alpha cardiac actirit: $B-M H C=$ beta myosin heawy chiatiti; cTnI = cardiac Lroponin I: sthI = stow sheletal Troponin 1 a $5 M A=$ alpha-smooth muscle actio:

VLDLr = very low density lipoprotein receptor; UBH = ubiquitin hydrolyzing enzyme 1 : HIF10 mypoxia inducible factor 1 alpha: ${ }^{*} p<0.05$

\begin{tabular}{|c|c|c|c|c|c|c|c|}
\hline \multicolumn{8}{|c|}{ Known } \\
\hline onclone & homologue & $\int w k$ & $2 w k$ & $4 \mathrm{wks}$ & $8 w k s$ & $164 k 5$ & profile \\
\hline$\underline{\gamma}$ & $O M A$ & $\begin{array}{r}-1 \\
+390 \%\end{array}$ & $\begin{array}{c}-30^{6 \%} \\
-36\end{array}$ & $\begin{array}{c}- \\
-25 \%\end{array}$ & $\begin{array}{c}- \\
+18 \%\end{array}$ & $\begin{array}{c}- \\
29 \%\end{array}$ & \\
\hline 34 & matrim & 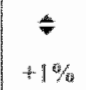 & $\begin{array}{c}* \\
+2 \%\end{array}$ & $\begin{array}{c}-17 \% \\
-\end{array}$ & 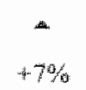 & $\begin{array}{l}- \\
+8 \%\end{array}$ & \\
\hline $4 H$ & B-MHC & $\begin{array}{c}* \\
-14 \%\end{array}$ & $\begin{array}{c}* \\
-4 \%\end{array}$ & $\begin{array}{c}-15 \% \\
-8\end{array}$ & $\begin{array}{c}* \\
-6 \%\end{array}$ & $\begin{array}{c}-31 \% \\
-3 \%\end{array}$ & \\
\hline 13 & riting & $\begin{array}{c}* * \\
-25 \% / 6\end{array}$ & $\begin{array}{c}-18 \% \\
-18 \%\end{array}$ & $\begin{array}{l}w \\
-27 \%\end{array}$ & $\begin{array}{c}-32 \% \\
-32 \%\end{array}$ & $\begin{array}{c}-\% \\
-20 \%\end{array}$ & \\
\hline 25 & and & $\begin{array}{c}-22 \% \\
-2 \%\end{array}$ & $\begin{array}{c}\bullet \\
+1 \%\end{array}$ & $\begin{array}{c}* \\
-27 \%\end{array}$ & $\begin{array}{c}-12 \% \\
-12 \%\end{array}$ & $\begin{array}{c}* * \\
-30 \%\end{array}$ & \\
\hline Wh & sethl & $\begin{array}{l}= \\
4 \%\end{array}$ & $\begin{array}{c}* * \\
-19 \% / 4\end{array}$ & $\begin{array}{c}-3 \% \\
-36 \%\end{array}$ & $\begin{array}{c}- \\
.12 \%\end{array}$ & $\begin{array}{c}-\% \\
-30 \%\end{array}$ & \\
\hline$N A$ & a $\$ M M$ & $\begin{array}{c}- \\
9 \%\end{array}$ & $\begin{array}{c}-9 \% \\
-9 \%\end{array}$ & $\begin{array}{c}-* \\
-23 \%\end{array}$ & $\begin{array}{c}- \\
-14 \%\end{array}$ & $\begin{array}{l}-15 \% \\
-15 \%\end{array}$ & \\
\hline 4 & WLDIne & $\begin{array}{c}* \\
-2 \%\end{array}$ & $\begin{array}{c}* \\
-40\end{array}$ & $\begin{array}{c}. \\
-22 \%\end{array}$ & $\begin{array}{c}= \\
-3 \%\end{array}$ & $\begin{array}{c}-38 \% \\
-38 \%\end{array}$ & \\
\hline $6 \mathrm{HI}$ & myoglobina & $\begin{array}{c}- \\
-24^{\prime} / 6\end{array}$ & $\begin{array}{c}-29^{\mathrm{k} / 13} \\
\end{array}$ & $\begin{array}{c} \\
+28 \%\end{array}$ & $-5 \%$ & $\begin{array}{c}\cdot \\
23 \%\end{array}$ & $v^{2}=$ \\
\hline 711 & UBSH & $\begin{array}{c}\sigma \\
-28 \%\end{array}$ & $\begin{array}{c}- \\
-19 \%\end{array}$ & $\begin{array}{c} \\
-22 \%\end{array}$ & $\begin{array}{c}- \\
-16 \%\end{array}$ & $\begin{array}{c}- \\
-28 \%\end{array}$ & 물 \\
\hline 17 & Elfor kinase & $\begin{array}{c}* \\
-34 \% / 6\end{array}$ & $\begin{array}{c}-34 \\
-34 \%\end{array}$ & $\begin{array}{c}* \\
-37 \%\end{array}$ & $\begin{array}{c}* \\
-34 \%\end{array}$ & $\begin{array}{l}-30 \% \\
-30 \%\end{array}$ & 田 \\
\hline NA & HIF $1 \alpha$ & $\begin{array}{r}-* \\
+58 \%\end{array}$ & $\begin{array}{c}* \\
-4 \%\end{array}$ & $\begin{array}{c}* \\
-18 \%\end{array}$ & $\begin{array}{c}- \\
+6 \%\end{array}$ & $\begin{array}{c} \\
-36 \%\end{array}$ & \\
\hline & & & unkno & Wn & & & \\
\hline 2 & und & $\begin{array}{l}* \% \\
24 \% / \%\end{array}$ & $\begin{array}{c}7 \\
+6 \%\end{array}$ & $\begin{array}{c}. \\
-11 \%\end{array}$ & $\begin{array}{c}-6 \\
+6 \%\end{array}$ & $\begin{array}{c}* \\
-11 \%\end{array}$ & \\
\hline 7 & 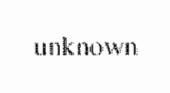 & $\begin{array}{r}-5 \\
+220\end{array}$ & $\begin{array}{c}* \\
+4 \%\end{array}$ & $\begin{array}{c}-23 \% \\
-23 \%\end{array}$ & $\begin{array}{c}* \\
-22 \%\end{array}$ & $\begin{array}{c}\bullet \\
+1 \%\end{array}$ & (1) \\
\hline 8 & unk nown & $\begin{array}{c}= \\
+4 \% 8\end{array}$ & $\begin{array}{c}* \\
0 \%\end{array}$ & $\begin{array}{c}* \\
+3 \%\end{array}$ & -8 & $\begin{array}{c}-21 \% \\
-21 \%\end{array}$ & -- \\
\hline 18 & nonknown & $\begin{array}{c}* \% \\
-19 \%\end{array}$ & $\begin{array}{c}-\| \% \\
-\| \%\end{array}$ & $\begin{array}{c}* \\
-24 \%\end{array}$ & $\begin{array}{c}* \\
+2 \%\end{array}$ & $\begin{array}{c}-31 \% \\
-310\end{array}$ & 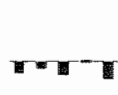 \\
\hline
\end{tabular}


immunohistochemistry and Western blotting.

Fig.2A shows immunolabelling patterns of representative sections of the atrial appendage from a goat in SR incubated with antibodies against $\alpha$-MHC or $\beta-$ MHC. Most cardiomyocytes ( $>90 \%$ ) stained positive for $\alpha-\mathrm{MHC}$ while only a sub-population (21.8 $2.1 \%$ (SEM)) expressed the $\beta$-isoform of $\mathrm{MHC}(+$ and +$)$. Within this sub-population a small fraction of cardiomyocytes $(3.2 \pm 0.7 \%$ ) expressed $B-M H C$ at high levels $(+)$. During sustained AF the percentage of cardiomyocytes expressing $\alpha-\mathrm{MHC}$ seemed unaffected, while the percentage of those expressing $\beta$-MHC ( + and ++ ) had clearly increased $(47.9 \pm 2.5 \%$ (SEM)). The percentage of cardiomyocytes expressing $\beta$-MHC at high levels $(+)$ had increased even more $(18.0 \pm 2.5 \%$ (SEM)). The observed AF-induced increase in the relative numbers of $\beta-\mathrm{MHC}$ expressing cells is in support of the DD-data. The relative levels of expressed $\alpha$ - and $\beta-\mathrm{MHC}$ protein were assessed by Western blot analysis (fig. 2B). Contrary to what has been shown for chicken atrium ${ }^{157}$, both antibodies reacted with several bands in the goat atrium extracts. We focused on bands with the same electrophoretic mobility as the $200 \mathrm{kD}$ marker, representing rabbit skeletal muscle myosin. Competitor studies could not be performed since specific peptides were not available. Consequently, we used adult mouse heart and goat blood extracts for controls. Cross-reactivity of the $\alpha$-(human)MHC antibody to mouse cardiac myosin in a Westem blot was stated by the supplier. Indeed a prominent $200 \mathrm{kD}$ band showed up, as can be seen in the positive $(+)$ control lane. There was no reaction with the goat blood sample (negative ( - control). The $\beta-$ MHC antibody was (almost) negative with the mouse cardiac extract, which is in accordance with the negligible expression of $\beta-\mathrm{MHC}$ in adult mouse heart ${ }^{15 \%}$. There was no specific reaction with goat blood. However, a nonspecific band with a higher molecular weight became visible, possibly as a result of the almost 100 times longer exposure time needed for ECL detection of $\beta-\mathrm{MHC}(30 \mathrm{~min})$ as compared to $\alpha-\mathrm{MHC}(20 \mathrm{sec})$. Fig. $2 \mathrm{~B}$ shows the goat atrial myosin expression in two representative experiments. The quantitative analysis of the data from 4 experiments revealed a significantly lower expression of $\alpha-\mathrm{MHC}$ in $\mathrm{AF}$ as compared to $\mathrm{SR}$ and a tendency of upregulated $\beta$-MHC expression (not statistically significant). 


\section{Figure 2}

Protein expression of $a-$ and $\beta$ MHC in goat athal myocytes.

A). Imnunolabelling of successive transversely cut

thin sections of atrial appendage prom a goat in AF wh antibodies against

or of $\beta$ - monc. Matching phase contrast images are given underneath each panel. Longitudinally sectioned rivocytes were double stained with arribodies against $B-M H C$ and desmin. Barsolopm. The histoguam shows the data of an

imenuotistochemical evaluation of thin sections from 6 goats in $S R$ and 6 goats in sustained AF. Frequencies are given of atrial myocytes that did not stain $(-)$, stanned positive (H) for $B-M H C$ or expressed it at very high levels $(+-)$. 78 B). Western blot analysis of the $\alpha$ and $\beta-M+H C$ protein levels in $S R$ and sustained

AF (16 weeks) from two representative experiments.

Positions of the $200 \mathrm{kD}$ rabbit skeletal muscle myosin marker are indicated. For contuls, adut mouse candiac (t) and goat blood (-) extracts were used. Band internstites were measured and average data from 4 experiments are given in the ba: plot.
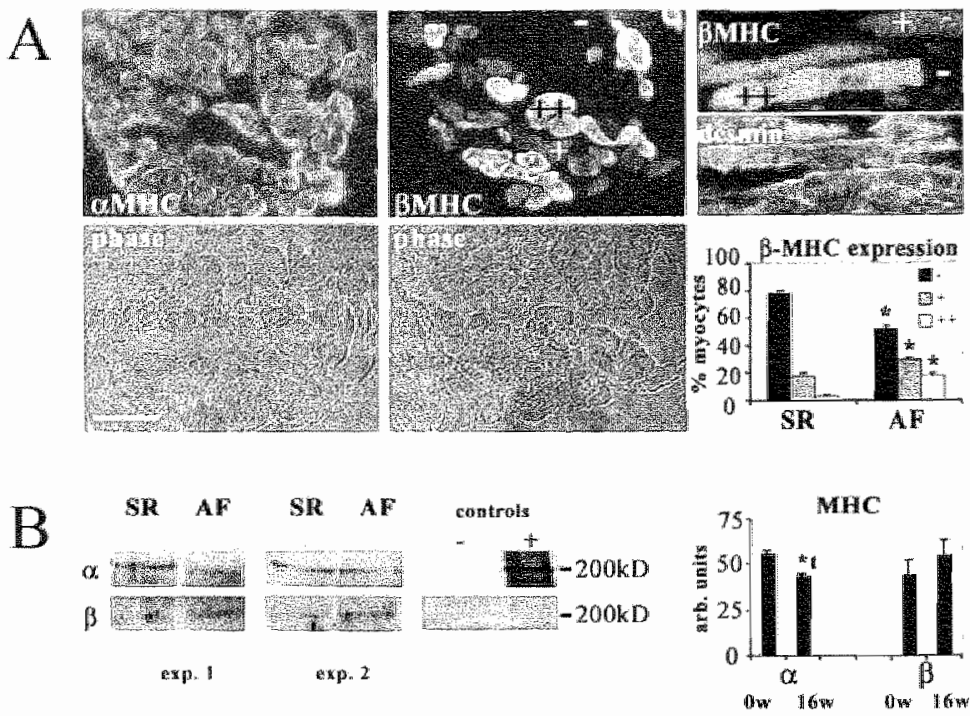

\section{4| Discussion}

AF is accompanied by electrical ${ }^{127,159}$, gap junctional $1^{128,138}$ and structural remodelling ${ }^{32.89}$ of the atria. In this study we have used the goat model of AF to obtain more insight into the underlying molecular processes. To identify genes involved in atrial remodelling, we have compared their expression profiles in SR with those during AF by means of the differential display (DD) technique. DD was used because at present no goat-specific micro-arrays are available. In addition, DD allows the direct identification of both upregulated and downregulated genes between multiple samples within one experiment ${ }^{\text {ts }}$. We have isolated a number of genes that were either upregulated or downregulated during sustained (chronic) AF. For approximately $60 \%$ of these genes differential expression could be confirmed by dot-blot analysis. Less than 10\% of the DD-signals turned out to be false positive, which is within the margins reported for the technique. In those situations, in which the dot-blot data did not corroborate the DD results, heterogeneity between tissue samples is the likely cause. Since relatively large tissue samples from 5 goats had to be pooled for the preparation of probes, relative numbers of remodelled cardiomyocytes in these mixed samples might be significantly different from those in the much smaller individual goat samples used for DD analysis. This might account for relatively mild overall changes in gene expression. 
However, locally these (focal) changes might be very pronounced and promote arrhythmogenic activity that could affect the atrial tissue as a whole.

Characteristic of AF-induced structural remodelling of cardiomyocytes is that several structural proteins adopt a foetallike expression ${ }^{3}$. The expression of several genes that were detected in our DD analyses and placed in the category "structure" appears to be in line with this phenomenon. The observed downregulation of the mRNA expression of titin is in agreement with observations at the protein level ${ }^{33}$. Downregulation of $\mathrm{cTnI}$ and $\alpha$-CA mRNA also correlates with the observed reduction in sarcomeres. It has been suggested that the 3 ' non-translated regions of both genes are involved in inhibition of proliferation and promotion of differentiation ${ }^{600}$, which suggests that downregulation of their expression might favour cellular de-differentiation. Yet, re-expression of the embryonically expressed ss $\mathrm{TnL}$ and $\alpha-\mathrm{SMA}^{94,100.161 .162}$ could not be detected. The absence of an increase in $\alpha$-SMA mRNA is in contrast with the observed increase in $\alpha$-SMA protein in the cardiomyocytes during $\mathrm{AF}^{33}$. However, since cTnI and $\alpha-C A$ are abundantly expressed and highly homologous to their embryonically expressed counterparts, the inconsistency is likely due to cross-reactivity of their mRNAs with the ssTnI and $\alpha$ SMA DNA on the filter, which would obscure any AF-induced effect in mRNA expression of the latter two. In addition, it has been reported that the expression of $\alpha-S M A$ is predominantly regulated at a post-transcriptional level ${ }^{163}$.

Cross-reactivity of $\alpha-M H C$ mRNA with $\beta$-MHC DNA (homology in humans $95 \%{ }^{164}$ ) on the filters is possibly also responsible for the observed inconsistency between DD and dotblot data. The relative proportions of the 2 isoforms of myosin heavy chain in mammalian heart are affected by a wide variety of pathological and physiological stimuli ${ }^{165}$. Cardiomyocytes that predominantly express the faster (higher ATPase activity) $\alpha-\mathrm{MHC}$ can generate more force than those expressing the slower $\beta$-isoform ${ }^{160}$. Human ventricular myocardium contains $93 \% \beta-\mathrm{MHC}$ and $7 \% \alpha-\mathrm{MHC}$, whereas $\alpha-\mathrm{MHC}$ mRNA makes up $30 \%$ of total MHC mRNA ${ }^{167}$. During heart failure $\alpha-\mathrm{MHC}$ decreases to a level 15-fold less for mRNA, while protein could hardly be detected anymore. Adult bovine atrium consists of $80-90 \% \alpha-\mathrm{MHC}$ and $10-20 \% \beta-\mathrm{MHC}^{16 \%}$. Also in adult human left atria $\alpha$-MHC comprises about $90 \%$ of total MHC, whereas 
this relative amount dropped to around $50 \%$ in individuals with dilated or ischaemic cardiomyopathy ${ }^{16 \%}$. Concomitant changes at the mRNA level are not known. An increase in the relative amount of $\beta-\mathrm{MHC}$ of the left atrium during the development of heart failure has been suggested to be beneficial by increasing the economy of contraction ${ }^{170}$. Consequently, an AF-induced increase in $\mathrm{B}-\mathrm{MHC}$ expression in combination with a reduction in $\alpha-\mathrm{MHC}$ expression would be in support of an observed reduction in atrial contractility. Since a downregulation of $\mathrm{MHC}$ expression could already be detected early (1 week) in the time course, it might be partly responsible for the developing atrial dysfunction.

Apart from structural remodelling, AF is accompanied by electrical and gap junctional remodelling and many authors including ourselves have described changes in the expression or distribution of channel proteins that might underlie these processes ${ }^{131.332 .135 .142}$. In the present study no changes in the levels of mRNAs that encode ion or gap junction channel proteins were identified. This might be due to the fact that these mRNAs are relatively low abundant or that their 3 ' non-translated sequences are not in the database.

We did find changes in expression of several genes involved in cellular metabolic pathways. Altered expression of proteins like myoglobin and the VLDLr are indicative of changes in energy utilisation. Downregulation of the VLDLr has been shown to occur in hypertrophied rat hearts ${ }^{131}$. A shift in the metabolic balance as a result of AF had already been suggested by Ausma et al. ${ }^{130}$. They concluded that a temporary metabolic imbalance was not the result of ischaemic injury ${ }^{1.30}$. However, the transient increase in the expression of HIF $1 \alpha$ as was observed in the present study, indicates that a certain amount of ischaemic stress during the onset of AF cannot be ruled out. It has been reported that HIF $1 \alpha$ upregulates the glucose transporter 1 and several glycolytic enzymes ${ }^{172.173 .}$. This, in combination with the observed downregulation of the VLDLr, is indicative of a switch from fatty acid metabolism to glucose metabolism, subsequently leading to increased glycogen storage, either due to excessive influx of glucose or to a decreasing energy demand as a result of impaired contractile activity.

Apart from known genes, we isolated a number of DD fragments without homology to any of the genes that are currently present in the GenBank database. Some of these might represent genes 
whose products play an important role in early response mechanisms, for they show an expression pattern similar to that of HIFI $\alpha$ (clones 2 and 7 , downregulated and upregulated in the first week of $A F$, respectively). We are currently trying to isolate and characterise full-length cDNAs of these unknown mRNA species.

In conclusion, we have used DD in our search for changes in gene expression due to AF in the goat. That this approach is feasible was proven by the identification of genes whose protein products are known to be involved in AF-induced structural remodelling. In addition, we found genes that might play an important role in this process, genes potentially involved in "AF induced de-differentiation", as well as genes whose expression is in favour of a short period of ischaemic stress during the onset of $\mathrm{AF}$.

\section{Acknowledgements}

The authors like to thank Dr. A.F.M. Moorman (Academic Medical Centre, Amsterdam) for providing them with the monoclonal antibody (169-ID5) against $\beta-\mathrm{MHC}$, and $\mathrm{M}$. van Zijverden and A.J.C.G.M. Hellemons for their technical assistance. Part of this study was supported by grants from the Dutch Heart Foundation (NHS M93.002 to H.M.W.v.d.V.; NHS 96.155 to J.A.) and the Dutch organisation for Scientific Research (NWO 900-516-318; M.A.A.). 



\section{Chapter 6 Discussion |}

adapted from

STRUCTURAL REMODELLING DURING

CHRONIC ATRIAL FIBRILLATION

'ACT OF PROGRAMMED CELL SURVIVAL'

V. Thijssen, J. Ausma, M. Borgers

Cardiovasc Res 2001; 52: 14-20

1 Background

2 Structural remodelling during Af

31 Molecular remodelling during Af

3.1 Chamel proteins

3.2 Gap junctional proteins

3.31 Metabolic proteins

3.4 Contractile and structural proteins

4. Mechanisms of remodelling.

4.1. Calcium aveload

4.2) Caraiac adaptation

5 Future perspectives

5.1 Molecular remodelling awring $A F$

5.2 Molecular remodelling during cardiac disease

5.31 Reversibility of molecular remadelling

61 Conclustions 


\section{1 | Background}

Atrial fibrillation (AF) is the most common arrhythmia observed in the western civilisation, with an overall prevalence of almost $\|$ percent. Based on 4 major population studies, Feinberg et al. calculated that the prevalence of $\mathrm{AF}$ ascends with increasing age, ranging from less than 1 percent in young adults to 2.3 percent in people over 40 years and over 5 percent in those older than 65 years ${ }^{2}$. In addition, the prevalence of AF is strongly influenced by the presence of underlying diseases like hypertension, valve disease, myocardial infarction, and ischaemic heart disease ${ }^{4.174}$. The growing prevalence together with the increased risk of stroke ${ }^{5}$ and mortality ${ }^{7}$ will increase the burden on the medical health care at the beginning of this new century. The development of safe and more effective medical treatments requires a better understanding of the pathophysiological aspects underlying AF.

\section{2 | Structural remodelling during AF}

In animal models it has been shown that AF changes the electrophysiological properties of the atrium which facilitates the maintenance of $\mathrm{AF}^{127}$. During the first days of pacing-induced $\mathrm{AF}$, the atrial effective refractory period is markedly shortened

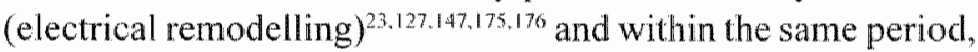
the atrial contractility measured during slow rate pacing, is completely abolished ${ }^{143}$. After short periods of AF, both phenomena are completely reversible and normal values are reached within 2-3 days ${ }^{127,143}$. After longer periods of AF (weeks to months), the atrial effective refractory period still normalises within a few days ${ }^{127.144 .177}$ and atrial conduction recovers within a few weeks $s^{145.146 .178}$. However, recovery from contractile dysfunction may take several weeks to months ${ }^{25-27,147}$. Thus, besides an early time window of atrial remodelling, which involves rapid and reversible electrical and contractile remodelling, a second time window exists during AF. This second time window is characterised by a considerably slower functional recovery following cardioversion. This discrepancy suggests the involvement of a second factor that plays a role in stabilisation of $\mathrm{AF}^{174}$. Recent studies support the existence of a slower second factor that is involved in the increasing stability of $\mathrm{AF}^{1800181}$. 
In chapter 2 the structural changes in patients with cardiac valve disease and AF are described. Light microscopy revealed that besides some degree of cardiomyocyte degeneration, the cellular changes in these patients mainly consisted of cardiomyocyte hypertrophy, depletion of sarcomeres and accumulation of glycogen. Remarkably, the localisation of glycogen differed between two groups of patients and was either found throughout the cytoplasm or confined to large vacuoles ${ }^{88}$. The difference in localisation as well as the presence of vacuoles appeared to be the result of the different underlying diseases ${ }^{88}$. Atrial vacuolisation has also been observed in patients undergoing coronary artery bypass grafting. Ninety percent of the patients which displayed large perinuclear vacuoles in most of the atrial cells, developed postoperative AF whereas AF occurred in only five percent of the patients with no or mild vacuolisation ${ }^{87}$. Many studies in which atrial structural remodelling is related to AF report similar observations. Both in patients and in animal models with AF, common characteristics are atrial dilatation, cardiomyocyte volume increase, myolysis, accumulation of glycogen and increased extracellular space en $^{29,31,32,77,88,29}$.

In addition to the light microscopic observations, Chapter 2 describes the structural changes revealed by electron microscopy. Several alterations of a non-degenerative nature were observed in atrial samples of patients suffering from cardiac valve disease, with or without AF. Characteristic observations were: i) The presence of a large number of small, abnormally shaped mitochondria, embedded in a matrix of glycogen granules. ii) The depletion of smooth sarcoplasmic reticulum. iii) The frequent occurrence of strands of rough endoplasmic reticulum. iv) Nuclei with dispersed heterochromatin. With respect to degenerative changes, cytosolic blebs filled with membranebound vesicles and amorphous bodies of unknown but most probably autophagic origin were observed, and in some samples, features were visible that might indicate the presence of apoptosis. The latter cells were, in contrast to the above mentioned myolytic cells, not hypertrophied and showed no loss of sarcomeres. In fact, a distinction could be made between adaptive and maladaptive (degeneration) changes ${ }^{\mathrm{sg}}$.

These observations with light and electron microscopy indicate that in patients, part of the cardiomyocytes dedifferentiate to a survival state in order to endure the altered environmental conditions during AF. In experimental models of AF, 
cardiomyocytes mainly adapt to a survival phenotype 3.36 .130 whereas in patients with AF both cellular degeneration and cellular adaptation occur $29,31,34,147,175$. This difference might be due to species variance but is probably related to differences in duration of AF and underlying cardiac pathology.

\section{$3 \mid$ Molecular remodelling during AF}

The histological studies show that cardiomyocytes undergo marked adaptive remodelling during AF. The altered morphology as well as the diminished functionality are a reflection of transitions that take place at the molecular level. The cardiomyocytes have to cope with abnormal conditions and consequently they change the expression and organisation pattern of proteins involved in atrial activation, conduction, and contraction. Over the last 5 years, the interest in the role of molecular remodelling in electrical and structural remodelling during AF increased, which resulted in a growing number of publications (Figure 1A). However, most studies have focussed on finding a molecular correlate for the observed electrical, structural, and contractile alterations during AF, i.e. expression of channel, gap junctional, and structural proteins (Figure 1B).

\section{Figure 1 |}

Publications on molecular remodelling during AF over the last 5 years.

A) The number of publications on molecular remodelling during $A F$ in the last 5 years (1997. 2001). Ir the first eight months of 2002, 11 papers. on molecular renodelling were published and a estimate of the final score for 2002 is represented by the grey bar.

a) The distribution of the publications over five main topics:" metabolism. structure, calcum homenctasis, gap junctions. and channel proteins.
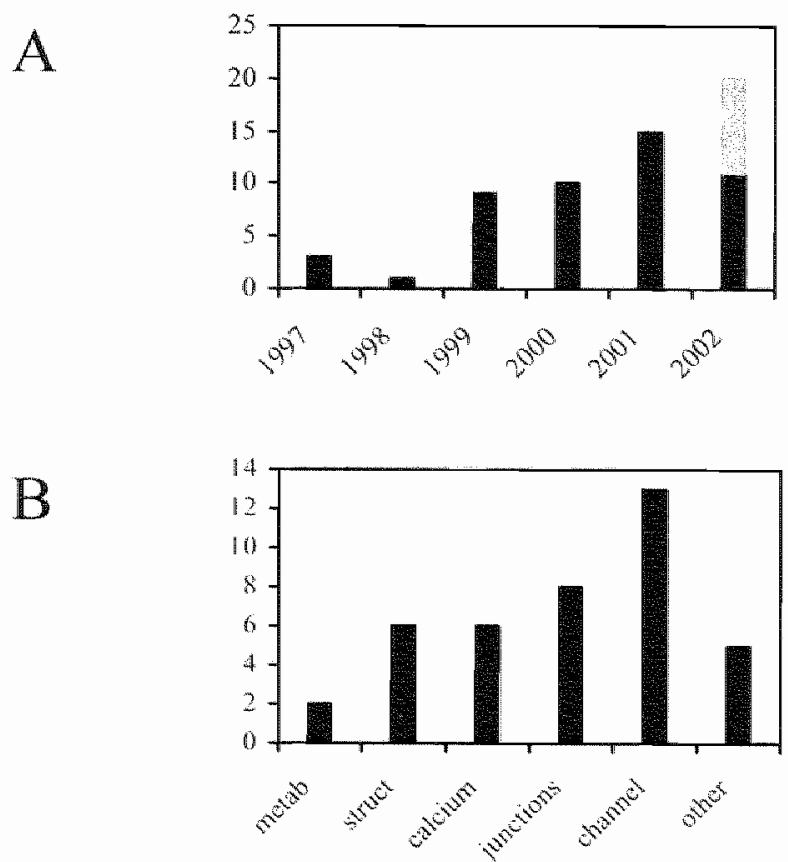
In the following paragraphs the contribution of this thesis to the current knowledge on molecular remodelling during $\mathrm{AF}$ will be discussed.

\section{1 | Channel proteins}

The most apparent outcome of molecular adaptations is probably the electrical remodelling because it occurs immediately at the onset of AF. Ions like calcium, sodium, and potassium are important players in the excitation/contraction cycle, and the expression patterns of their channels and other proteins involved in ion homeostasis have been extensively studied. Several authors have found altered mRNA and/or protein levels of ion channels during $A F^{65.133-13 \%}$. Downregulation has been described for the L-type calcium channel $1^{15,133,134,182}$, the sarcoplasmic reticulum calcium ATPase ${ }^{15,1,3,1,34}$, and several potassium channel subunits ${ }^{65,115,13,3,135-137,183}$. The decreased level of L-type calcium channel expression was correlated with the shortening of the atrial effective refractory period ${ }^{135}$. Previously, it had been shown in patients and animals with AF that the reduced density of potassium currents, were influenced by alterations at the expression level of potassium channel subunits $\mathrm{s}^{2.65 .66 .631 .18 .3}$.

These data show that the cardionyocytes regulate channel expression, alter channel properties, and co-ordinate channel interactions, which all contribute to the electrical remodelling during AF. Surprisingly, a survey of the overall changes in gene expression during AF in goats (Chapter 5) did not identify any genes representing channel proteins. This is in contrast with the observation that AF in the goat decreased the expression of calcium and potassium channel subunits ${ }^{132}$. This discrepancy can be explained by the fact that only 34 out of the 125 DNA fragments that were identified as being differentially expressed were characterised. Probably, several genes encoding channel proteins are present among the remaining 91 DNA fragments. In addition, the technique used to detect the changes in gene expression (differential display) is prone to pick up the $3^{\prime}$ untranslated regions of mRNAs. Apart form the high variability amongst these regions between different species, the non-coding sequences are not always submitted to the databanks. This could hamper the proper identification of the clones and some of the unknown sequences that were picked up might actually represent channel proteins. 


\subsection{Gap junctional proteins}

Similar to the channel proteins, the analysis of altered gene expression did not pick up any changes in expression of gap junctional proteins (connexins) during AF. Changes in connexin distribution and expression have been described in literature. Persistent AF was shown to affect connexin 40 distribution in the goat model on $\mathrm{AF}^{228}$. A time course experiment in this model revealed that from two weeks onward, the heterogeneity in connexin40 distribution increased leading to a reduction in the levels of connexin 40 . The localisation of connexin 43 remained unaltered but the changes in connexin 40 distribution correlated with $\mathrm{AF}$ stability ${ }^{142}$. In contrast, rapid atrial pacing-induced AF in dogs resulted in increased expression of connexin $43^{184}$. Unfortunately, in the latter study the connexin 40 levels were not addressed. Patients with persistent AF also displayed a heterogeneous distribution of connexin 40 and, to a lesser extent, of connexin $43^{139}$. A recent clinical study indicated that the heterogeneous distribution of connexin 40 , as observed in goats during $\mathrm{AF}$, is a common feature in humans, irrespective of the presence of AF. Furthermore it was shown that patients susceptible to postoperative AF had elevated levels of connexin $40^{14}$. However, AF patients with complex atrial activation (chronic AF) had lower levels of connexin 40 compared to patients with induced AF (no history of AF) ${ }^{1 / 4}$. All. in all, there appear to exist some discrepancies concerning the gap junctional remodelling during AF. This might be due to species differences, variations in experimental set up in the case of animal models or differences in underlying heart disease whenever patients were involved.

\section{$3.3 \mid$ Metabolic proteins}

The effect of AF on the expression of proteins that are involved in the cardiomyocyte metabolism has not been well studied. In pigs with $\mathrm{AF}$, the creatine phosphate content in atrial tissue declined slightly, ATP and lactate remained unchanged ${ }^{+4}$. In sheep, two hours of AF resulted in activation of the protontranslocating ATPase, while the activity of cytochrome coxidase remained unchanged ${ }^{185}$. The proton-translocating ATPase activity was not altered in goats with $\mathrm{AF}^{130}$. The discrepancy between sheep and goats in activation of proton-translocating 
ATPase is most likely related to the duration of AF (hours and weeks, respectively). In the goat model of AF, no changes in the concentration of adenine nucleotides and their degradation products could be detected. The activity of mitochondrial cytochrome $c$ oxidase and mitochondrial NADH-oxidase was also unaltered ${ }^{13 \%}$. Only a decrease in the tissue content of phosphocreatine occurred during the first 8 weeks of AF, which is indicative of an increased energy demand ${ }^{130}$.

Circumstantial evidence does indicate that the metabolism of cardiomyocytes is altered in response to $\mathrm{AF}$ (Chapter 5$)^{186}$. First, during cardiac development the glucose metabolism is a major energy source for the cardiomyocyte. Adult cardiomyocytes rely on the fatty acid metabolism for energy production ${ }^{187-198}$. The observation that one of the features of structural remodelling, i.e. increased glycogen storage, is also found in foetal cardiomyocytes suggests that cardiomyocytes switch to the glucose metabolism during AF. Fujii et al. recently described an increased uptake of fluoro-2-deoxy-D-glucose in the right atrial wall of patients suffering from cardiac disease, and mainly $\mathrm{AF}$, which is suggestive of an increased glucose metabolism ${ }^{186}$. Second, the altered expression of the very low density lipoprotein receptor (VLDLr) also suggests a switch from fatty acid to glucose metabolism (Chapter 5). Expression of the VLDLr has been found in the heart, where it is presumed to supply the cardiomyocytes with triglycerides for the fatty acid metabolism ${ }^{192-194}$. During AF, the expression of the VLDLr was downregulated by approximately $40 \%$. Finally, in the first week of $\mathrm{AF}$, the hypoxia inducible factor $1 \alpha$ (HIF $1 \alpha$ ) is upregulated by approximately $60 \%$ (Chapter 5 ) which indicates a reduced oxygen tension ${ }^{195}$. The transcription factor HIFl $\alpha$ has been shown to upregulate expression of the glucose transporter 1 and enzymes involved in the glycolytic pathway, e.g. aldolase A, phosphoglycerate kinase 1 , and pyruvate kinase $\mathrm{M}^{172.173}$. Altogether, a possible oxygen deficit at the onset of AF might induce a switch from the fatty acid metabolism to the glucose metabolism. When the oxygen supply is limited, the glucose metabolism is a more economic way to generate energy because it requires less oxygen. In addition, the increase in glucose uptake and glycolytic activity could explain the observed accumulation of glycogen in the cardiomyocytes as a result of AF. This corroborates with the important role of glycolysis in the maintenance of intracellular calcium homeostasis during severe overload ${ }^{1 \%}$. 


\subsection{Contractile and structural proteins}

The expression of contractile and structural proteins has been extensively studied in the goat model on AF. Immunohistochemical staining was used to assess the effect of AF on protein levels and organisation, and to establish the degree of cardiomyocyte remodelling. During AF, myolytic cardiomyocytes reduced the concentration of several of their structural proteins like myosin, tropomyosin, actin and alphaactinin $^{33}$. Only at the periphery of the cells, where the remaining sarcomeres resided, normal cross-striation patterns of these proteins could be observed ${ }^{33}$. In the myolytic areas the distribution of desmin appeared disorganised and other proteins adapted a foetal expression pattern, i.e. titin and cardiotin ${ }^{33}$. In line with the previously described observations, the remodelling of structural proteins became apparent after 1-2 weeks of AF and progressively increased ${ }^{37.90}$. The changes occurred without signs of apoptosis ${ }^{35}$ and re-expression of alpha-smooth muscle actin supported the hypothesis of cardiomyocyte adaptation through dedifferentiation ${ }^{33.37 .88}$.

The alterations in Tnl isoform expression during AF in humans and goats are described in chapter 3 and 4 , respectively. The expression of Troponin $1(\mathrm{TnI})$ isoforms in cardiomyocytes is related to the degree of differentiation during embryonic development ${ }^{43-95.97-100}$. In the heart the slow-skeletal TnI (ss TnI) isoform is normally only expressed during foetal or neonatal stages and re-expression of ss Tnl in adult hearts could be an indication of cardiomyocyte dedifferentiation. In addition, the expression of the different isoforms in cardiomyocytes influences the calcium sensitivity and renders the myofilaments protected against acidosis ${ }^{101.102 .118}$ which could underlie the altered contractile properties of the atrium during AF. In patients with cardiac disease with or without $\mathrm{AF}$, the expression of slowtwitch skeletal TnI (ssTnI) protein could be detected (Chapter 3). Only the atrial cardiomyocytes of patients with chronic AF did not show expression of ssTnl. Instead, the expression of the adult cardiac isoform (cTnl) was increased, which is in disagreement with cardiomyocyte dedifferentiation. In goats with AF there was a trend towards increased ssTnl mRNA expression after 2 weeks of AF although no ssTnl protein could be detected (Chapter 4). Degradation of c TnI which was only sporadically observed in the first 4 weeks of $\mathrm{AF}$ was absent 
Figure 2 |

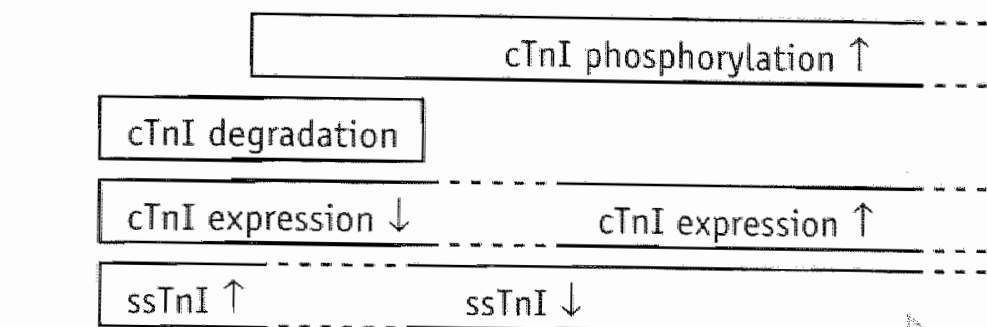

\section{SR}

PAF

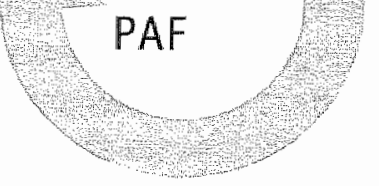

goats onset AF patients PAF patients chronic AF goats chronic AF

after longer periods of AF. Similar to the observations in patients, the expression of cTnI appeared to increase after prolonged duration of $\mathrm{AF}$.

The functional implications of the changes in TnI isoform expression are not fully understood. Figure 2 shows a hypothetical mechanism of $\mathrm{Tnl}$ expression regulation that could explain the observations in humans as well as in goats.

Early during AI", some degradation of $\mathrm{Chl}$ might occur, possibly as a result of activation of the proteolytic enzyme Calpain $\|^{113}$ which has been shown to degrade cTn I07.100:11. Re-expression of ssTnI which protects the cardionyocyte from acidic stress ${ }^{118}$ and improves the calcium sensitivity ${ }^{101.112}$ is a response to the unstable early phase characterised by acidic stress, and ischaemia. Following longer episodes of $\mathrm{AF}$, the calcium homeostasis normalises, ssTnI expression decreases and protection against cTnl degradation is achieved by protein phosphorylation ${ }^{109}$. However, phosphorylation decreases the calcium sensitivity of oTnI ${ }^{122-124}$ which could be compensated for by upregulation of cTnl expression. In patients with paroxysmal $\mathrm{AF}$, the repetitive nature of $\mathrm{AF}$ episodes might

Hypothetical expression regulation of ThI derimg AF.

The early stage of AF is characterised by an unstable situation, caused by calcium owerlond and acidosis which müght result in degradation of chor, reexpression of ssTni and downeguation of CTrl expression. To protect cin from degradation the protein is phosplonylated and its expression is upregulated. Following the early unstable period, the situation stabutises, and 5sTril expression is downregulated. In the in vivo situation, the unstatble condition is represented by patients with PAF and goats at the onset of AF (cTnI degradation, 55 ThI expressioni) wheneas patients and goats with a represent the stable situation (no sstinl expression, increased cTml expression). 
compromise the stabilisation which results in continuous activation of ss $T$ nI expression. During chronic AF, normalisation may occur and the expression of Ss TnI returns to normal levels. In addition, the expression of $\mathrm{cTnl}$ is upregulated, either as a response to compensate for the decreased calcium sensitivity of phosphorylated cTnI or because of an increased protein/ mRNA turnover. Thus, rather than cardiomyocyte dedifferentiation, the expression of $\mathrm{TnI}$ isoforms appears to be involved in protection of the contractile apparatus against the cellular stress induced by AF. The mechanisms of this protective response, i.e. cTnI degradation, $\mathrm{CTnI}$ phosphorylation, and $\mathrm{ss} \mathrm{Tn}$ I expression are likely to contribute to the contractile dysfunction. An additional contributor to contractile dysfunction might be the altered expression of myosin heavy chain (MHC) isoforms (Chapter 5). Cardiomyocytes that express $\alpha-\mathrm{MHC}$ can generate more force than those expressing $\beta-\mathrm{MHC}$ due to the lower ATPase activity of the latter isoform ${ }^{165}$. Immunohistochemistry on atrial cardiomyocytes indicated that during $\mathrm{SR}$ more than $90 \%$ of the cells expressed $\alpha-\mathrm{MHC}$. Beta-MHC was present in almost $22 \%$ of the cells, and $3 \%$ of this population expressed $\beta$ $\mathrm{MHC}$ at high levels. During sustained AF the percentage of cardiomyocytes expressing $\beta-\mathrm{MHC}$ increased up to almost $50 \%$. The percentage of cardiomyocytes expressing $\beta-\mathrm{MHC}$ at high levels increased up to $18 \%$. Although the percentage of cells expressing $\alpha-M H C$ seemed unaffected, Western blotting revealed a significant decrease in the expression level of this isoform. This observed increase in $\beta-\mathrm{MHC}$ expression during AF in combination with a reduction in $\alpha$-MHC expression might explain the observed reduction in atrial contractility. Because the downregulation of $\mathrm{MHC}$ expression could already be detected after 1 week of $\mathrm{AF}$, it might be partly responsible for the developing atrial dysfunction. The exact involvement of changes in expression of TnI, MHC, or other structural proteins in the altered contractile function of the atrium during AF still needs to be established.

\section{4 | Mechanisms of remodelling}

\subsection{Calcium overload}

One of the main actors in the complex regulation of electrical and morphological remodelling appears to be calcium, a 
common messenger in signalling pathways ${ }^{107}$. It has been shown that the calcium antagonist verapamil is able to reduce the electrical remodelling ${ }^{57.198 .199}$ and attenuate the contractile dysfunction $^{27.44,56}$ during short term AF. After longer duration of $\mathrm{AF}$, the protective effect of verapamil disappears ${ }^{200}$ indicating a transient calcium overload at the onset of AF. There are several mechanisms by which AF might induce a calcium overload:

\section{i| atrial activity rate}

At the onset of $A F$ the atrial activation rate is high which causes an excessive influx of calcium ${ }^{4,201}$. In dogs, atrial tachycardia increased cellular calcium loading, which induced abnormalities in intracellular calcium handling ${ }^{601.201}$. In the goat model of AF, the levels of sarcolemma-bound and mitochondria bound calcium increased within the first two weeks of AF. From four weeks onward, the calcium level normalised, and control values are reached at 16 weeks of AF $^{59}$.

\section{ii | atrial stretch:}

During AF, the atrial contractile function is depressed ${ }^{27.56,600.201}$ which will lead to volume overload and subsequently increased passive stretch. Increased atrial pressure has been shown to induce calcium overload ${ }^{195}$ and shortening of the atrial effective refractory period ${ }^{52.199,202}$. In addition, atrial stretch influences protein expression ${ }^{45-48}$ and has a positive effect on cell size $\mathrm{s}^{49-51}$. Thus apart from calcium overload, atrial stretch could be involved in the observed structural remodelling and cardiomyocyte hypertrophy during $\mathrm{AF}$.

\section{iii | atrial ischaemia:}

It is well established that ischaemia results in cellular acidosis and calcium overload. However, the role of ischaemia during AF is controversial. The viable appearance of mitochondria during $\mathrm{AF}$ suggests that severe ischaemic stress does not occur $\mathrm{AF}^{29-32.88}$. The absence of changes in the metabolites of cardiomyocytes, such at ATP, also indicates that severe ischaemia is absent during $\mathrm{AF}^{44.130}$. Nevertheless, it was found that during acute AF the atrial flow was high and the flow reserve was limited $^{38.203}$. As a consequence, additional metabolic demands 
Figure $3 \|$

Cardiac response to

See text far explanation of the figure

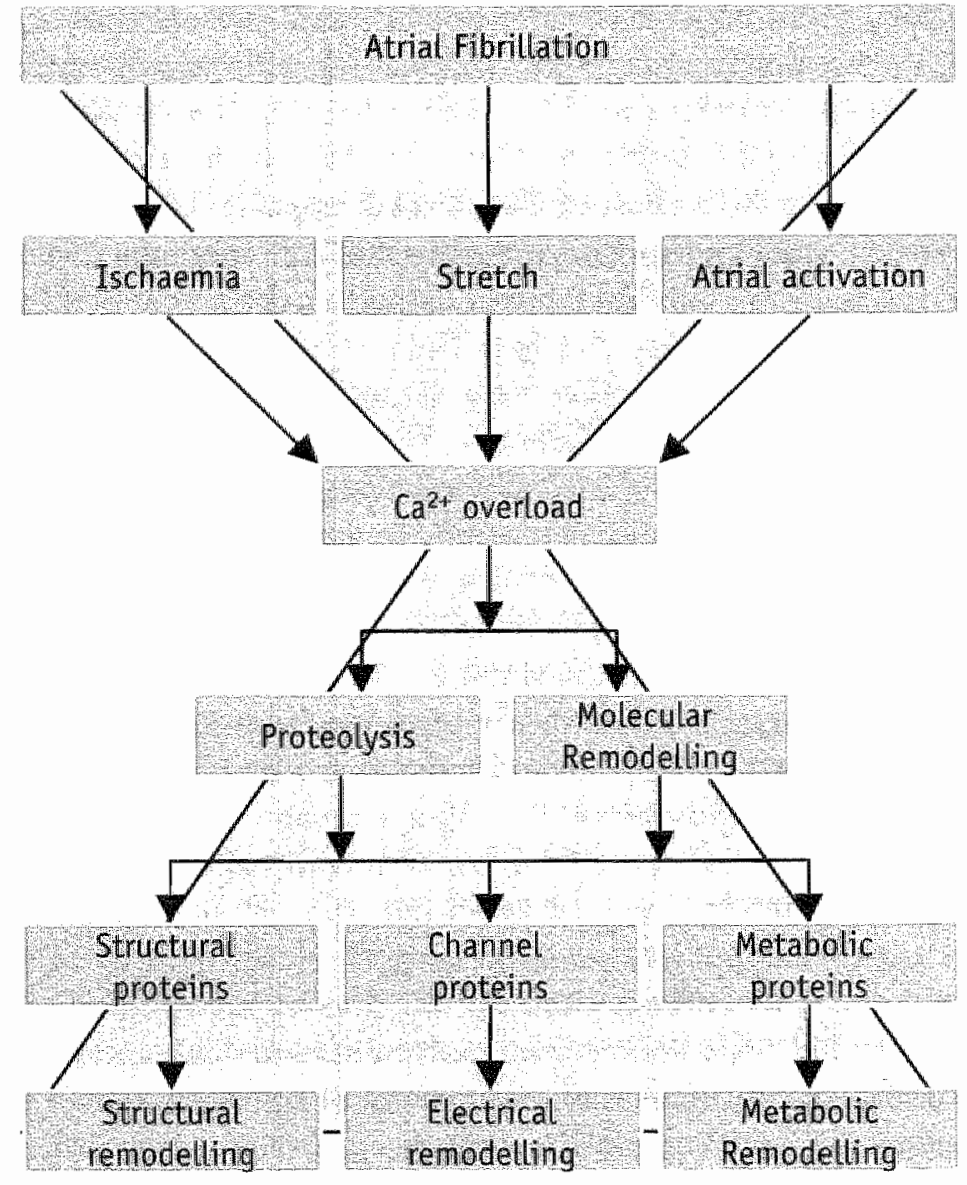

could lead to a metabolic mismatch ${ }^{38}$. This could explain the transient decrease in phosphocreatine content in atrial cells at the onset of $\mathrm{AF}^{43.44}$. Furthermore, the observed upregulation of the hypoxia inducible factor $1 \alpha$ in the first weeks of AF indicates that oxidative stress does occur at the onset of AF (Chapter 5). Thus, although severe ischaemia does not seem to play a role during $\mathrm{AF}$, some degree of ischaemic stress could be involved in atrial remodelling. Figure 3 shows the most likely mechanism by which AF induces the changes that are characteristic of atrial remodelling.

At the onset of AF, calcium overload occurs in response to an increased activation rate, stretch, and/or ischaemia. Excess calcium results in the activation of proteolytic pathways. A recent study in patients with persistent and paroxysmal AF described increased levels of the calcium activated proteolytic protein 
calpain 1 , located in the nucleus, the cytoplasm and at the intercalated discs ${ }^{112}$. The induction of calpain activity correlated with shortening of the atrial effective refractory period, increased structural alterations in the atrial myocytes, and decreased protein levels of channel proteins ${ }^{12}$. Degradation of calcium channel proteins ${ }^{204}$ and contractile/structural proteins by calpain was also observed by others ${ }^{107.130 .205 .206}$.

Besides the activation of proteolytic proteins like calpains, calcium overload is involved in the altered expression of proteins during AF, i.e. molecular remodelling (Figure 3). Calcium overload has been shown to downregulate sodium channel expression $^{67}$ which could explain the reduced sodium current density in atrial myocytes from dogs with pacing induced $\mathrm{AF}^{\circ 6}$. A recent study found a relation between calcium overload and HIF $1 \propto$ protein levels. In $\mathrm{H} 9 \mathrm{c} 2$ cardiomyoblasts the hypoxiainduced increase in HIFI $\alpha$ protein could be attenuated by verapamil ${ }^{207}$. Salnikow et al. did not find alterations in HIF $1 \alpha$ protein or expression levels but observed a calcium-induced activation of signalling pathways involving transcription factor AP-1. They concluded that the co-operation between the HIFI $\alpha$ and AP-1 pathways allowed the fine regulation of gene expression during hypoxia ${ }^{208}$.

In all, these data show that calcium overload does occur during $\mathrm{AF}$ and that calcium overload is involved in activation of protein degradation and initiation of protein expression regulation. The subsequent alterations in structural, channel, and metabolic proteins results in structural, electrical and metabolic remodelling which are responsible for induction and maintenance of atrial dysfunction during $\mathrm{AF}$.

\section{2 | Cardiac adaptation}

As described in the previous section, calcium overload is an important regulator of cardiomyocyte structural remodelling in response to cardiac stresses like ischaemia and stretch. However, the observed response appears not to be restricted to AF. Several studies have shown that structural remodelling occurs in several other cardiac diseases, e.g. cardiac valve disease, chronic hibernating myocardium, myocardial infaretion $32.33,41341.88 .269$. This observation, together with the knowledge that many cardiac diseases induce ischaemia and/or stretch suggests the existence of an uniform response mechanism of cardiomyocytes in 


\section{Figure 41}

General cardiac response to cardiac disease.

See text for explanation of the figure.

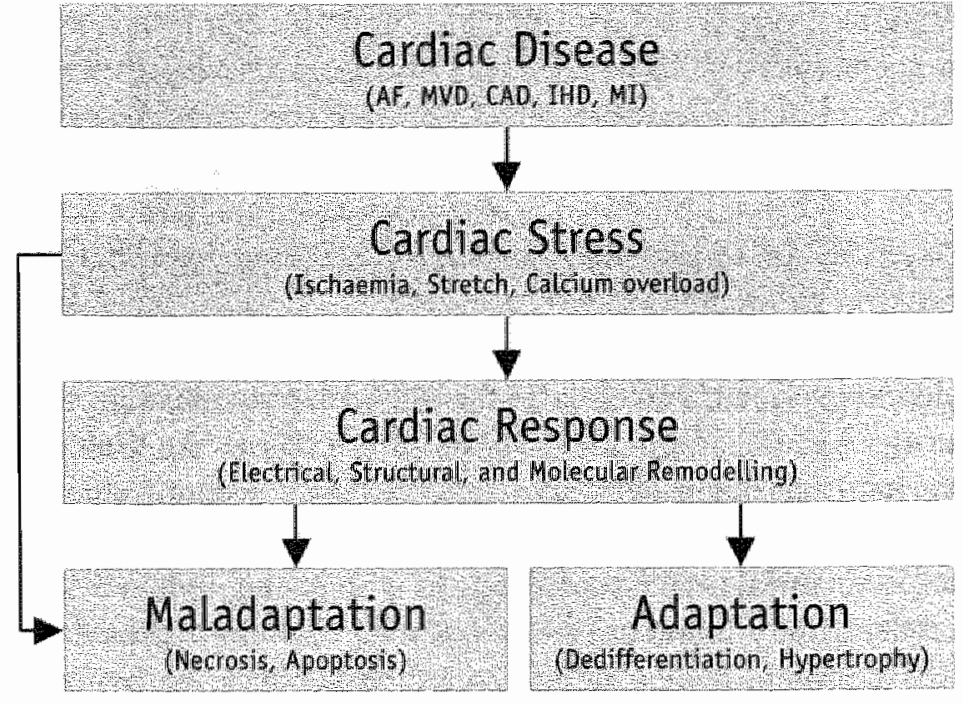

jeopardy. Figure 4 shows a model of how cardiac disease in general could induce an adaptive and/or maladaptive response of the cardiomyocytes. As depicted in the figure, a broad spectrum of cardiac diseases induces common cardiac stresses like ischaemia or stretch. Cardiac stress usually induces calcium overload which initiates proteolysis and molecular remodelling. Depending on the degree of cardiomyocyte stress, the cells either die by necrosis and apoptosis, or they adapt through dedifferentiation and hypertrophy. The observations in patients and goats with AF suggest that the adaptive response occurs apart from necrosis and apoptosis or programmed cell death ${ }^{35.85}$. The adaptive response might be considered as programmed cell survival", as it appears to render the cardiomyocytes the ability to survive stress conditions including ischaemia and stretch $^{12}$. This would also explain the capacity of cells to regain function, although delayed, once environmental conditions have become normalised ${ }^{25,27,4+?, 214}$.

\section{5 | Future perspectives}

\subsection{Molecular remodelling in AF}

Since the first description of AF in 1628 by the English physician William Harvey (1578-1657) $)^{211}$ our knowledge of this arrhythmic disease has increased substantially. The multiple wavelet hypothesis of Gordon K. Moe ${ }^{12.13}$, the paradigm of AF 
begets $\mathrm{AF}^{27}$, and the theory of $\mathrm{AF}$-induced cardiomyocyte dedifferentiation ${ }^{32.33}$ are examples of the scientific contributions to our current understanding of the cause and maintenance of AF. Despite the increasing comprehension of atrial remodelling during AF, many questions concerning the molecular mechanisms that underlie atrial remodelling remain unanswered. Most research has focussed on molecular alteration in the more obvious proteins like ion channels and structural proteins. The use of techniques that allow a random screen of the overall changes in gene expression (differential display, expression arrays) might contribute to resolving the exact molecular pathways that are involved in molecular remodelling during AF. However, the aetiology of patients with AF is often diverse which conceals the true contribution of AF to altered gene expression. Although the use of animal models can overcome this problem, the mix of different cell types within the atrial tissue, the heterogeneity in the response of the atrial cells to $\mathrm{AF}$, and the interspecies differences complicate the gene expression analysis. Only in vitro systems provide the most optimal conditions to perform gene expression analysis because they consist of an indefinite source of well defined cells. Unfortunately, up to now no good in vitro models for AF induced remodelling exist. When most of the problems using expression screening techniques have been overcome, such techniques might be used successfully in basic science to unravel the molecular aspects of AF. Furthermore, they might be used in the clinical setting as a diagnostic tool to determine the degree or stage of cardiac remodelling during AF. Eventually, expression screening techniques might provide clinicians with information on which specific and individual patient treatment can be based.

\section{2 | Molecular remodelling in cardiac disease}

Different cardiac diseases may result in a general response at the level of cardiomyocyte morphology and protein expression patterns. Atrial fibrillation, chronic hibernating myocardium, and cardiac valve disease all result in changes that are reminiscent of cardiomyocyte dedifferentiation ${ }^{33,40.41 .88}$. A switch towards foetal gene expression programs and metabolism has also been described in cardiac hypertrophy ${ }^{212,213}$. This indicates that the primary response of the heart to cardiac stress consists of a return to a less differentiated phenotype. One of the questions 
that has to be answered in the near future is whether the dedifferentiation is a response in order to survive the altered conditions or is it an attempt to enter the cell cycle again, as a countermeasure against cell loss? A comparison of the similarities and the differences between the molecular responses during different cardiac diseases could reveal the nature of cardiomyocyte dedifferentiation, not only in AF, but in cardiac diseases in general.

\section{3 | Reversibility of molecular remodelling}

Little is known about the reversibility of molecular remodelling after restoration of sinus rhythm. The observed changes in expression of ion channels, e.g. L-type calcium channel, and alterations in the atrial effective refractory period indicate that changes in cardiac gene expression are responsible for electrical remodelling during $\mathrm{AF}^{65,133-135,214}$. After restoration of sinus rhythm the atrial effective refractory period normalises within a few days ${ }^{127.144,177}$. Atrial conduction normalises somewhat slower but still recovers within a few weeks ${ }^{1+5,140}$. These data indicate that upon normalisation of the atrial rhythm, the changes in atrial activation and conduction are completely reversible and that the underlying changes in gene expression of channels and connexins most likely also return to normal values. Indeed, in the goat model, the expression of connexin 40 normalised within 8 weeks of SR following 16 weeks of $\mathrm{AF}^{215,216}$.

As stated before, the rapid normalisation of the electrical properties after normalisation of SR is not in line with the slow recovery of contractile function ${ }^{25,27.147}$. A slow recovery of function is also noted in patients with hibernating myocardium ${ }^{25.216}$, a cardiac disease which is characterised by cardionyocyte dedifferentiation ${ }^{40.41}$. In goats, 8 or 16 weeks of SR following 16 weeks of AF resulted in a slow recovery of the structural changes ${ }^{217}$, which could explain the delay in functional improvement. Whether the structural remodelling is completely reversible and whether or not the slow recovery of structural remodelling is accompanied by an equal slow normalisation in the expression levels of structural proteins is not known. In goats, the expression of titin had not reached normal levels 16 weeks post cardioversion whereas the expression of cardiotin looked normal ${ }^{217}$. A factor that could hamper the complete normalisation of structural remodelling is fibrobis. Several authors have 
described the presence of substantial fibrosis besides the structural changes in patients with $\mathrm{AF}^{217}$. The removal of this fibrotic tissue, if possible at all, might take a long time. Thus, the concept that "SR begets SR" ${ }^{159}$, analogous to "AF begets $A F$ ' 22 , might not hold true when molecular and structural remodelling is too extended. The reversibility of molecular remodelling and subsequent electrical and structural remodelling will be one of the important issues in the future research of AF.

\section{6 | Conclusions}

AF induces electrical and structural remodelling which results in contractile dysfunction of the atrium. It has been shown that electrical and structural remodelling during $\mathrm{AF}$ are the result of far-reaching molecular remodelling that affects the function of cardiomyocytes in various ways, e.g. excitation, contraction, metabolism. The triggers for molecular remodelling might involve calcium overload, stretch, and ischaemia. The observed cardiomyocyte remodelling is not restricted to $\mathrm{AF}$ but appears to be a common response mechanism to cardiac stress. Unravelling the exact mechanisms and triggers that are involved in molecular remodelling and the reversibility of remodelling should be main targets in future research, not only to provide a better understanding of AF but also to generate new tools for better treatment. 



\section{Appendix | Summary |}

Atrial fibrillation (AF) is a cardiac arrhythmia that is characterised by irregular and disorganised atrial activity with respect to rate and rhythm. It has an overall prevalence of allmost one percent and it is the most common arrihythmia encountered in the clinical setting. It has been shown that AF is accompanied by electrical remodelling and contractile dysfunction. Both phenomena are reversible but after prolonged periods of $\mathrm{AF}^{\text {; }}$, a discrepancy occurs between a rapid normalisation of electrical function and the delay in recovery of contractility. One possible explanation for this incongruity is the occurrence of structural remodelling of the cardiomyocytes during $A F$.

Structural remodelling could be observed in atrial cardiomyocytes of patients suffering from cardiac valve disease with or without AF (Chapter 2). The size of cardiomyocytes increased in patients with $\mathrm{AF}$ as compared to patients with no AF. Additional structural changes were present in patients with or without AF and mainly consisted of extensive myolysis, glycogen accumulation, sarcoplasmic reticulum disorganisation, mitochondrial changes, and redistribution of the nuclear heterochromatin. These changes are indicative of an adaptive response through cardiomyocyte dedifferentiation and the 
observations were in agreement with previous studies in humans and animal models.

Because AF is accompanied by cardiomyocyte dedifferentiation and contractile dysfunction the effect of $\mathrm{AF}$ on the expression of Troponin $\mathbb{I}$ isoforms was analysed (Chapter 3 and 4). Troponin I (TnI) is a sub-unit of the troponin complex which regulates actin-myosin interaction during contraction. Different isoforms of $\mathrm{Tnl}$ are expressed in different muscle types and several species, including humans, show a switch in expression from the foetal slow-twitch skeletal isoform (ssTnI) to the adult cardiac isoform (cTnI) during heart development. Furthermore, degradation of $\mathrm{AF}$ might occur during $\mathrm{AF}$ as a result of increased proteolytic activity. First, the changes in TnI expression were analysed in patients with cardiac valve disease and/or AF (Chapter 3). Several patients showed expression of ssTnI, irrespective of the presence of cardiac valve disease or AF. Although the re-expression of ssTnI is indicative of cardiomyocyte dedifferentiation, patients with chronic AF did not re-express ss TnI. Rather than re-expression of ss TnI, chronic AF resulted in increased expression of cTnI. In none of the patients degradation of cTnl could be detected. Because of the differences between the individual patients with respect to duration of $\mathrm{AF}$ and underlying cardiac disease, changes in the expression of $\mathrm{TnI}$ isoforms were further characterised in the goat model of lone AF (Chapter 4). In contrast to the observations in patients, AF in the goat did not result in detectable protein levels of ssTnI. Degradation of $\mathrm{Tnl}$ could only be observed in a few samples but was confined to the first 4 weeks of $\mathrm{AF}$. After prolonged duration of $\mathrm{AF}$ the degradation of cTnl was no longer detectable and cTnl expression appeared to be increased, although not significantly. The results in the goat together with the observations in patients suggest that the alterations in TnI expression are not the result of ongoing cardiomyocyte dedifferentiation. Nevertheless, the changes in Tnl expression might be one of the contributors to the contractile dysfunction.

To obtain a more complete picture of the effect of AF on atrial gene expression the goat model was used to isolate and characterise genes of which the expression changed during AF (Chapter 5). The differential display technique was used to isolate genes that might be involved in atrial remodelling. The majority of these genes were involved in cardiomyocyte 
structure, metabolism, expression regulation, or (de)differentiation. Several of the genes that were isolated confirmed or supported the current knowledge on structural remodelling and AF-induced cardiomyocyte dedifferentiation. Time course analysis of the expression revealed an increased expression of the transcription factor HIF $1 \alpha$ in the first week of $\mathrm{AF}$, which is indicative of atrial ischaemia at the onset of AF and that provides evidence for a switch in metabolism and subsequent glycogen accumulation.

In short, the studies presented in this thesis show that AF is accompanied by altered gene expression in the atria. Part of the changes in expression are involved in the structural remodelling of the atrial cells. In addition, a stress response appears to occur at the onset of AF which could not only initiate the structural remodelling but may also account for a metabolic remodelling of the cardiomyocyte. Future studies on the exact role of molecular remodelling in atrial adaptation and the involvement of ischaemia, stretch, and calcium overload in this process might provide new tools for a better treatment of $\mathrm{AF}$. 



\section{Appendix Samenvatting |}

Boezemfibrilleren is een hartritmestoomis die zich kenmerkt door onregelmatigheden en disorganisatie in zowel het tempo als het ritme van de boezemcontracties. Ongeveer 1 procent van de bevolking lijdt aan boezemfibrilleren en daarmee is het de meest voorkomende ritmestoornis. Onderzoek heeft aangetoond dat boezemfibrilleren gepaard gaat met veranderingen in de electrische eigenschappen van de boezem. Daarnaast vindt er een verslechtering plaats in het samentrekken van de boezem. Hoewel beide fenomenen normaliter volledig omkeerbaar zijn, is gebleken dat naamate de duur van boezemfibrilleren toeneemt het herstel van de contractie langer duurt dan het herstel van de electrische patronen. Een mogelijke verklaring voor dit ongelijk herstel kan liggen in het feit dat de hartspiercellen structurele veranderingen ondergaan ten gevolge van het boezemfibrilleren.

Structurele veranderingen waren aanwezig in de hartspiercellen uit de boezems van patienten met een hartklep aandoening met of zonder boezemfibrilleren (Hoofdstuk 2). De hartspiercellen van patienten met boezemfibrilleren waren groter dan de cellen van patienten zonder boezemfibrilleren. Tevens waren in alle patienten, ongeacht de aanwezigheid van boezemfibrilleren, 
structurele veranderingen zichtbaar die voornamelijk bestonden uit het verdwijnen van de contractiele elementen, het opstapelen van glycogeen, een verminderde organisatie van het sarcoplasmatisch reticulum, veranderingen in de grootte en de vorm van de mitochondriën en een regelmatige verdeling van het heterochromatine in de kem. Al deze veranderingen kwamen overeen met waarnemingen uit andere studies in zowel mensen als dieren en ze wijzen op een mechanisme waarbij de hartspiercel zich aanpast aan een nieuwe situatie door terug te gaan naar een vroeger ontwikkelingsstadium (dedifferentiatie). Aangezien boezemfibrilleren gepaard gaat met hartspiercel dedifferentiatie en verminderde contractiliteit is effect van boezemfibrilleren op de expressie van Troponine I onderzocht (Hoofdstuk 3 en 4). Troponine I is een eiwit dat onderdeel uitmaakt van het Troponine complex. Dit complex regelt de interactie tussen actine en myosine tijdens het samentrekken van hartspiercellen. Verschillende spiertypes hebben elk hun eigen specifieke isovorm wan Troponine I, aangepast aan de contractiele eigenschappen van het spiertype. Tijdens de ontwikkeling van het hart vindt er wisseling plaats in de expressie van deze isovormen. In het foetale hart wordt voornamelijk een variant tot expressie gebracht die ook te vinden is in skeletspieren. In het volwassen hart komt alleen nog maar de hartspecifieke isovorm tot expressie. Kortom, als er tijdens het boezemfibrilleren veranderingen plaatsvinden in de expressie van de Troponine I isovormen zou dit een aanwijzing kunnen zijn voor de dedifferentiatie van hartspiercellen. Daarnaast zou er ook afbraak kunnen plaatsvinden van het Troponine I eiwit. Allereerst is er gekeken naar veranderingen in de Troponine I expressie in de boezems van patienten die lijden aan een hartklepaandoening en/of boezemfibrilleren (Hoofdstuk 3). Hierbij is zowel de samenstelling van de Troponine eiwitten als de expressie van het mRNA bestudeerd. Bij een aantal patienten kon de aanwezigheid van de skeletspier isovorm van Troponine op eiwitniveau worden aangetoond, ongeacht of deze patienten een hartklepaandoening dan wel boezemfibrilleren hadden. Hoewel de aanwezigheid van ssTnI een indicatie is voor hartspiercel dedifferentiatie kon het eiwit niet aangetoond worden in patienten met chronisch boezemfibrilleren. In plaats van een toename in ssTnl ging bij patienten met chronisch boezemfibrilleren de expressie van de hartspierspecieke isovorm omhoog. In geen van de patienten was afbraak van het 
hartspecifieke eiwit meetbaar.

Aangezien de patienten nogal verschillend waren ten aanzien van de duur van boezemfibrilleren en onderliggende hartziekten, is de expressie van de Troponine I eiwitten verder onderzocht in een diermodel (geit) van boezemfibrilleren (Hoofdstuk 4). In tegenstelling tot wat we bij de patienten hadden gevonden resulteerde boezemfibrilleren in de geit niet tot een waarneembare toename van het skeletspierspecifieke eiwit. Afbraak van het hartspecifieke Troponine I was maar in een zeer klein aantal gevallen zichtbaar en alleen maar in de eerste 4 weken van boezemfibrillatie. Na een langere periode van boezemfibrilleren was er geen afbraak meer zichtbaar en leek de mRNA expressie van de hartspecifieke isovorm weer toe te nemen. Samen met de observaties in de patienten lijken deze resultaten aan te geven dat de verschuivingen in de expressie van Troponine I isovormen tijdens boezemfibrilleren geen gevolg zijn van hartspiercel dedifferentiatie. De verandering in de expressie zouden wel een bijdrage kunnen leveren aan de verslechterde contractiliteit van de boezem.

Om een completer beeld te krijgen van het effect van boezemfibrilleren op de expressie van genen in het algemeen is vervolgens het geit model gebruikt om genen te isoleren waarvan de expressie veranderde ten gevolge van boezemfibrilleren (Hoofdlstuk 5). Met behulp de "differential display' techniek werd, naast een aantal nog onbekende genen, een aantal genen geïsoleerd dat mogelijk een rol speelt tijdens boezemfibrilleren. Het merendeel van de geïdentificeerde genen speelt een rol in de structur van hartspiercellen, de energiehuishouding van cellen, de regulatie van gen-expressie, of in de (de)differentiatie van hartspiercellen. Een aantal van de geïsoleerde genen bevestigde of ondersteunde onze huidige kennis van zaken met betrekking tot de structele veranderingen en dedifferentiatie van hartspiercellen. Het verloop van de expressiepatronen van genen gedurende het boezemfibrilleren werd ook onderzocht en het bleek dat in de eerste week van $\mathrm{AF}^{\mathrm{F}}$ een eiwit tot overexpressie werd gebracht (HIFI $\alpha$ ) dat aangeeft dat er bij de aanvang van boezemfibrilleren wel eens sprake kon zijn van een zuurstoftekort en dat de hartspiercellen hun energiehuishouding dusdanig veranderden dat er glycogeenstapeling kon plaatsvinden.

Kortom, de in dit proefschrift gepresenteerde studies geven aan dat boezemfibrilleren gepaard gaat met vergaande moleculaire 
veranderingen. Een deel van deze veranderingen is betrokken bij de structurele veranderingen van hartspiercellen in de boezem. Verder is gebleken dat bij aanvang van boezemfibrilleren een tijdelijke stress wel eens verantwoordelijk zou kunnen zijn voor het inzetten van de structurele veranderingen en het aanpassen van de energiehuishouding door hartspiercellen. Toekomstig onderzoek naar de exacte rol van de moleculaire veranderingen en de invloed van het mogelijke zuurstoftekort, rek en calcium op het proces van de verminderde boezemfunctie zou nieuwe handvatten kunnen reiken voor een betere behandeling van boezemfibrilleren. 


\section{Appendix Curriculum Vitae}

Personal |

Name

Date of birth

Place of birth

Education |

$1978-1984$

$1984-1990$

$1990-1997$

$1997-2001$

$2001-2002$

2002 - present
Victor L.J.L. Thijssen

March 8, 1972

Tegelen, The Netherlands

Primary school (Basisschool)

St. Jozefschool, Beesel

Secondary (high) school (VWO)

Bisschoppelijke College, Roermond

Msc programme Biotechnology

Agricultural University, Wageningen

PhD Student

Dept. Molecular cell biology \& Genetics, University of Maastricht (UM)

Research fellow

Dept. Cardiologie

Academic Hospital Maastricht (azM) / UM

Research fellow

Dept. Internal medicine/ Pathology

azM / UM 



\section{Appendix List of publications |}

Papers |

V.L.J.L. Thijssen, J. Ausma, G-S. Liu, M.A. Allessie, G.J. van Eys, M. Borgers. Structural Changes of Atrial Myocardium During Chronic Atrial Fibrillation. Cardiovasc Pathol $2000 ; 9(1): 17-28$

L Wouters, G-S Liu, W Flameng, V Thijssen, F Thone, M Borgers. Structural remodelling of atrial myocardium in patients with cardiac valve disease and atrial fibrillation. Exp Clin Cardiol $2001 ; 5(3): 158-163$

V.L.J.L. Thijssen, J. Ausma, M Borgers. Structural remodelling during chronic atrial fibrillation: act of programmed cell survival. Cardiovasc Res 2001;52: 14-20

V.L.J.L. Thijssen, H.M.W. van der Velden, E.P. van Ankeren, J.Ausma, M.A. Allessie, M.Borgers, G.J.J.M. van Eys, H.J. Jongsma. Analysis of altered gene expression during sustained atrial fibrillation in the goat. Cardiovasc Res, 2002;54(2): 427-437 
V.L.J.L. Thijssen, J. Ausma, L. Gorza, I.C. van Gelder, G.J.J.M. van Eys, $M$. Borgers. Expression of Troponin $I$ isoforms in patients with atrial fibrillation. In preparation.

V.L.J.L. Thijssen, J. Ausma, L. Gorza, M.A. Allessie, M. Borgers, G.J.J.M. van Eys. Troponin I isoform expression during chronic atrial fibrillation in the goat. In preparation

S.S.M. Rensen, V.L.J.L. Thijssen, C.J. de Vries, P.A. Doevendans, S.D. Detera-Wadleigh, G.J.J.M. van Eys. Expression of the smoothelin gene is mediated by alternative promoters. Accepted for publication in Cardiovasc Res.

\section{Chapters |}

G.J.J.M. van Eys, C.J.M. de Vries, S.S.M. Rensen, V.L.J.L. Thijssen, E.L.C. Verkaar, G.P.G.M. Coolen, W.M.H. Debie, M.C. de Ruiter, S.D. Wadleigh-Detera. Smoothelins: one gene, two proteins, three muscle cell types ... so far. In: Cardiovascular specific gene expression, P.A. Doevendans, R.S. Reneman, and M. van Bilsen, Editors. 1999, Kluwer Academic Publishers: Dordrecht, The Netherlands. p. 49-66.

Abstracts |

V.L.J.L. Thijssen, G.J.I.M. van Eys, J. Ausma, M. Borgers, M.

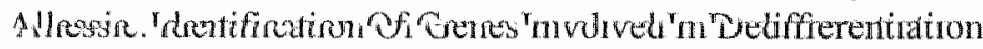
Of Cardiomyocytes. J Mol Cell Cardiol, 1999;31:A93

V.L.J.L. Thijssen, G.JJ.M. van Eys, J. Ausma, M. Borgers. Dedifferentiation Of Cardiomyocytes During Atrial Fibrillation: Analysis Of Gene Expression By Differential Display. J Muscle Res Cell Motil. 1999;20(8): 845

V.L.J.L. Thijssen, J. Ausma, L. Gorza, M. Borgers, G.J.J.M. van Eys. Expression of Troponin I Isoforms During Chronic Hibernation And Chronic Atrial Fibrillation. Exp Clin Cardiol $2000 ; 5(1): 49$ 


\section{Appendix | Dankwoord |}

Er zou weinig wan mij overblijven als ik alles terug moest geven wat ik aan anderen te danken heb.

Johann Wolfgang von Goethe

\begin{tabular}{|c|c|c|c|c|c|c|c|c|c|c|c|c|c|c|c|c|c|c|c|c|c|}
\hline & $E$ & I & 5 & 7) & & L & & & & & & & & & & & & & & & \\
\hline 0 & $\mathrm{P}$ & 1 & $\bar{E}$ & $\mathrm{~T}$ & $\mathrm{E}$ & $R$ & $\bar{n}$ & 0 & & $\bar{W}$ & & $\mathbb{N}$ & & $\bar{A}$ & & 5 & it & $\mathrm{H}$ & & $\bar{c}$ & \\
\hline B & I & $A$ & $\overline{\mathbb{N}}$ & $\bar{c}$ & $\mathrm{~A}$ & $\bar{B}$ & $\overline{\mathrm{R}}$ & 10 & & & & & & $\mathrm{R}$ & $\bar{M}$ & $\vec{A}$ & $\bar{M}$ & A. & M & $\bar{I}$ & \\
\hline$R$ & $\bar{B}$ & $\mathrm{~L}$ & $\overline{10}$ & $\bar{V}$ & $\bar{A}$ & $\mathbb{N}$ & $E$ & $\mathbb{D}$ & & & & $\mathbb{R}$ & K & D & $\mathbb{N}$ & $A$ & & 8 & $\overline{11}$ & uा & \\
\hline $\mathbb{E}$ & $B$ & $E$ & W & $I$ & $\bar{E}$ & $\bar{R}$ & $\mathbb{I}$ & $\mathrm{N}$ & $\mathrm{G}$ & $\bar{A}$ & $\mathbb{I}_{1}$ & $\mathbb{N}$ & H & $E$ & & $\mathbb{R}$ & & E & $B$ & $E$ & \\
\hline N & 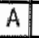 & W & $\mathbb{N}$ & $\bar{N}$ & 5 & $\bar{A}$ & 5 & $\mathrm{k}$ & 1 & $\bar{A}$ & B & 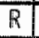 & $I$ & $\mathbb{N}$ & K & $M$ & & 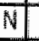 & $\mathrm{K}$ & $\bar{E}$ & \\
\hline$E$ & $\mathbf{N}$ & U & $E$ & 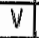 & 0 & $\overline{0}$ & $R$ & 0 & $M$ & - & $\mathbb{E}$ & $w$ & I & $E$ & K & 5 & & WI & $\mathbf{N}$ & $B$ & \\
\hline$M$ & $\overline{I J J}$ & $\mathrm{E}$ & $\bar{Z}$ & 5 & D & $R$ & $\bar{A}$ & 5 & G & $\bar{E}$ & $\mathbb{A}$ & 7 & $\bar{M}$ & 0 & D) & $\overline{0}$ & $\mathrm{~L}$ & $A \mid$ & $E$ & A & \\
\hline $\bar{A}$ & $\mathbb{N}$ & $R$ & 0 & $D$ & $\mathrm{~N}$ & $\bar{E}$ & $T$ & $T$ & $\mathrm{H}$ & $\bar{E}$ & $\mathrm{~L}$ & $\bar{M}$ & $\vec{A}$ & $\bar{K}$ & 0 & 10 & $P$ & EI & $\bar{R}$ & 5 & \\
\hline $\mathbb{N}$ & $N$ & $\bar{K}$ & $\mathrm{~L}$ & 0 & $\pi$ & IDI & 5 & $\mathrm{~L}$ & $\mathrm{E}$ & $\bar{H}$ & C & $\bar{A}$ & $\bar{R}$ & $T$ & T & $\bar{A}$ & & 0 & $E$ & $R$ & \\
\hline $\mathrm{H}$ & $E$ & 8 & 5 & $\mathrm{~K}$ & $\mathrm{MI}$ & 0 & 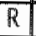 & $\mathrm{M}$ & $N$ & $\overline{\mathbb{I}}$ & $\mathbb{N}$ & $G$ & $\bar{V}$ & $\bar{R}$ & A & $\mathbb{N}$ & & If & $\bar{k}$ & $E$ & \\
\hline $\bar{A}$ & 5 & U) & $\mathrm{N}$ & 5 & $T$ & $P$ & $R$ & $c$ & $\mathrm{R}$ & 0 & $\mathbb{E}$ & $F$ & 5 & E & $\mathrm{H}$ & $\bar{F}$ & & 3 & $\mathbb{N}$ & $\mathrm{k}$ & \\
\hline B & $\mathrm{N}$ & 0 & $\mathrm{~A}$ & $\mathrm{H}$ & 8 & $\mathrm{E}$ & $\mathbf{R}$ & $R$ & $y^{\prime}$ & 5 & 0 & III & $T$ & $\bar{E}$ & $\mathrm{~A}$ & $\vec{R}$ & & 0 & $\bar{A}$ & $E$ & \\
\hline 0 & $\mathrm{E}$ & H & $\bar{k}$ & $R$ & $\bar{I}$ & $F$ & 8 & $\bar{E}$ & s & \begin{tabular}{|l|}
$R$ \\
\end{tabular} & $\mathbf{N}$ & $F$ & $\bar{E}$ & $\bar{G}$ & N & $\overline{\mathrm{A}}$ & & $\mathrm{E}$ & $\bar{N}$ & A & \\
\hline ] & $R$ & 1 & $I$ & $c$ & $I$ & $T$ & $E$ & $\mathbb{R}$ & p & $\bar{E}$ & $\mathbb{R}$ & $\mathrm{N}$ & 3) & $\bar{M}$ & $\bar{S}$ & $\bar{N}$ & & $\vec{P}$ & $\bar{A}$ & 何 & \\
\hline 0 & $\mathrm{R}$ & $\mathrm{L}$ & U. & $I$ & $\bar{s}$ & $\bar{A}$ & 6 & 0 & $\mathrm{R}$ & $\bar{z}$ & $\bar{A}$ & $\bar{A}$ & 0 & $E$ & D & $\mathrm{C}$ & & 6 & $\bar{V}$ & A & $\bar{L}$ \\
\hline $\mathbb{N}$ & $E$ & 0 & $\begin{array}{l}\mathbb{R} \\
\end{array}$ & A. & $\bar{G}$ & $D$ & $\bar{N}$ & पu & 0 & 5 & $\mathrm{~T}$ & $\bar{D}$ & $\overrightarrow{\mathrm{H}}$ & $\mathrm{E}$ & 0 & $I$ & & $E$ & $\mathbb{N}$ & $\mathrm{R}$ & \\
\hline$\overline{\mathrm{G}}$ & 0 & 6 & 0 & 5 & $\overline{0}$ & $R$ & \begin{tabular}{l|l}
$I$ \\
\end{tabular} & $B$ & $\mathbb{N}$ & I & $\bar{A}$ & $\bar{R}$ & $\overline{\mathrm{N}}$ & $\bar{E}$ & I & N & $\bar{E}$ & $R$ & $\bar{I}$ & 5 & \\
\hline 5 & $\bar{N}$ & D & $E$ & 0 & $\bar{p}$ & $\mathrm{~L}$ & $\overline{0}$ & $5]$ & [ & $\bar{S}$ & I & $M$ & $\bar{c}$ & $\bar{G}$ & $M$ & $\bar{E}$ & II & A & $\bar{W}$ & Ni & $\bar{B}$ \\
\hline$M$ & $\bar{A}$ & $\mathbb{R}$ & $\bar{T}$ & $E$ & $\bar{N}$ & $\mathrm{H}$ & 0 & $F$ & K & $\bar{E}$ & $\mathbb{R}$ & $y$ & $\overline{\mathrm{A}}$ & $\bar{A}$ & $\underline{E}$ & $T$ & N & $\mathbb{E}$ & $R$ & A & \\
\hline$\overline{\mathrm{A}}$ & $\overline{\mathrm{S}}$ & $\mathbb{N}$ & D & $M$ & $\bar{A}$ & $R$ & $I$ & $E$ & $\mathrm{H}$ & $E$ & $L$ & $\mathbb{E}$ & $\mathbb{N}$ & $E$ & 1 & $E$ & N & 0 & $\mathrm{E}$ & 9 & \\
\hline$M$ & $A_{1}$ & $R$ & $\bar{c}$ & $E$ & $\bar{L}$ & $B$ & 0 & $R$ & $\mathrm{G}$ & $\bar{E}$ & $\mathbb{R}^{2}$ & 3 & $T$ & $E$ & $\mathbb{P}$ & $\bar{N}$ & $\overline{\mathrm{A}}$ & & U & $F$ & \\
\hline & - & & LI & & & & M] & & & A & & $t$ & & s. & & & & & & & \\
\hline
\end{tabular}

\section{Promotion Team}

Marcel Borgers

Guillaume van Eys

Jannie Ausma

\section{Review Board}

Rob Reneman

Harry Grijns

Marten Hofker

Frans Ramaekers

Be Wieringa

Paramimfen

Hans Duimel

Sander Rensem

\section{Last line of Defense John Canty}

Joep Geraedts

Maurits Allessie

Pieter Doevendans

Habo Jongsma

Technical support

Helma Kuijpers

Marie-Helene Lenders

Erwin van Ankeren

Francine Teng

\section{Collaborators}

Luisa Gorza

Bianca Brundel
Isabelle van Gelder

Huub van der Velden

\section{Students}

Geert Koene

Saskia Brinkman

Mayriam Stijns

Sequencing Team

Berry Soute

Henry Spronck

Musícal Support

Rainbirds

Soundgarden

\section{BedankPuzzel}

Helaas is een dankwoond nooit volledig. Voor eenieder die teleurgesteld. verdnetig danwet verontwardiad is ondat ziju/haar nam niet in het damkwoord vorlkomt vormt deze puzzel de oplosing. Hat doel van de puratel is tweeledig. Allereerst stelt: hilj je in staat je frustaties bot te vieren op allo mensen die we genoend zinjn in het dankwoond. Darmaast streelt de oplossing wan de puzzet het gederkte ego.

Zoek de namen wan de lijst in her diagram en streep ze door met een pen danwel een dikke zwarte stift. De namen staan hortizontaal, werthcal ent diagonal werborgen in de letterbrij. Een aantal namer stad zelfs anterscevoren (how moeilijk kun je thet naken...). De letters die overbljuen vomen cart hoostende en heilzame ophossing. Verel succes...

\section{Left-overs}

MCB

Huub Kreume!

Kanslozen

Last but not Least

LudoMia

GeWiekst

MamaMia

Rachel 



\section{Appendix | References |}

1. Myerbarg R, Kessler KM, Castellanos A, O Rourke RA, Roberts $\mathrm{K}_{\text {, }}$ Sonnenblick EH. Recognition, clmical assesment, and managenent of arthythmias and conduction distubances. In: Alexander RW, Schant RC. Fuster V, eds. Hurst s The Heart. 9 ad. New York MoGraw-Hill; 1998:873-94l.

2. Feinberg WM, Blackshem $\mathrm{L}$, Laupacis A. Kronmal R, Har RG. Prevalence, age distribution, and gender of patients with atral fibribation. Anatysis and implications, Arch Intern Med. 1995;155:469.73.

3. Benjamin ES, Levy D, Vazir SM, D'Agostino RB, Belanger A, Wolf PA. Independent risk factors for atrial fibrillation in a population-based cohort. The Framingham Hear Study. Jowh. 1994,271:849-4.

4. Krahn AD, Manfredis, Tate RB, Mahewson FA, Cuddy TE. The natural history of atrial fibrilltion: incidence, risk factors, and prognosis in the Manitoba Follow-Up Study Am I Med 1995;98:476-84.

5. Wolf $\mathrm{PA}$, Abbott RD, Kamel WB. Atral fibrillation as an independent risk factor for stroke: the Framingham study. Stroke. 1991;22:983-988.

6. Trueken $T$, Lindenstrom $E$, Boysen $G$. Comparison of probability of stroke between the Copenhagen City Heart Sudy and the Framinghan Study. Stroke. 1994,25:802-7.

7. Benjamin EJ, Wol PA, D'Agostino RB, Sibershatz H, Kannel WB, Levy D. Impact of atrial fibrillation on the risk of death: the ramingham Heat Study. Circtlation. 1998;98946-52.

8. Lewis T Drury AN Ifiescu CC A denonstration of circus movenent in chical

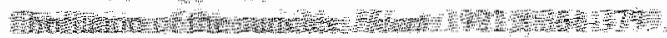

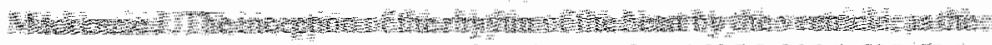

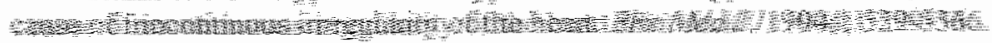
HWA

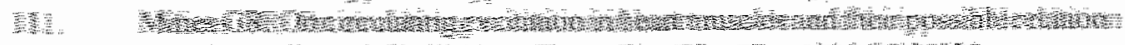

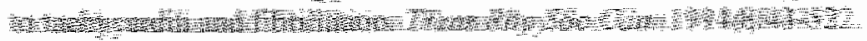

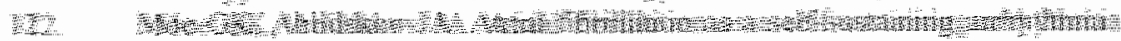

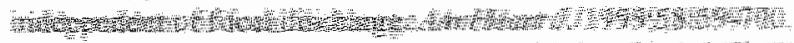

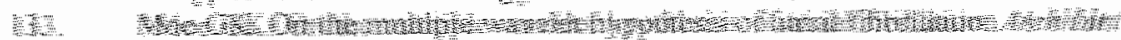
Ar

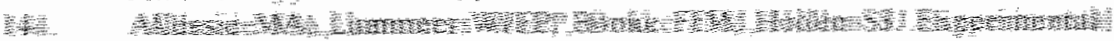

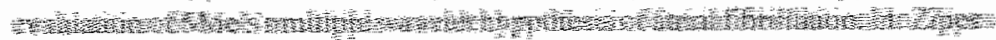

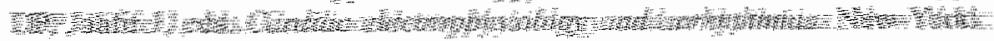

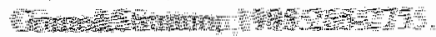

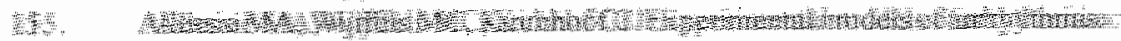

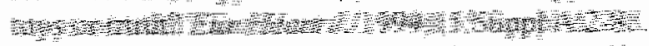

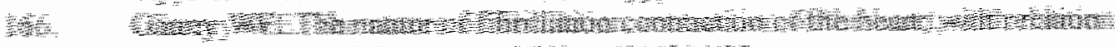

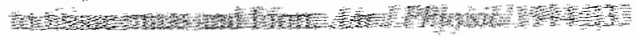


18. Powell AC, Garan H, McGovern BA, Fallon JT, Krishnan SC, Ruskin $\mathbb{N}$. Low energy conversion of atrial fibrillation in the sheep. $J$ Am Coll Cardiol. 1992;20:707-11.

19. Whittington JR, Cross MR, Raftery EB. An effective conscious animal model of atrial fibrilation. Cardiovasc Res. 1979,13:105-12.

20. Elvan A. Pride HP, Eble JN, Zipes DP. Radiofirequency catheter ablation of the atria reduces inducibillty and duration of atrial fibrillation in dogs. Circulation. 1995;91:2235-44.

21. Iskos D, Lurie KG, Adler SW, Shultz IJ, Coffeen PR, Mulligan KA, Benditt DG. Effect of parenteral d-sotalol on transvenous atrial defibrillation threshold in a canine model of atrial fibrillation. Am Hear J. 1996;132:116-9.

22. Gray RA, Pertsov AM, Jalife J. Incomplete reentry and epicardial breakthrough pattens during atrial fibrillation in the sheep heart. Circulation. 1996;94:2649-61.

23. Gaspo R, Bosch RF, Talajic M, Nattel S. Functional mechanisms underlying tachycardia-induced sustained atrial fibrillation in a chronic dog model. Circulation. 1997;96:4027-35.

24. Yue L, Feng J, Gaspo R, Li GR, Wang Z, Nattel S. Ionic remodeling underlying action potential changes in a canine model of atrial fibrillation. Circ Res. $1997 ; 81: 512-25$.

25. Manning WJ, Silverman DI, Katz SE, Riley MF, Come PC, Doherty RM, Munson JT, Douglas. PS. Impaired left atrial mechanical function after cardioversion: relation to the duration of atrial fibrillation. $J$ An Coll Cardiol. $1994: 23: 1535-40$.

26. Shapiro EP, Effron MB, Lima S, Ouyang P, Siu CO, Bush D. Transient atrial dysfunction after comversion of chronic atrial fibrillation to simus rhythm. $A \mathrm{~m}$ I Cardial. 1988;62:1202-7.

27. Daoud EG, Marcovitz P, Knight BP, Goyal R, Man KC, Strickberger SA, Armstrong WF, Morady F. Short-term effect of atrial fibrillation on atrial contractile function in humans. Circulation. 1999,99:3024-7.

28. Van Gelder IC, Crijns HI, Blanksma PK, Landsman ML, Posma IL, Van Den Berg MP. Meijler FL, Lie KI. Time course of hemodynamic changes and improvenent of exercise tolerance after cardioversion of chronic atrial fibrillation unassociated with cardiac valve disease. Am $J$ Cardiol. $1993 ; 72: 560-6$.

29. Mary-Rabine L, Abert A, Pham TD, Hordof A, Fenoglio JJ, Jr., Malm JR, Rosen MR. The relationship of human atrial cellular electrophysiology to clinical function and ultrastructure. Circ Res. 1983;52:188-99.

30. Frustaci A, Chimenti C, Bellocei F, Morgante E, Russo MA, Maseri A. Histological substrate of atrial biopsies in patients with lone atrial fibrillation. Circulation. 1997;96:1180-4.

31. Thiedemann $K U$, Ferrans VJ. Left atrial ultrastructure in mitral valvular disense. Am J Pathol. 1977;89:575-604.

32. Ausma J, Wijffels M, Thone F, Wouters L, Allessie M, Borgers M. Suructural changes of atrial myocardium due to sustained atrial fibrillation in the goat. Circulation. 1997;96:3157-63.

33. Ausma J, Wiffels M, wan Eys G, Koide M, Ramaekers F, Allessie M, Borgers $M$. Dedifferentiation of atrial cardiomyocytes as a result of chronic atrial fibrillation. Am I Pathol. 1997;151:985-97.

34. Boyden PA, Tilley LP, Pham TD, Liu SK, Fenoglic JJ, Jr., Wit AL. Effects of left atrial enlargement on atrial transmembrane potentials and structure in dogs with mitral valve fibrosis. Am I Cardiol 1982;49:1896-908.

35. Dispersyn GD, Ausma J, Thone F, Flameng W, Vanoverschelde JL, Allessie MA, Ramaekers FC, Borgers M. Cardiomyocyte remodelling during myocardial hibernation and atriad fibrillation: prelude to apoptosis. Cardiovasc Res. 1999;43:947-57. 
36. Ausma J, Lenders M-H, Mast F, Allessie MA, Ramackers F, Wouters L, Thoné F, Borgers $M$. Time course of structural clanges due to atrial fibrillation in the goat. Circulation. 1998:98:1683 (abstract).

37. Ausma J, Ramaekers FCS, Allessie MA, Mast F, Borgers M. Time course of cardiomyocyte dedifferentiation due to atrial fibrillation in a goat model. $J$ Mol Cel Card 1999;31:A62.

38. White CW, Kerber RE, Weiss HR, Marcus ML. The effects of atrial fibrillation on atrial pressure-volume and fow relationships. Circ Res. 1982,51:205-15.

39. Jayachandran $\mathrm{V}$, Winkle W, Sih HJ, Zipes DP, Olgin JE. Chronic atrial fibrillation from rapid atrial pacing is associated with reduced atrial blood flow: a positron emission tomography study. Circulation. 1998;98:1209.

40. Borgers M., Thoné F, Wouters L, Ausma J, Shivalkar B, Flameng W. Structural correlates of regional myocardial dystunction in patients with critical coronary artery stenosis: chronic hibernation? Cardiovasc Pathol. 1993;2:237-245.

41. Ausma J, Schaart G, Thoné F, Schivalkar B, Flameng W, Depré C, Vanoverschelde I- $L$, Ramaekers F, Borgers $M$. Chronic ischemic viable myocardium in man: aspects of dedifferentiation. Cardiovasc pahol. 1995:4:29-37.

42. Ausma J, Thoné F, Dispersyn GD, Flameng $W$, Vanoverschelde $\|$ L, Ramaekers $\mathrm{FC}$, Borgers $M$. Dedifferentiated cardiomyocytes from chromic hibernating myocardium are ischemia-tolerant. Mol Cell Biochem. $1998 ; 186: 159-68$.

43. Ausma J, Coumans W, Duimel $H_{3}$ van der Vusse GJ, Allessie MA, Borgers M. Atrial high energy phosphate content and mitochondrial enzyme activity during chronic atrial fibrillation. Cardiovasc Res. 2000;47:788-96.

44. Leistad E, Aksnes G, Verburg E, Christensen G. Atrial contractile dysfunction after short-term atrial fibrillation is reduced by verapamil bul increased by BAY K8644. Cinculation. 1996;93:1747-54.

45. Buttrick PM, Malhotra A, Brodman R, MoDermott L, Lam L. Myosin isoenzyme distribution in overloaded human atrial tissue. Circulation. $1986 ; 74: 477-83$.

46. Naruse M, Hiroe M, Naruse K, Nagata M, Ohno H, Hashimoto A, Koyanagi $H$, Sekiguchi $M$, Demura $H$, Hirosawa $K$, ef al. Increased levells of betahuman atrial natriuretic peptide-like immunoreactivity in chronically overloaded atrial tissue. Am J Hypertens. 1990;3:105-10.

47. Sadoshima J, Takahashi T, Jahn L, Izumo S. Roles of mechano-sensitive ion channels, cytoskeleton, and contractile activity in stretch-induced immediateearly gene expression and hypertrophy of cardiac myocytes. Proc Nall Acad Sci USA. 1992;89:9905-9.

48. Christensen $G_{3}$ Leistad E. Atrial systolic pressure, as well as stretch, is a principal stimulus for release of ANF. Am J Physiol. 1997;272:H820-6.

49. Yanazaki T, Komuro I, Kudoh S, Zou Y, Shiojima I, Mizuno T, Takano H, Hiroi $\mathrm{Y}$, Ueki $\mathrm{K}$, Tobe $\mathrm{K}$, et all. Angiotensin II partly mediates mechanical stress-induced cardiac hypertrophy. Circ Res. 1995;77:258-65.

50. Yamazaki T, Komuro I, Yazaki Y. Molecular mechantsm of cardiac cellular hypertrophy by mechanical stress.J Mol Cell Cardiol. 1995;27:133-40.

51. Yamazaki T, Komuro 1, Kudoh $\$$, Zou $Y$, Shiojima I, Hiroi $Y$, Mizuno T, Maemura K, Kurihara H, Aikawa R. Takano H, Yazaki Y. Endothelin-l is involved in mechanical stress-induced cardiomyocyte hypertrophy. $J$ Biol Chem. 1996;271:3221-8.

52. Sideris DA, Toumanid is ST, Tselepatiotis E, Kostopoulos K, Stringli T, Kitsiou T, Moulopoulos SD. Atrial pressure and experimental atrial fibrillation. Pacing Clin Electrophysiol. 1995;18:1679-85.

53. Zipes DP. The seventh annual Gordon $\mathbb{K}$ Moe Lecture. Atrial fibrillation: from cell $t$ bedside. J Cardiowasc Elecrophysiol. 1997;8:927-38. 
54. Nijjar MS, Dhalla NS. Biochemical basis of calcium handing in developing myocardium. In: Ost'adal $B$, Nagano $M$, Takeda $N$, Dhalla NS, eds. The developing heart. I d. Philadelphia: Lippincot-Raven publishers; 1997:189-217.

55. Vomanen M. Postnatal changes in cardiac calcium regulation. In: Ost'adal $B$, Nagano $M$, Takeda $N$, Dhalla NS, eds. The developing heart. Philadelphia: Lippincott-Raven publishers; 1997:219-229.

56. Leistad E, Borgers M., Christensen $G$. Atrial contractile dysfunction after shortterm atrial fibrillation can be explained by changes in intracellular calcrum, but not by atrial ischemia. Circulation. 1996;94:1386-387.

57. Goette $\mathrm{A}$, Honeycutt $\mathrm{C}$, Langberg $\mathrm{JJ}$. Electrical remodeling in atrial fibrillation. Time course and mechanisms. Circulation. 1996,94:2968-74.

58. Tieleman RG, De Langen C, Van Gelder IC, de Kam PJ, Grandjean J, Bel KJ, Wijffels MC, Allessie MA, Crijns HJ. Verapamil reduces tachycardia-induced electrical remodeling of the atria. Circulation. 1997:95:1945-53.

59. Ausma I, Dispersyn GD, Duimel H, Thone F, ver Donck L, Allessie MA, Borgers M. Changes in ultrastructural calcium distribution in goat atria during atrial tibrillation. J Mol Cell Cardiol, 2000;32;355-64.

60. Sun H, Gaspo R, Leblanc $\mathrm{N}$, Nattel S. Cellular mechanisms of atrial contractile dysfunction caused by sustained atrial tachycardia. Circulation. 1998;98:719. 27.

61. Sun $\mathrm{H}$, Leblanc $\mathrm{N}, \mathrm{Nattel} \mathrm{S}$. Mechanisms of inactivation of L-type calcium channels in human atrial myocytes. Am J P/hysiol. 1997;272:H1625-35.

62. Gomez JP, Potreau D. Branka JE, Raymond G. Developmental changes in $\mathrm{Ca} 2$ + currents from newborn rat cardiomyocytes in primary culture. Pflugers Arch. 1994:428:241-9.

63. Wetzel GT, Chen F, Klitzner TS. Ca2+ channel kinetics in acutely isolated fetal, neonatal, and adult rabbit cardiac myocytes. Circ Res. 1993;72:1065-74.

64. Sharp WW, Terracio L, Borg TK, Samarel AM. Contraciile activity modulates actin synthesis and tumover in cultured neonatal rat heart cells. Circ Res. 1993;73:172-83.

65. Van Wagoner DR, Pond AL, McCarthy PM, Trimmer IS, Nerbonne JM. Outward $\mathrm{K}+$ current densities and KVI.5 expression are reduced in chronic human atrial fibrillation. Circ Res. 1997,80:772-81.

66. Gaspo R, Bosch RF, Bou-Abboud E, Nattel S. Tachycardia-induced changes in Nat current in a chronic dog model of atrial fibrillation. Circ Res. $1997 ; 81: 1045-52$.

67. Duff HJ, Offord J, West $J$, Catterall WA. Class I and IV antiarrhythmic drugs and cytosolic catcium regulate mRNA encoding the sodium channel alpha subunit in rat cardiac muscle. Mol Pharmacot. 1992;42:570-4.

68. Liang P, Pardee AB. Differential display of eukaryotic messenger RNA by means of the polymerase chain reaction. Science. 1992;257:967-71.

69. Tyagi SC, Kumar S, Voelker DI, Reddy HK, Janicki IS, Curtis JJ. Differential gene expression of extracellular matrix components in dilated cardiomyopathy. JCell Biochen. 1996;63:185-98.

70. Strokman $\mathrm{G}$ Humphries DE, Bing OH. Endogenous retroviral transcripts in myocytes from spontaneouslly hypertensive rats. Hypertension. 1997;30:88-93.

71. Singh K, Sirokman G, Communal C, Robinson KG, Conrad CH, Brooks WW, Bing $\mathrm{OH}_{\text {, Coluce }}$ WS. Myocardial osteopontin expression coincides with the development of heart failure Hypertension. 1999;33:663-70.

72. Venkataraman R, Presser J, Vaillancourt RE, West AK. Identification of a new noradrenaline induced gene in the rat heart by differential mRNA display. Cardiovase Res. 1995;29:490-4.

73. Cormier-Regard $\mathrm{S}$, Egeland DB, Tannoch VJ, Claycomb WC. Differential display: identifying genes involved in cardionyocyte proliferation. Mol Cell Biochem. 1997;1172:111-20. 
74. Utans U, Liang P, Wyner LR, Kamovsky MJ, Russell ME. Chronic cardiac refection: identification of five upregulated genes in transplanted hearts by differential mRNA display. Proc Nall Acad Sci U S A. 1994;91:64637.

75. Manning W1, Leeman DE, Gotch PJ, Come PC. Pulsed Doppler evaluation of atrial mechanical function after electrical cardioversion of atrial fibrillation. $J$ Am Coll Cardiol. 1989;13:617-23.

76. Cote $\mathrm{G}$, Mohiuddin SM, Roy PE. Occurrence of Z-band widening in human atrial cells. Exp Mol Panol. 1970;13:307-18.

77. Aimé-Sempe C, Folliguet T, Rucker-Martin C, Krajewska M, Krajewska S, Heimburger M, Aubier M, Mercadier J, Reed JC, Hatem SN. Myocardial cell death in fibrillating and dilated human right atria. J Am Coll Cardiol. 1999;34:1577-86.

78. Flameng W, Wouters $L$, Sergeant P, Lewi $\mathbb{P}$, Borgers M, Thone F. Suy $\mathbb{R}$. Multivariate analysis of anglographic, histologic, and electrocardiographic data in patients with coronary heart disease. Cirolation. 1984;70:7-17.

79. Thijssen VLJ, Ausma 1, Liu GS, Allessie MA, van Eys GI, Borgers M. Structural Changes of Atrial Myocardium During Chronic Atrial Fibrilation. Cardiovase Pathol. 2000;9:17-28.

80. Haunstetter A, Izumo S. Apoptosis: basic mechanisms and implications for cardiovascular disease. Circ Res. 1998;82:1111-29.

81. Anversa P, Leri A, Beltrami CA, Guerra $\mathrm{S}$, Kajstura J. Myocyte death and growth in the failing heart. Lab lmest. 1998;78:767-86.

82. Elsasser A, Schlepper M, Klovekorn WP, Cai WJ, Zimmermann R, Muller KD, Strasser R, Kostin S, Gagel C, Munkel B, Schaper W, Schaper J. Hibernating myocardium: an incomplete adaptation to ischemia. Circulation. 1997;96:2920-31.

83. Freude B, Masters TN, Kostin S, Robicsek F, Schaper J. Cardiomyocyte apoptosis in acute and chronic conditions. Basic Res Cardiol 1998;93:85-9.

84. Schaper I. Lorenz-Meyer $S$, Suzuki $K$. The role of apoptosis in dilated cardiomyopatliy. Herz. 1999,24:219-24.

85. Otivett $G$, Abbi R, Quaini F, Kajstura J, Cheng W, Nitahara JA, Quaimi E, Di Loreto C, Beltrami CA, Krajewski S, Reed JC, Anversa P. Apoptosis in the failing human heart. $N$ Engl J Med. 1997;336:1131-41.

86. Pirolo JS, Hutchins GM, Moore GW. Myocyte vacuolization in infaret border zones is reversible. An J Pathol. 1985;121:444-50.

87. AdN, Snir E, Vidne $13 A$, Golomb E Potential preoperative markers for the risk of developing atrial fibrillation ater carduc surgery. Semin Thorac Cardiovase Surg. 1999;11:308-13.

88. Wouters L, Liu G-S, Flameng W, Thissen V, Thond F, Borgers M. Structural remodelling of atrial myocardium in patients with cardiac valve disease and atrial fibrillation. Exp Clin Cardiol. 20015:5:158-163.

89. Thijsen V, Ausma J, Borgers M. Structural renodelling during chronic atrial fibrillation: act of programmed cell survival. Cardiovasc Res, 2001;52:14-20.

90. Ausma J, Borgers M, Allessie MA. Struchural changes due to atrial fibrillation: resemblance with hibemation and dedifferentiation. In: Santini M, ed. Progress in Clinical Pacing 2000. Rome: Tipolithografia Fernando Begliomini; 2000:198-205.

91. Wikinson JM, Grand R. Comparison of amino acid sequence of troponin 1 from different striated muscles. Nature. 1978;271:31-5.

92. Cummins P, Perry SV. Troponin I from human skeletal and cardiac muscles. Biochem J. 1978;171:251-9.

93. Sasse $\mathrm{S}$, Brand NJ, Kyprianou P, Dhoot GK, Wade R, Arai M, Periasamy M, Yacoub MH, Barton PJ. Troponin I gene expression during humarn cardiac development and in end- stage heart failure. Circ Res. 1993;72:932-8. 
94. Bhavsar PK, Dhoot GK, Cumming DV, Butler-Browne GS, Yacoub $M H$, Barton PJ. Developmental expression of troponin $I$ isoforms in fetal human heart. FEBS Lett. 1991;292:5-8.

95. Hunkeler NM, Kullman J, Murphy AM. Troponin I isoform expression in human heart. Circ Res. 1991;69:1409-14.

96. Gorza L, Ausoni S, Merciai N, Hastings KE, Schiaffino S. Regionall differences in troponin I isoform switching during rat heart development. Dev Biol. $1993 ; 156: 253-64$.

97. L'Ecuyer TJ, Schulte D, Lin JJ. Thin filament changes during in vivo rat heari development. Pediatr Res. $1991 ; 30: 232-8$.

98. Saggin L, Gorza L, Ausoni S, Schiaffino S. Troponin I switching in the developing heart. J Biol Chem. 1989:264:16299-302.

99. Sabry MA. Dhoot GK. Identification and pattern of expression of a developmental isoform of troponin I in chicken and rat cardiac muscie. $J$ Muscle Res Cell Motil. 1989;10:85-91.

100. Ausoni S, De Nardi C, Moretti P, Gorza L, Schiaffino S. Developmental expression of rat cardiac troponin I mRNA. Development. 1991:112:104 L-51.

101. Martin AF, Ball K, Gao LZ, Kumar P, Solaro RJ. Identification and functional significance of troponin I isoforms in neonatal rat heart myofibrils. Civc Res. $1991 ; 69: 1244-52$.

102. Reiser PJ, Westfall MV, Schiaffino S, Solaro RJ. Tension production and thinfilament protein isoforms in developing rat myocardium. Am J Physiol. $1.994 ; 267: H 1589-96$.

103. Zakhary DR, Moravec CS, Stewart RW, Bond M. Protein kinase A (PKA)dependent troponin-1 phosphorylation and PKA regulatory subunits are decreased in human dilated cardiomyopathy. Circulation. 1999;99:505-10.

104. Bodor GS, Oakeley AE, Allen PD, Crimmins DL, Ladenson JH, Anderson PA. Troponin I phosphorylation in the normal and failing adult human theart. Circulation. 1997:96:1495-500.

105. McConnell BK, Moravec CS, Bond M. Troponin I phosphorylation and myofilament calcium sensitivity during decompensated cardiac hypertrophy. Am I Physiol. 1998;274:H385-96.

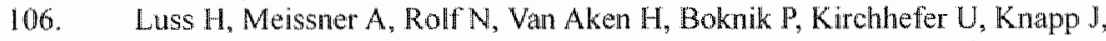
Laer S, Linck B, Luss I, Muller FU, Neumann J, Schmitz W. Biochemical mechanism(s) of stunning in conscious dogs. Am J Physiol Heart Circ Physiol. 2000;279:41176-84.

107. Gaw WD, Aar D, Liu Y, Perez NG Murphy AM, Marban E. Role of troponin I proteolysis in the pathogenesis of stunned myocardium. Circ Res. 1997;80:393-9.

108. Van Eyk JE, Powers F, Law W, Larue C, Hodges RS, Solaro RJ. Breakdown and release of myofilament proteins during ischenia and ischemia/reperfusion in rat hearts: identification of degradation products and effects on the pCaforce relation. Circ Res, 1998:82:261 71.

109. McDonough JL, Arrell DK, Van Eyk JE. Troponin I degradation and covalent complex formation accompanies myocardial ischemia/reperfusion injury. Circ Res. 1999:84:9-20.

110. Kositprapa C, Zhang B, Berger S, Canty J, Lee T. Calpain-mediated proteolytic cleavage of troponin I induced by hypoxia or metabolic inhibition in cultured neonatal cardiomyocytes. Mol Cell Biochem. 2000;214:47-55.

111. Feng J, Schaus BJ, Fallavollita JA, Lee TC, Canty JM, Jr. Preload Induces Troponin I Degradation Independently of Myocardial Ischemia. Circulation. 2001;103:2035-2037.

1112. Brundel BJM, Ausma J, wan Gelder IC, Crijns HJGM, van Gilst WH, Tieleman $R G$ Van Der Want JlL, Henning RH. Calpain activity is related to ion-channel, structural and electrical remodeling in human paroxysmal and persistent atrial fibrillation. (Thesis). 2000. 


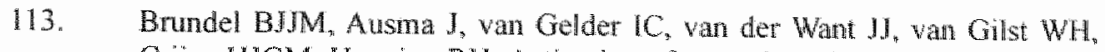
Crijns HJGM, Heming RH. Activation of proteolysis by calpains in human paroxysmal and persistem atrial fibrillation. Cardiowarc Res. 2002;54:380\%.

114. Tuinenburg AE, Brundel BJ, Van Gelder $1 \mathrm{C}$. Henning $\mathrm{RH}$, Van Den Berg MP. Driessen C, Grandjean JG, Van Gilst WH, Crijns HJ. Gene expression of the natriuretic peptide system in atrial tissue of patients with paroxysmal and persistent atrial fibrillation. J Cardiovosc Electrophysiol. 1999,10:827-35.

115. Brundel BJ, wan Gelder IC, Herning RH, Tumenburg AE, Deelman LE, Tieleman RG, Grandjean JG, van Gilst WH, Crijns H. Gene expression of proteins influencing the calcium homeostasis in patients with persistent and paroxysmal atrial fibrillation. Cardiovase Res. 1999,42:443-54.

116. Gibson UE, Heid CA. Williams PM. A novel method for real time quantitative RT-PCR. Genome Res. 1996;6:995-1001.

117. Heid CA, Stevens J, Livak KJ, Willians PM. Real time quantitative PCR. Genone Res. 1996;6:986-94.

118. Westfall MV, Albayya FP, Metzger JM. Functional analysis of troponin I regulatory domains in the intact myofilament of adult single cardiac myocytes. $J$ Biol Chem. 1999;274:22508-16.

119. McDonough JL, Labugger R, Picket W, Tse MY, Mackenzie S, Pang SC, Atar D, Ropchan G, Van Eyk IE. Cardiac troponin I is modified in the myocardium of bypass patients. Circulation. 2001:103:58-64.

120. Thomas SA, Fallavollita JA, Lee TC, Feng J, Canty JM, Jr. Absence of troponin I degradation or altered sarcoplasmic reliculum uptake protein expression after reversible ischemia in swine. Circ Res. 1999;85:446-56.

121. Vitadello M, Ausma J, Borgers M, Gambino A, Casarotto DC, Gorza L. Increased myocardial GRP94 amounts during sustained atrial fibrillation: a protective response? Circulation. 2001,103:2201-6.

122. Wattanapermpool $J$, Guo $X$, solaro RJ. The unique amino-terminal pepide of cardiac troponin I regulates myofibrillar activity only when it is phosphorylated. I Mol Cell Cardiol. 1995;27:1383-91.

123. Ray KP, England PJ. Phosphorylation of the inhibitory subunit of troponin and its effect on the calcium dependence of cardiac myolibril adenosine triphosphatase. FEBS Lett. 1976;70:11-6.

124. Noland TA, Jr., Guo X, Raynor RL, Jideama NM, Averyhart-Fullard V, Solaro RI, Kuo JF. Cardiac troponin I mutants. Phosphorylation by protein finases $\mathrm{C}$ and $\mathrm{A}$ and regulation of $\mathrm{Ca}(2+)$-stimulated MgATPase of reconstituted actomyosin S-1.J Biol Chem. 1995:270:25445-54.

125. Adamcova M, Pelouch V. Isoforms of troponin in normal and diseased myocardium. Physiol Rex. 1999:48:235-47.

126. Borgers $M$, De Nollin $S$, Thone F, Wouters L, Van Vaeck L, Flameng W. Distribution of calcium in a subser of chronic hibernating myocardium in man. Histochem J. 1993:25:312-8.

127. Wijfels MC, Kirchihof CJ, Dorland R, Allessie MA. Atrial fibrillation begets atrial fibrillation. A study in awake chronically instrumented goats. Circulation. 1995:92:1954-68.

128. van der Velden HM, wan Kempen MJ, Wijfels MC, van Zijverden M, Groenewegen WA, Allessie MA, Jongsma H. Altered pattern of connexin40 distribution in persistent atrial fibrillation in the goat. I Cardiovase Electrophysiol. 1998:9:596-607.

129. Schotten U, Ausma J, Stellbrink C, Sabatschus I, Vogel M, Frechen D, Schoendube $F$, Hanrath P, Allessie MA. Cellular Mechanisns of Depressed Atrial Contractility in Patients With Chronic Atrial Fibrillation. Circalation. 2001;103:691-698.

130. Ausma J, Coumans WA, Dumel H, Van der Vusse GJ, Allessie MA, Borgers M. Atrial high energy phosphate content and mitochondrial enzyme activity during chronic atrial fibrillation. Cardiovase Res. 2000;47:788 96 . 
131. Yue L, Melnyk P, Gaspo R, Wang Z, Nattel S. Molecular mechanisms underlying ionic remodeling in a dog model of atriall fibrillation. Circ Res. $1999 ; 84: 776-84$.

132. van der Velden HMW, van der Zee $L$, Wijfels $M C$, van Lewven $C$, Dorland $R$, Vos MA, Jongsma HU, Allessie MA Atrial fibrillation in the goat induces changes in monophasic action potential and mRNA expression of ion channels involved in repolarization. I Cardiowasc Electrophysiol. 2000;11:1262-9.

133. Van Gelder IC, Brundel BJ, Henning RH, Tuinenburg AE, Tieleman RG, Deelman L, Grandjean JG, De Kam PJ, Van Gilst WH, Crijns HJ. Alterations in gene expression of proteins inwolved in the calcium handling in patients with atrial fibrillation. I Cardiovase Electrophysiol. 1999;10:552-60.

134. Lai LP, Su MI, Lin JL, Lin FY, Tsai CH, Chen YS, Huang SK, Tseng YZ, Lien WP. Down-regulation of L-type calcium channel and sarcoplasmic reticular $\mathrm{Ca}(2+)$-ATPase $m$ RNA in human atrial fibrillation without significant change in the mRNA of ryanodine receptor, calsequestrin and phospholamban: an insight into the mechanism of atrial electrical remodeling. $J$ Am Coll Cordiol. 1999;33:1231.7.

135. Brundel $B J_{*}$ Van Gelder IC, Henning RH, Tieleman RG, Tuinenburg AE, Wietses M, Grandjean JG, Van Gilst WW, Crijns HJ. Ion Channel Remodeling Is Related to Intraoperative Atrial Effective Refractory Periods in Patients With Paroxysmal and Persistent Atrial Fibrillation. Circulation. 2001;103:684690 .

136. Lai LP, Su MJ, Lin JL, Lin FY, Tsai CH, Chen YS, Tseng YZ, Lien WP, Huang SK. Changes in the mRNA levels of delayed rectifier potassium channels in human atrial fibrillation. Cardiology. 1999;92:248-55.

137. Brundel BJIM, Van Gelder IC, Henning RH, Tuinenburg AE, Wietses M, Grandjean $\mathrm{JG}_{3}$ Wilde AAM, Van Gilst WH, Crijns HJGM. Alterations in potassium channel gene expression in atria of patients with persistent and paroxysmal atrial fibrillation: differential regulation of protein and $\mathrm{mRNA}$ levels for K+ channels. J Am Col Cardiol. 2001;37;926-932.

138. Wan der Velden HM, Jongsma HJ. Connexin types and distribution in normal and electrically remodeled atria. In: Santini M, ed. Progress in Clinical Pacing 2000. Rome: Tipolitograha Fernando Begliomini; 2000:190-197.

139. Van der Velden HM, van Kempen MJ, Groenewegen WA, Jongsma HJ. Comparative analysis of the distribution of the gap junction proteins connexins 40 and 43 in chronic atrial fibrillation (AF) in patients and a goat model. Circulation. 1997;96:1-237 (abstract).

140. Kanganatnan P. Severs NJ, Peters NS. The relationship between conduction, activation pattem and quantity of immunoreactive connexin in chronic human atrial fubrillation. Eur Hearr J. 2000;21:240 (abstract).

141. Dupont E, Ko Y, Rothery S, Coppen SR, Baghai M, Haw M, Severs NJ. The Gap-junctional protein connexin 40 is elevated in patients susceptible to postoperative atrial fibrillation. Circulation. 2001;103:842-9.

142. van der Velden HM, Ausma I, Rook MB, Hellemons AJ, van Veen TA, Allessie $\mathrm{MA}$, Jongsma $\mathrm{HJ}$. Gap junctional remodeling in relation to stabilization of atrial fibrillation in the goat. Cardiovase Res. 2000;46:476-86.

143. Schotten $U$. Allessie $M$. Electrical and contractile remodeling during atrial fibrillation go hand-in-hand. P.CE. 2001:24:572 (abstract).

144. Yu WC, Lee SH, Tai CT, Tsai CF, Hsieh MH, Chen CC, Ding YA, Chang MS, Chen SA. Reversal of atrial electrical remodeling following cardioversion of long-standing atrial fibrillation in man. Cardiovasc Res. 1999:42:470-6.

145. Manios EG, Kanoupakis EM, Chlouverakis GI, Kaleboubas MD, Mavrakis HE, Vardas PE. Changes in atrial electrical properties folliowing cardioversion of chronic atrial fibrillation: relation with recurrence. Cardiovase Res. $2000 ; 47: 244-53$. 
146. Elvan A, Wylle K. Zipes DP. Pacinginduced chronic atral fibrillation mpairs sinus node function in dogs. Electrophysiological remodeling. Circulation. 1996;94:2953-60.

147. Ewerett THL, Li H, Mangnum JM, McRury ID, Mitchell MA, Redick JA, Haines DE. Electrical, morphological, and ultrastrucural remodeling and treverse rumodeling in a canine model of chronic atrial fibrillation. Circulation. 2000;102:1454-60.

148. Allessie MA. Atrial electrophysiologic remodeling: another vicious circle? $J$ Cardiowasc Electrophysiol. 1998;9:1378-93.

149. Mou L, Miller H, Li J, Wang E, Chalifour L. Improvements to the differential display method for gene analysis. Biochem Biophys Res Commun. 1994:199:564-9.

150. Gros D, Jarry-Guichard T, Ten Velde I, de Maziere A, van Kempen MI, Davoust J, Briand JP, Moorman AF, Jongsma HJ. Restricted distribution of connexin 40 , a gap junctional protein, in mammalian heart. Circ Res. 1994;74:839-51.

151. Delorme B, Dahl E, Jarry-Guichard T, Marics I, Briand JP, Willecke K, Gros $D$, Theveniau-Ruissy M. Developmental regulation of comnexin 40 gene expression in mouse heart correlates with the differentiation of the conduction system. Dev Dyn. 1995;204:358-71.

152. Bater D, Muller H, Reich J, Riedel H, Ahrenkiel V, Warthoe P, Strauss M. Identification of differentially expressed mRNA spectes by an improved display technique (DDRT-PCR). Nucleic Acids Res. 1993;21:4272-80.

153. Chen X, Overstreet E, Wood SA, Fischer JA. On the conservation of function of the Drosophila fat facets deubiquitinating enzyme and Fam, its motse homolog. Dev Genes Evol. 2000;210:603-10.

154. Paterno GD, Li Y, Luchman HA, Ryan PJ, Gillespie LL. cDNA cloning of novel, developmentally regulated immediate early gene activated by fibroblast growth factor and encoding a nuclear protein. I Biol Chen. 1997;272:25591-5.

155. Radice $\mathrm{G}$, Lee J, Costantini $\mathrm{F}$. H. beta $58_{n}$ an insertional mutation affecting early postimplantation development of the mouse embryo. Development. $1991 ; 111: 801-11$.

156. Martin KJ, Pardee AB. Principles of differential display. Methods Enzymol. $1999 ; 303: 234-58$.

157. de Groot IJ, Hardy GP, Sanders E, Los JA, Moorman AF. The conducting tissue in the adult chicken atria. A histological and immunohistochemical analysis. Anat Embryol. 1985:172:239-45.

158. Lyons GE, Ontell M, Cox R, Sassoon D, Buckingham M. The expression of myosin genes in developing skeletal muscle in the mouse embryo. $J \mathrm{Ce} / \mathrm{l}$ Biol. 1990; 111:1465-76.

159. Nattel S, Li D, Yue L. Basic mechanisms of atrial fibrillation-wery new insights into very old ideas. Anm Rev Physiol, 2000;62:51-77.

160. Rastinejad F, Blau HM. Genetic complementation reveals a novel regulatory role for $3^{2}$ untranslated regions in growth and differentiation. Cel. $1993 ; 72: 903-17$

161. Ya J, Markman MW, Wagenaar GT, Blommaart PJ, Moorman AF, Lamers WH. Expression of the smooth-muscle proteins alpha-smooth-nuscle actutand calponin, and of the intermediate filament protein desinin are parameters of cardiomyocyte maturation in the prenatal rat heart. Anat Rec. 1997:249:405-50\%.

162. Woodcock-Mitchell J, Mitchell J, Low RB, Kieny M, Sengel P, Rubbia

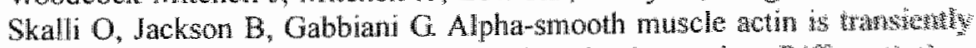
expressed in embryonic rat cardiac and skeletal muscles. Dhferestiontion. 1988;39:161-6.

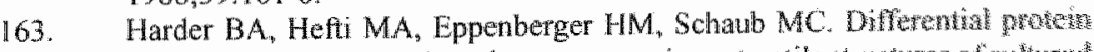

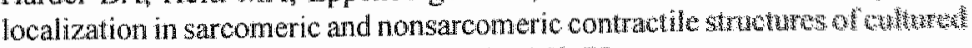
cardiomyocytes. J Siruch Biol. $1998 ; 122: 162-75$. 
164. Kurabayashi M, Tsuchimochi H, Komuro I, Takaku F, Yazaki Y. Molecular cloning and characterization of human cardiac alpha and beta- form myosin heawy chain complementary DNA clones. Regulation of expression during development and pressure owerload in human atrium. J Clin Irvesi. 1988;82:524-31.

165. Wessels A. Spatial distribution of "Tissue-specific" antigens in the developing human heart. In. Amsterdam: University of Amsterdam; 1991.

166. Pope $B$, Hoh JF, Weeds $A$. The ATPase activities of rat cardiac myosin isoenzymes. FEBS Lett. 1980;118:205-8.

167. Miyata S, Minobe W, Bristow MR, Leinwand LA. Myosin heavy chain isoform expression in the failing and nonfailing human heart. Circ Res. 2000;86:386-90.

168. Komuro I, Nomoto K. Sugiyama T, Kurabayashi M, Takaku F, Yazaki Y. Isolation and characterization of myosin heavy chain isozymes of the bowne conduction system. Circ Res. 1987;61:859-65.

169. Reiser PJ, Portman MA, Ning XH, Schomisch Moravec C. Human cardiac myosin heavy chain isoforms in fetal and failing adult atria and ventricles. Am J Physiol Hear Cinc Physiol 2001;280:H1814-20.

170. Holubarsch C, Goulette RP, Litten RZ, Martin BJ, Mulieri LA, Alpert NR. The economy of isometric force development, myosin isoenzyme pattern and myofibrillar ATPase activity in normal and hypothyroid rat myocardium. Circ Res. 1985;56:78-86.

171. Masuzaki H, Jingami H, Matsuoka N, Nakagawa O, Ogawa Y, Mizuno M, Yoshimasa Y, Yamamoto T, Nakao K. Regulation of very-low-density lipoprotein receptor in hypertrophic rat heart. Circ Res. 1996:78:8-14.

172. Semenza GL, Roth PH, Fang HM, Wang GL. Transcriptional regulation of genes encoding glycolytic enzymes by hypoxia-inducible factor 1 . J Biol Chen. 1994;269:23757-63.

173. Chen C. Pore N, Behrooz A, Ismail-Beigi F, Maity A. Regulation of glut I mRNA by hypoxia-inducible factor-1. Interaction between H-ras and hypoxia. $J$ Biol Chem. 2001;276:9519-25.

174. Kannel WB, Abbott RD, Savage DD, McNamara PM. Epidemiologic features of chronic atrial fibrillation: the Framingham study. $N$ Engl $J$ Med. 1982;306:1018-22.

175. Morillo CA, Klein GI, Jones DL, Guiraudon CM. Chronic rapid atrial pacing. Structural, functional, athd electrophysiological characteristics of a new model of sustained atrial fibrillation. Circulation. 1995:91:1588-95.

176. Fareh $\mathrm{S}$, Villemaire C, Nattel S. Importance of refractoriness heterogeneity in the enhanced vulnerability to atrial fibrillation induction caused by tachycardia-induced atrial electrical remodeling. Circwlation. 1998;98:22029.

177. Todd D, AP W, Fym S, Hobbs W, Garratt C. Repetitive one-month periods of atrial electrical remodeling promote stability of atrial fibrillation. Circulation. $2000 ; 102: 11-154$.

178. Sparks PB, Jayaprakash S, Vohra JK, Kalman JM. Electrical remodeling of the atria associated with paroxysmal and chronic atrial flutter. Circulation. $2000: 102: 1807-13$.

179. Tieleman $\mathrm{RG}_{\text {, }}$ Crims H. The 'second factor' of tachycardia-induced atrial remodelling. Cardiovasc Res. 2000;46:364-6.

180. Ausma J, Duytschaever M, Wiffels MC, Borgers M., Allessie MA. Loss of efficacy of cardioversion by class Ic drugs after long term atrial fibrillation in the goat. Em Heart J. $2001: 21: 543$

181. Garratt CJ, Duytschaever M, Killian M, Dorland $R$, Mast $\mathbb{F}$, Allessie MA. Repetitive electrical remodeling by paroxysms of atrial fibrillation in the goat: no cumulative effect on inducibility or stability of atrial fibrillation. I Cardiovase Electrophystol. $1999 ; 10: \| 101-8$. 
182. Grammer JB, Zeng X, Bosch RF, Kuhlkamp V. Atral L-type Ca2+-channel, beta-adrenorecptor, and 5-hydroxytryptamine type 4 receptor mRNAs in human atrial fibrillation. Basic Res Cardol. 2001:96:82-90.

183. Grammer JB, Bosch RF, Kuhlkamp V. Seipell L. Molecular remodeling of Kv4.3 potassium channels in luman atria! fibrillation. $J$ Cordiovase Electrophysiol. 2000;11:626-33.

184. Elvan A, Huang XD, Pressler ML, Zipes DP, Radiofrequency catheter ablation of the atria eliminates pacing-induced sustained atrial fibrillation and reduces connexin 43 in dogs. Circulation. 1997;96:1675-85.

185. Barbey O, Pierre S, Duran MJ, Semoune S, Levy S, Maixen JM. Specifio up-regulation of mitochondrial FOFI-ATPase activity after short episodes of atrial fibriltation in sheep. $J$ Cardionase Electrophysiol. 2000;11:432-8.

186. Fujii H, Ide M, Yasuda S, Takahashi W, Shohtsu A, Kubo A. Increased FDG uptake in the wall of the right atrium in people who participated in a cancer screening program with whole-body PET. Ann Nucl Med. 1999;13:55-9.

187. Warshaw JB, Terry ML. Cellular energy metabolism during fetal development. II. Fatty acid oxidation by the developing heart. $J \mathrm{Cell}$ Biol. 1970;44:354-60.

188. Warshaw JB. Cellular energy metabolism during fetal development. 3. Deficient acetyl-CoA synthetase, acetylcarnitine transferase and oxidation of acetate in the fetal bovine heart. Biochim Biophys Acto. 1970;223:409-15.

189. Warshaw JB. Cellular energy metabolism during fetal development. IV. Fatty acid activation, acyl transfer and fatty acid oxidation during development of the chick and rat. Dev Biol. 1972;28:537-44.

190. Warshaw JB, Kimura RE. Cellular energy metabolism during fetal development. V. Fatty acid synthesis by the developing heart. Dev Biol. $1973 ; 33: 224-8$.

191. Kimura RE, Warshaw IB. Metabolic adaptations of the fetus and newbom. Pediatm Gastroenterol Nur. 1983;2:S12-5.

192. Webb $\mathbb{I C}$, Patel DD, Jones MD, Knight BL, Soutar AK. Characterization and tissue-specific expression of the human "very low density lipoprotein (VLDL) receptor' mRNA. Hum Mol Genet. 1994;3:531-7.

193. Oka K, Ishmura-Oka K, Chu MJ, Sullivan M, Krushkal J, Li WH, Chan L. Mouse very-low-density-lipoprotein receptor (VLDLR) cDNA cloning, tissuespecific expression and evolutionary relationship with the low-densitylipoprotein receptor. Eur J Biochem. 1994;224:975-82.

194. Kwok S, Singh-Bist A, Natu V, Kraemer FB. Dietary regulation of the very low density lipoprotein receptor in mouse heart and fat. Horm Metab Res. 1997:29:524-9.

195. Wang GL, Jiang BH, Rue EA, Semenza GL. Hypoxia-inducible factor 1 is a basic-helix-loop-helix-PAS heterodimer regulated by cellular 02 tersion. PNAS. 1995;92:5510-4.

196. Aasum E, Lathrop DA, Henden T, Sundset R, Larsen TS. The role of glycolysis in myocardial calcium control. J Mol Cell Cartiol. 1998;30:1703-12.

197. Clapham DE, Calcium signaling. Cell. 1995-80:259-68.

198. Daoud EG, Knight BP, Weiss R, Bahu M, Paladino W, Goyal R, Man KC. Strickberger SA, Morady $\mathrm{F}$. Effect of verapamil and procainamide on arral fibrillation-indaced electrical remodeling in humans. Circulation. $1997: 96: 1542-50$

199. Zarse M, Stellbrink C. Athanatou E, Roberd J, Schotten U, Hanrath P. Verapamil prevents stretch-induced shortening of atrial affective refractory period in langendorff-perfused rabbit heart, ICardiovase Elecrrophysiol, 2001:12:8592.

200. Lee SH, Yu WC, Cheng J, Hung CR, Ding YA, Chang MS, Chen SA. Effect of verapamil on long-term tachycardia-induced atrial electrical remodeling. Circulation. 2000; 101:200-6. 